\title{
Overcoming Halide Inhibition of Suzuki- Miyaura Couplings with Biaryl Monophosphine-Based Catalysts
}

José J. Fuentes-Rivera, ${ }^{\ddagger}$ Mary E. Zick, ${ }^{\ddagger}$ M. Alexander Düfert, ${ }^{*}{ }^{\S}$ Phillip J. Milner, ${ }^{*} \star$

Department of Chemistry and Chemical Biology, Cornell University, Ithaca, NY, 14853, United States

${ }^{\dagger}$ BASF SE, Carl-Bosch-Straße 38, D-67056 Ludwigshafen, Germany.

Supporting Information 


\section{Table of contents.}

1. General information. $\quad$ S3

2. Synthesis of potassium phenylboronate. $\quad$ S4

3. Synthesis of Pd complexes. S5

4. Partition coefficients of potassium salts between THF and $\mathrm{H}_{2} \mathrm{O}$. S9

5. Determination of reagent orders (Figure 2 and Table 1). S10

$\begin{array}{lr}\text { 6. Aryl halide effect on catalytic reactions (Figure 3). } & \text { S17 }\end{array}$

7. Effect of added KX on catalytic reactions (Table 2). S20

8. Stoichiometric transmetalation experiments (Figure 4). S22

9. Equilibria between $\mathbf{L 1} \cdot \mathrm{Pd}(\mathrm{Ph}) \mathrm{X}(\mathrm{X}=\mathrm{Cl}, \mathrm{Br}, \mathrm{I})$ and $\mathbf{L 1} \cdot \mathrm{Pd}(\mathrm{Ph}) \mathrm{OH}$ (Figure 5). $\quad \mathrm{S} 33$

10. Additional catalytic experiments.

11. Catalytic reactions of aryl iodides in toluene/water (Figure 6). S42

12. References $\quad$ S46

$\begin{array}{lr}\text { 13. NMR spectra of isolated substrates (Table 6). } & \text { S47 }\end{array}$ 


\section{General information.}

Reactions were set up in fume hoods using standard Schlenk techniques, except where noted otherwise. Catalytic reactions were performed in screw-cap reaction tubes fitted with Teflonsealed screw-caps under an atmosphere of nitrogen. THF, diethyl ether, and toluene were vigorously purged with argon for $2 \mathrm{~h}$ and further purified by passing it under argon pressure through two packed columns of neutral alumina. All other reagents and solvents were purchased from commercial suppliers and used without further purification. The SPhos Pd G3 (P1) used in this work was prepared following the literature procedure. ${ }^{1}$

All compounds were characterized by ${ }^{1} \mathrm{H}$ NMR, ${ }^{13} \mathrm{C}$ NMR, ${ }^{19} \mathrm{~F}$ NMR, and/or ${ }^{11} \mathrm{~B}$ NMR spectroscopy, as well as IR spectroscopy, elemental analysis, and/or high resolution mass spectrometry (HRMS), where appropriate. Copies of the ${ }^{1} \mathrm{H},{ }^{13} \mathrm{C}$ and ${ }^{19} \mathrm{~F}$ NMR spectra for isolated substrates (Table S6) are located at the end of the Supporting Information. NMR spectra were recorded on Varian 300 or $500 \mathrm{MHz}$ or Bruker $500 \mathrm{MHz}$ instruments. All ${ }^{1} \mathrm{H}$ and ${ }^{13} \mathrm{C}$ NMR spectra are referenced to the signals for residual solvents $\left(\mathrm{CD}_{3} \mathrm{OD}, \mathrm{CD}_{2} \mathrm{Cl}_{2}\right.$ or THF$\left.\mathrm{d}_{8}\right)$. All ${ }^{31} \mathrm{P}$ NMR spectra are reported relative to $85 \%$ aq. phosphoric acid $(\delta 0.00 \mathrm{ppm})$. All ${ }^{11} \mathrm{~B}$ NMR spectra are reported relative to $\mathrm{BF}_{3} \cdot \mathrm{OEt}_{2}$ as reference $(\delta 0.00 \mathrm{ppm})$. All ${ }^{19} \mathrm{~F}$ NMR spectra are reported relative to $\mathrm{CFCl}_{3}$ as reference $(\delta 0.00 \mathrm{ppm})$. The following abbreviations are used singularly or in combination to indicate the multiplicity of signals: $s$ (singlet), $d$ (doublet), $t$ (triplet), q (quartet), m (multiplet), p (pseudo). Infrared spectra were collected on a ThermoFischer Nicolet iS5 FT-ATR spectrometer. Selected absorption maxima are reported in wavenumbers $\left(\mathrm{cm}^{-1}\right)$. Elemental analyses were performed by Atlantic Microlabs Inc., Norcross, GA. All synthesized compounds are estimated to be $\geq 95 \%$ pure as determined by ${ }^{1} \mathrm{H}$ NMR, ${ }^{19} \mathrm{~F}$ NMR, and ${ }^{31} \mathrm{P}$ NMR spectroscopy, where applicable. All GC analyses were performed on an Agilent 6890A gas chromatograph with an FID detector or a Shimadzu Nexus GC-2030 gas chromatograph with an FID detector. Reaction calorimetry was performed using an Omnical CRC reaction calorimeter. 


\section{Synthesis of potassium phenylboronate.}

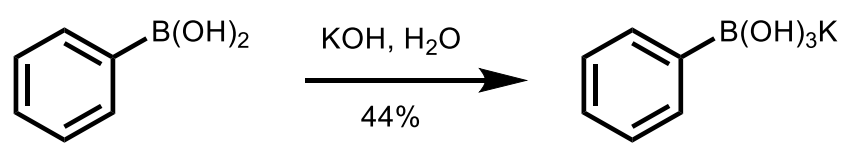

$\mathbf{P h B}(\mathrm{OH})_{3}$ K. Synthesized following a modified literature procedure. ${ }^{2}$ A roundbottom flask was charged with phenylboronic acid (1.22 g, $10.0 \mathrm{mmol}, 1.00$ equiv.) and $\mathrm{KOH}$ (561 mg, 10.0 mmol, 1.00 equiv.). $\mathrm{H}_{2} \mathrm{O}$ (1.5 mL) was added and the mixture was heated to $100{ }^{\circ} \mathrm{C}$ until all solids were dissolved (5-10 $\mathrm{min})$. Isopropanol $(200 \mathrm{~mL})$ was added and the solution was allowed to cool to room temperature. The mixture was cooled to $4{ }^{\circ} \mathrm{C}$, and colorless crystals formed after $2 \mathrm{~d}$ at this temperature. The crystals were filtered and washed with isopropanol (3 $\mathrm{x} 10 \mathrm{~mL})$ and $\mathrm{Et}_{2} \mathrm{O}(3 \times 15 \mathrm{~mL})$ and dried under high vacuum to yield the desired product as a colorless, crystalline solid (790 mg, $4.43 \mathrm{mmol}, 44 \%) .{ }^{1} \mathbf{H}$ NMR (500 MHz, CD 3 OD): $\delta 7.50$ $(\mathrm{d}, J=7 \mathrm{~Hz}, 2 \mathrm{H}), 7.14(\mathrm{t}, J=7 \mathrm{~Hz}, 2 \mathrm{H}), 7.03(\mathrm{t}, J=7 \mathrm{~Hz}, 1 \mathrm{H}) \mathrm{ppm} ;{ }^{13} \mathbf{C}$ NMR $(125 \mathrm{MHz}$, $\left.\mathrm{CD}_{3} \mathrm{OD}\right): \delta 133.4,126.7,125.1,100.5$ ppm; ${ }^{11} \mathbf{B}$ NMR (160 MHz, CD $\left.{ }_{3} \mathrm{OD}\right): \delta 5.3$ ppm. 


\section{Synthesis of Pd complexes.}

The (1,5-COD)Pd( $\left(\mathrm{CH}_{2} \mathrm{TMS}\right)_{2}$ used in this work was synthesized according to a literature procedure. $^{3}$

General Procedure 1: An oven-dried test-tube was charged with $(1,5-\mathrm{COD}) \mathrm{Pd}\left(\mathrm{CH}_{2} \mathrm{TMS}\right)_{2}$ (1.00 equiv.) and SPhos (1.00 equiv.). The reaction vessel was evacuated and backfilled with argon (this process was repeated a total of three times). After addition of cyclohexane (8 $\mathrm{mL} / \mathrm{mmol}$ ) and the aryl halide (4.00 equiv.), the reaction was stirred at room temperature for 10-15 h. After completion of the reaction, hexane was added $(10 \mathrm{~mL} / \mathrm{mmol})$, the precipitate was washed with hexane $(2 \times 10 \mathrm{~mL})$, and the resulting solid was dried under high vacuum. All Pd(II) complexes are stable on the bench for weeks to months under an atmosphere of air. This reaction can be set up inside or outside of a nitrogen-filled glovebox to provide oxidative addition complexes of comparable purity.

$(1,5-\mathrm{COD}) \mathrm{Pd}\left(\mathrm{CH}_{2} \mathrm{TMS}\right)_{2}$

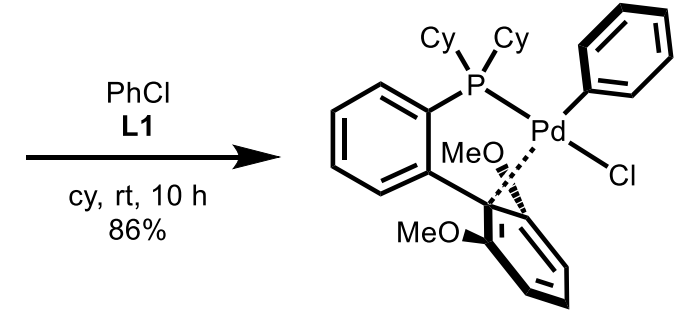

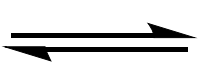

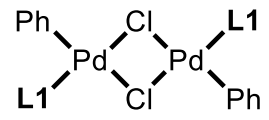

L1•Pd(Ph)Cl. Following General Procedure 1, (1,5-COD)Pd(CH $\left.\mathrm{CH}_{2} \mathrm{TMS}\right)_{2}(200 \mathrm{mg}, 0.51 \mathrm{mmol}$, 1.00 equiv.), SPhos (211 mg, $0.51 \mathrm{mmol}, 1.00$ equiv.) and chlorobenzene (231 mg, $209 \mu \mathrm{L}$, $2.06 \mathrm{mmol}, 4.00$ equiv.) were combined and allowed to react for $10 \mathrm{~h}$. Drying under high vacuum yielded $\mathbf{L 1} \cdot \mathrm{Pd}(\mathrm{Ph}) \mathrm{Cl}$ as an off-white solid (278 $\mathrm{mg}, 0.44 \mathrm{mmol}, 86 \%)$. This complex, including single-crystal X-ray diffraction structures of both the monomeric and dimeric forms, has been previously reported., ${ }^{4,5}$

${ }^{1} \mathbf{H}$ NMR $\left(500 \mathrm{MHz}, \mathrm{CDCl}_{3}\right): \delta 7.77(\mathrm{t}, J=8 \mathrm{~Hz}, 1 \mathrm{H}), 7.61(\mathrm{t}, J=7 \mathrm{~Hz}, 1 \mathrm{H}), 7.35-7.50(\mathrm{~m}$, 2H), $7.07(\mathrm{~d}, J=7 \mathrm{~Hz}, 2 \mathrm{H}), 6.80-6.95(\mathrm{~m}, 4 \mathrm{H}), 6.63(\mathrm{~d}, J=8 \mathrm{~Hz}, 2 \mathrm{H}), 3.76(\mathrm{~s}, 6 \mathrm{H}), 2.04-2.29$ $(\mathrm{m}, 2 \mathrm{H}), 1.56-1.93(\mathrm{~m}, 12 \mathrm{H}), 0.96-1.36(\mathrm{~m}, 7 \mathrm{H}), 0.57(\mathrm{~d}, J=13 \mathrm{~Hz}, 1 \mathrm{H}) \mathrm{ppm} ;{ }^{13} \mathbf{C}$ NMR $(125$ MHz, THF- $\left.\mathrm{d}_{8}\right): \delta 161.1,158.3,138.9,137.4,136.4,134.5,133.6,132.2,131.8,129.9,129.3$, 
$127.7,127.4,126.7,126.3,124.0,122.9,106.3,104.5,56.4,38.5,34.8,34.5,33.0,31.0,29.0$, $28.9,28.6,28.3,28.2,28.1,28.0,27.7,27.6,27.3,26.5$ ppm (observed complexity due to P-C splitting and monomer/dimer equilibrium); ${ }^{31} \mathbf{P}$ NMR (162 MHz, THF-d 8 ): $\delta$ 40.0, 35.5 (monomer/dimer equilibrium); HRMS for $\mathrm{C}_{32} \mathrm{H}_{40} \mathrm{ClO}_{2} \mathrm{PPd}$ : calcd. 593.1801 [M-Cl] $]^{+}$, found 593.1840 [ESI-HRMS]. Anal. Calcd. for $\mathrm{C}_{32} \mathrm{H}_{40} \mathrm{ClO}_{2} \mathrm{PPd}$ : C, 61.05; H, 6.40. Found: C, 61.48; H, 6.73 .

$(1,5-\mathrm{COD}) \mathrm{Pd}\left(\mathrm{CH}_{2} \mathrm{TMS}\right)_{2}$

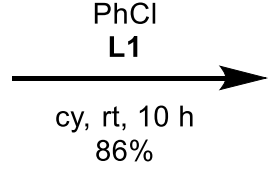

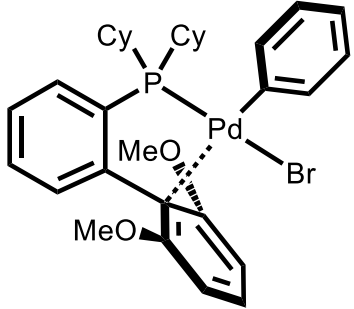
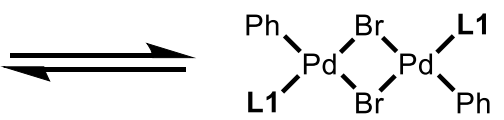

L1•Pd(Ph)Br. Following General Procedure 1, (COD)Pd( $\left.\mathrm{CH}_{2} \mathrm{TMS}\right)_{2}(100 \mathrm{mg}, 0.26 \mathrm{mmol}$, 1.00 equiv.), SPhos (106 mg, $0.26 \mathrm{mmol}, 1.00$ equiv.) and bromobenzene (161 mg, $108 \mu \mathrm{L}$, $1.03 \mathrm{mmol}, 4.00$ equiv.) were combined and allowed to react for $15 \mathrm{~h}$. Drying under high vacuum yielded $\mathbf{L 1} \cdot \mathrm{Pd}(\mathrm{Ph}) \mathrm{Br}$ as an off-white solid (95 mg, $0.14 \mathrm{mmol}, 55 \%)$.

${ }^{1} \mathbf{H}$ NMR $\left(500 \mathrm{MHz}, \mathrm{CD}_{2} \mathrm{Cl}_{2}\right): \delta 7.76(\mathrm{t}, J=8 \mathrm{~Hz}, 1 \mathrm{H}), 7.69(\mathrm{t}, J=7 \mathrm{~Hz}, 1 \mathrm{H}), 7.39-7.55(\mathrm{~m}$, 2H), 7.26-7.35 (m, 1H), 7.07 (ddd, $J=8,2,1 \mathrm{~Hz}, 2 \mathrm{H}), 6.95(\mathrm{t}, J=7 \mathrm{~Hz}, 2 \mathrm{H}), 6.81-6.90(\mathrm{~m}$, $2 \mathrm{H}), 6.65(\mathrm{~d}, J=8 \mathrm{~Hz}, 2 \mathrm{H}), 3.87(\mathrm{~s}, 1 \mathrm{H}), 3.80(\mathrm{~d}, J=4 \mathrm{~Hz}, 5 \mathrm{H}), 2.11-2.29(\mathrm{~m}, 2 \mathrm{H}), 1.48-1.95$ $(\mathrm{m}, 13 \mathrm{H}), 1.05-1.37(\mathrm{~m}, 9 \mathrm{H}), 0.82-0.95(\mathrm{~m}, 3 \mathrm{H}), 0.51-0.71(\mathrm{~m}, 2 \mathrm{H}) \mathrm{ppm} ;{ }^{13} \mathbf{C}$ NMR $(125 \mathrm{MHz}$, $\left.\mathrm{CD}_{2} \mathrm{Cl}_{2}\right): \delta 161.3,158.5,144.8,144.7,138.1,138.1,136.8,136.3,136.1,134.4,134.1,132.4$ $132.3,132.1,131.8,130.8,130.0,129.3,127.5,127.4,127.4,126.8,126.4,126.3,123.9,122.9$, $106.7,104.7,56.5,38.8,34.9,34.7,32.7,32.3,31.0,28.7,28.3,28.2,28.1,27.8,27.7,27.2$, 26.6, 23.3, $14.6 \mathrm{ppm}$ (observed complexity due to $\mathrm{P}-\mathrm{C}$ splitting and monomer/dimer equilibrium); ${ }^{31}$ P NMR (202 MHz, $\mathrm{CD}_{2} \mathrm{Cl}_{2}$ ): $\delta 35.9,34.2$ ppm (monomer/dimer equilibrium). 
$(1,5-\mathrm{COD}) \mathrm{Pd}\left(\mathrm{CH}_{2} \mathrm{TMS}\right)_{2}$
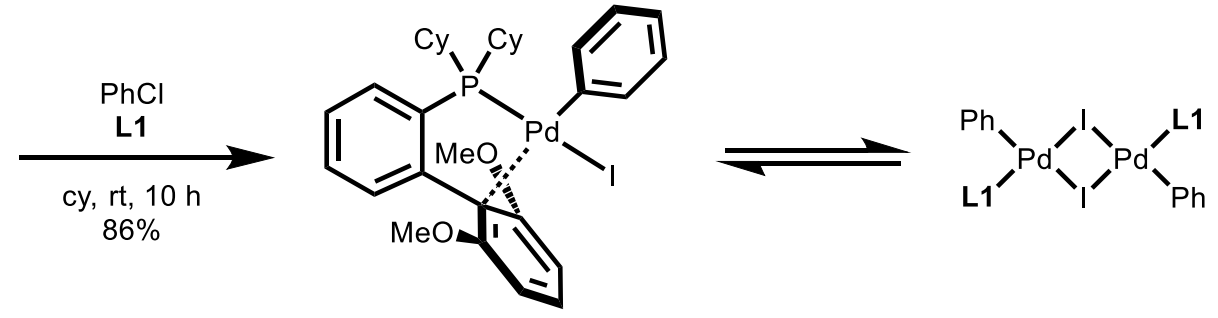

L1•Pd(Ph)I. Following General Procedure 1, (COD)Pd( $\left(\mathrm{CH}_{2} \mathrm{TMS}\right)_{2}(100 \mathrm{mg}, 0.26 \mathrm{mmol}$, 1.00 equiv.), SPhos (106 mg, $0.26 \mathrm{mmol}, 1.00$ equiv.) and iodobenzene (210 mg, $115 \mu \mathrm{L}, 1.03$ mmol, 4.00 equiv.) were combined and allowed to react for $15 \mathrm{~h}$. Drying under high vacuum yielded $\mathbf{L 1} \cdot \mathrm{Pd}(\mathrm{Ph}) \mathrm{I}$ as a light yellow solid (135 $\mathrm{mg}, 0.19 \mathrm{mmol}, 73 \%)$.

${ }^{1} \mathbf{H}$ NMR $\left(500 \mathrm{MHz}, \mathrm{CD}_{2} \mathrm{Cl}_{2}\right): \delta 7.82-7.62(\mathrm{~m}, 2 \mathrm{H}), 7.54-7.31(\mathrm{~m}, 3 \mathrm{H}), 7.21-6.57(\mathrm{~m}, 7 \mathrm{H})$, 4.02-3.62 (m, 6H), 2.30-2.01 (m, 2H), 1.95-1.44 (m, 10H), 1.44-1.06 (m, 7H), 1.04-0.74 (m, 2H), $0.58(\mathrm{~s}, 1 \mathrm{H}) \mathrm{ppm} ;{ }^{13} \mathrm{C}$ NMR $\left(125 \mathrm{MHz}, \mathrm{CD}_{2} \mathrm{Cl}_{2}\right): \delta 161.4,158.6,139.2,138.1,136.3$, $134.3,132.4,131.8,131.0,130.7,130.0,129.3,127.3,127.1,126.3,124.0,122.8,119.3,107.5$, $104.8,56.8,56.6,35.0,34.7,32.7,32.3,31.1,28.7,28.6,28.3,28.2,28.0,27.8,27.7,27.1,26.5$, 23.4, $14.6 \mathrm{ppm}$ (observed complexity due to $\mathrm{P}-\mathrm{C}$ splitting and monomer/dimer equilibrium); ${ }^{31}$ P NMR (202 MHz, $\mathrm{CD}_{2} \mathrm{Cl}_{2}$ ): $\delta 35.9,30.1$ ppm (monomer/dimer equilibrium).
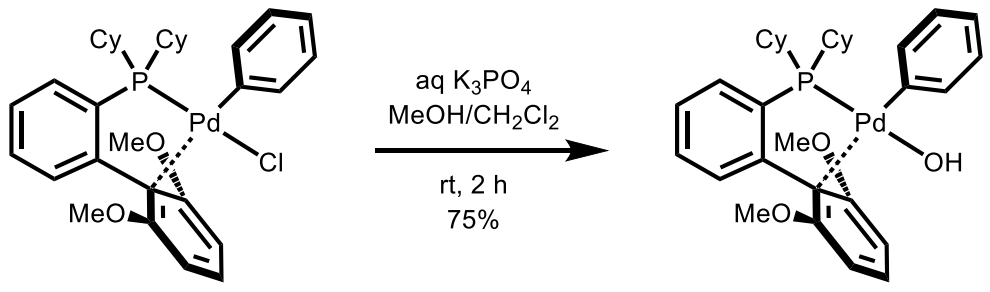

$\mathbf{L 1} \cdot \mathbf{P d}(\mathbf{P h}) \mathbf{O H}$. An oven-dried test tube equipped with a stir bar was charged with $\mathbf{L} \mathbf{1} \cdot \mathrm{Pd}(\mathrm{Ph}) \mathrm{Cl}$ (40.0 mg, $0.06 \mathrm{mmol}, 1.00$ equiv.). The reaction vessel was evacuated and backfilled with argon (this process was repeated a total of three times). $\mathrm{CH}_{2} \mathrm{Cl}_{2}(0.4 \mathrm{~mL}$, freshly degassed) was added and the reaction mixture was stirred rapidly until a clear solution was obtained. $\mathrm{MeOH}(1.6 \mathrm{~mL}$, freshly degassed) was added quickly, followed by dropwise addition of $4 \mathrm{M} a q . \mathrm{K}_{3} \mathrm{PO}_{4}$ solution $\left(640 \mu \mathrm{L}, 2.06 \mathrm{mmol}, 40.0\right.$ equiv., freshly degassed) over $2 \mathrm{~min}$. Note that the $a q . \mathrm{K}_{3} \mathrm{PO}_{4}$ solution has to be added very quickly after the addition of $\mathrm{MeOH}$ to prevent precipitation of 
L1 $\cdot \mathrm{Pd}(\mathrm{Ph}) \mathrm{Cl}$. After $2 \mathrm{~h}$ at room temperature, $\mathrm{MeOH}(0.5 \mathrm{~mL})$ and $\mathrm{H}_{2} \mathrm{O}(1.0 \mathrm{~mL})$ were added and the reaction mixture was stirred for an additional $5 \mathrm{~min}$. The precipitate was filtered and washed successively with $\mathrm{MeOH}(1 \mathrm{~mL}), \mathrm{H}_{2} \mathrm{O}(1 \mathrm{~mL})$, and $\mathrm{MeOH}(1 \mathrm{~mL})$ and dried on high vacuum. $\mathbf{L 1} \cdot \mathrm{Pd}(\mathrm{Ph}) \mathrm{OH}$ was obtained as an off-white to light-grey solid $(31 \mathrm{mg}, 0.05 \mathrm{mmol}$, 75\%). This complex, including a single-crystal X-ray diffraction structure, has been previously reported. ${ }^{5}$

${ }^{1} \mathbf{H}$ NMR $\left(500 \mathrm{MHz}, \mathrm{CD}_{2} \mathrm{Cl}_{2}\right): \delta 8.53(\mathrm{dd}, J=14,9 \mathrm{~Hz}, 1 \mathrm{H}), 7.32-7.40(\mathrm{~m}, 2 \mathrm{H}), 7.21-7.30(\mathrm{~m}$, 3H), $6.84(\mathrm{dd}, J=9,3 \mathrm{~Hz}, 1 \mathrm{H}), 6.65-6.78(\mathrm{~m}, 3 \mathrm{H}), 6.52(\mathrm{~d}, J=8 \mathrm{~Hz}, 2 \mathrm{H}), 3.34(\mathrm{~s}, 6 \mathrm{H}), 1.34-$ $1.78(\mathrm{~m}, 12 \mathrm{H}), 1.12(\mathrm{dt}, J=13,10 \mathrm{~Hz}, 4 \mathrm{H}), 0.64-0.82(\mathrm{~m}, 4 \mathrm{H}),-2.26(\mathrm{~d}, J=3 \mathrm{~Hz}, 1 \mathrm{H}) \mathrm{ppm}$; ${ }^{13}$ C NMR (125 MHz, THF-d 8 ): $\delta$ 159.0, 158.7, 151.5, 139.6, 137.6, 137.3, 137.2, 136.9, 134.3, $134.3,133.9,133.9,130.2,130.0,129.8,129.1,128.8,125.9,125.8,122.0,121.9,119.8,104.0$, $103.9,100.5,55.8,55.3,37.1,36.4,36.2,32.5,32.0,30.9,30.3,29.0,28.9,28.4,28.3,28.2$, 27.3, $27.1 \mathrm{ppm}$ (observed complexity due to P-C splitting); ${ }^{31} \mathbf{P}$ NMR (121 MHz, THF-d $)$ : $\delta$ 51.6. HRMS for $\mathrm{C}_{32} \mathrm{H}_{41} \mathrm{O}_{3} \mathrm{PPd}$ : calcd. $1223.3769[2 \mathrm{M}+\mathrm{H}]^{+}, 593.1801[\mathrm{M}-\mathrm{OH}]^{+}$, found 1223.3809, 593.1895 [ESI-HRMS]. 


\section{Partition coefficients of potassium salts between THF and $\mathrm{H}_{2} \mathrm{O}$.}

$\mathbf{K}_{3} \mathbf{P O}_{4}$ : A mixture of $1.5 \mathrm{M}$ aq. $\mathrm{K}_{3} \mathrm{PO}_{4}(30.0 \mathrm{~mL}, 45.0 \mathrm{mmol})$ and $\mathrm{THF}(69 \mathrm{~mL})$ was vigorously stirred in a roundbottom flask for $30 \mathrm{~min}$. After separation of the phases, the organic phase was concentrated in vacuo. The residual solid amounted to $17 \mathrm{mg}$. Evaporation of pure THF (69 mL) led to $3 \mathrm{mg}$ of residual solid. Thus, the difference of $14 \mathrm{mg}(0.066 \mathrm{mmol})$ should equal a ratio of $\mathrm{K}_{3} \mathrm{PO}_{4}$ in $\mathrm{THF} / \mathrm{H}_{2} \mathrm{O}$ of 1:682, which is in accord with a previously report that showed three orders of magnitude difference in $\mathrm{K}_{3} \mathrm{PO}_{4}$ concentration between the two phases. ${ }^{1}$

$\mathbf{K X}(\mathbf{X}=\mathbf{C l}, \mathbf{B r}, \mathbf{I})$ : Solid KX (22.5 mmol, 1.0 equiv. $)$ was dissolved in a vigorously stirred mixture of $1.5 \mathrm{M}$ aq. $\mathrm{K}_{3} \mathrm{PO}_{4}(30.0 \mathrm{~mL}, 45.0 \mathrm{mmol}, 2.0$ equiv.) and THF (69 mL). After separation of the phases, the organic phase was concentrated, and water $(5 \mathrm{~mL})$ was added. Then, $0.5 \mathrm{M} a q . \mathrm{AgNO}_{3}$ (10-50 $\mathrm{mL}, 5-25 \mathrm{mmol}$ ) was added until no further precipitation was observed. Precipitated AgX was collected by filtration and dried under high vacuum for $1 \mathrm{~h}$. The molar ratio of the corresponding halide in the organic and aqueous phases was calculated from the weight of $\mathrm{AgX}$. This finding confirms that a significant portion of KI generated during the coupling of aryl iodides is present in the organic phase with the catalyst.

When this partitioning experiment was carried out with toluene in place of $\mathrm{THF},<5 \mathrm{mg}$ of $\mathrm{AgI}$ was observed upon the addition of $a q . \mathrm{AgNO}_{3}$ to the toluene layer. However, immediate precipitation of $\mathrm{AgI}$ was observed from the aqueous phase, confirming that KI partitions nearly exclusively into the aqueous phase in a toluene/water mixture.

Table S1. Partition coefficients for $\mathrm{KX}$ salts in a THF/aq. $\mathrm{K}_{3} \mathrm{PO}_{4}$ mixture.

\begin{tabular}{ccc}
\hline Halide & $\mathrm{AgX}(\mathrm{g})$ & Partition coefficient $\mathrm{H}_{2} \mathrm{O}:$ THF \\
\hline $\mathrm{Cl}$ & 0.101 & $31.9: 1$ \\
$\mathrm{Br}$ & 0.256 & $16.5: 1$ \\
$\mathrm{I}$ & 4.160 & $1.3: 1$ \\
\hline
\end{tabular}




\section{Determination of reagent orders (Figure 2 and Table 1).}<smiles>Oc1ccccc1</smiles><smiles>Clc1ccccc1</smiles>

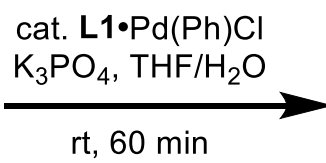<smiles>c1ccc(-c2ccccc2)cc1</smiles>

Standard procedure. A screw-cap reaction tube equipped with a stir bar was charged with $\mathbf{L 1} \cdot \mathrm{Pd}(\mathrm{Ph}) \mathrm{Cl}(6.29 \mathrm{mg}, 0.01 \mathrm{mmol}, 0.02$ equiv.) and phenylboronic acid (61.0 $\mathrm{mg}, 0.50 \mathrm{mmol}$, 1.00 equiv.). The reaction vessel was evacuated and backfilled with nitrogen (this process was repeated a total of three times). Then, chlorobenzene (50.7 $\mu \mathrm{L}, 0.50 \mathrm{mmol}, 1.00$ equiv.), dodecane (114 $\mu \mathrm{L}, 0.50 \mathrm{mmol}, 1.00$ equiv. $)$ and THF ( $2 \mathrm{~mL})$ were added and the reaction mixture was briefly stirred until a homogeneous solution was obtained. The first aliquot $(50 \mu \mathrm{L})$ was taken as reference. Afterwards, a degassed solution of $1.0 \mathrm{M}$ aq. $\mathrm{K}_{3} \mathrm{PO}_{4}(1.0 \mathrm{~mL}, 1.0 \mathrm{mmol}, 2.0$ equiv.) was injected rapidly and the reaction was allowed to stir at $400 \mathrm{rpm}$ at room temperature for $60 \mathrm{~min}$. The reaction was analyzed by withdrawing aliquots $(50 \mu \mathrm{L})$ from the reaction mixture by syringe after $2,4,8,15,30,45$, and 60 min and submitting them to GC analysis to determine the consumption of the starting material using dodecane as internal standard. The reactions used to probe the reagent orders in the various reaction components were carried out similarly, except that the reaction involving twice the concentration of chlorobenzene was carried out using only $1.9 \mathrm{~mL}$ of THF to keep the volume of the organic phase approximately constant between experiments.

In nearly all cases, extremely rapid consumption of starting material was observed during the first $2 \mathrm{~min}$ of the reaction, followed by slower conversion. As such, the first data point was excluded from subsequent kinetic analyses, as this initial rapid consumption is likely due to nonequilibrium effects at the start of the reaction. The kinetic data and corresponding first-order kinetic models are included below for each experiment. 
Table S2. Kinetic data for the catalytic reaction of $\mathrm{PhCl}$ and $\mathrm{PhB}(\mathrm{OH})_{2}$ under the standard reaction conditions.

\begin{tabular}{ccc}
\hline Time $(\min )$ & \% PhCl Remaining & {$[\mathrm{PhCl}](\mathrm{M})^{a}$} \\
\hline 0 & 100 & 0.25 \\
2 & 93 & 0.23 \\
4 & 91 & 0.23 \\
8 & 89 & 0.22 \\
15 & 86 & 0.21 \\
30 & 79 & 0.19 \\
45 & 72 & 0.18 \\
60 & 67 & 0.17 \\
${ }^{a}$ Assuming that $\mathrm{PhCl}$ and dodecane are present entirely in the THF layer.
\end{tabular}

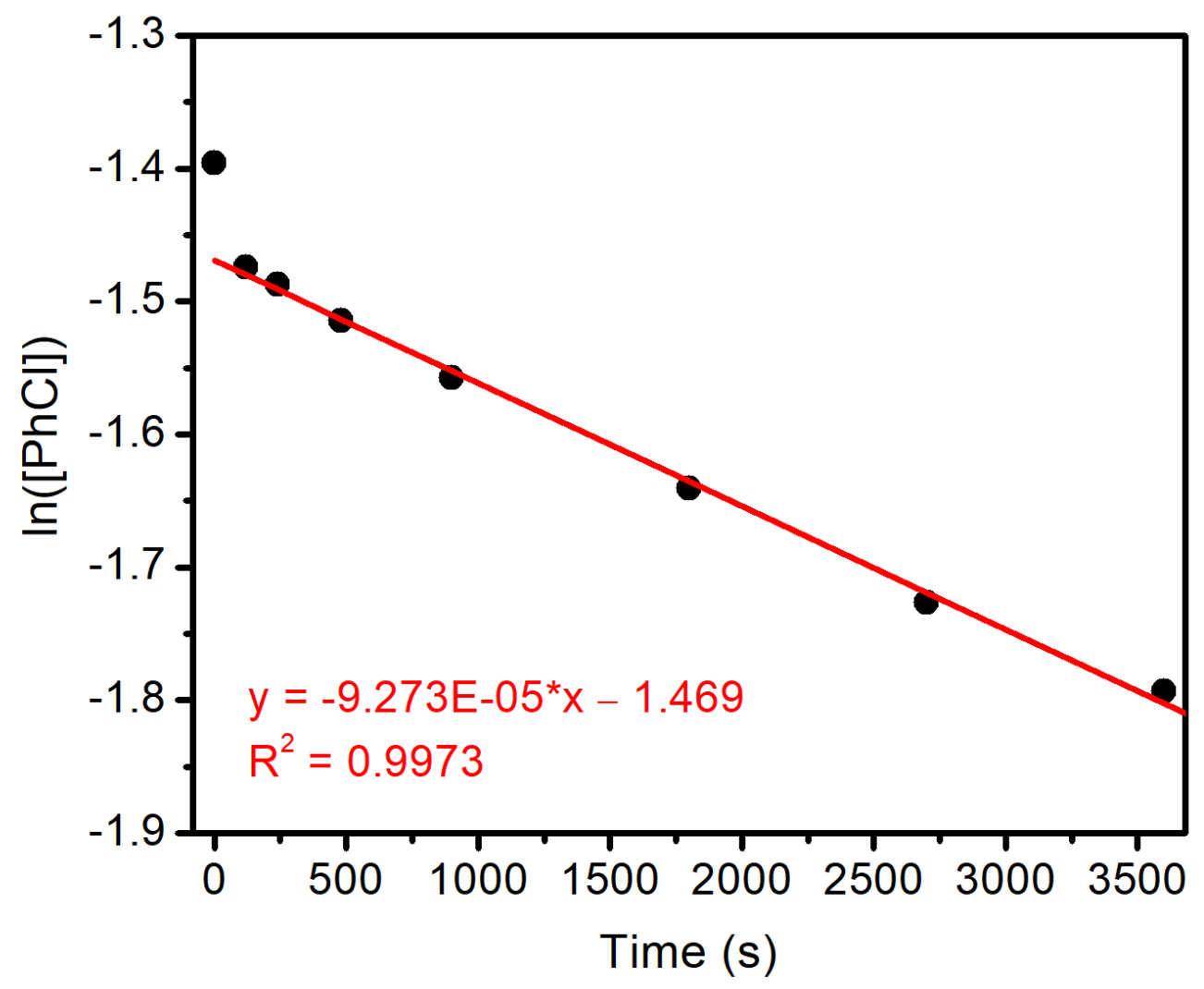

Figure S1. First-order kinetic plot for the kinetic data from the standard reaction. The first data point was not included in the linear fit. 


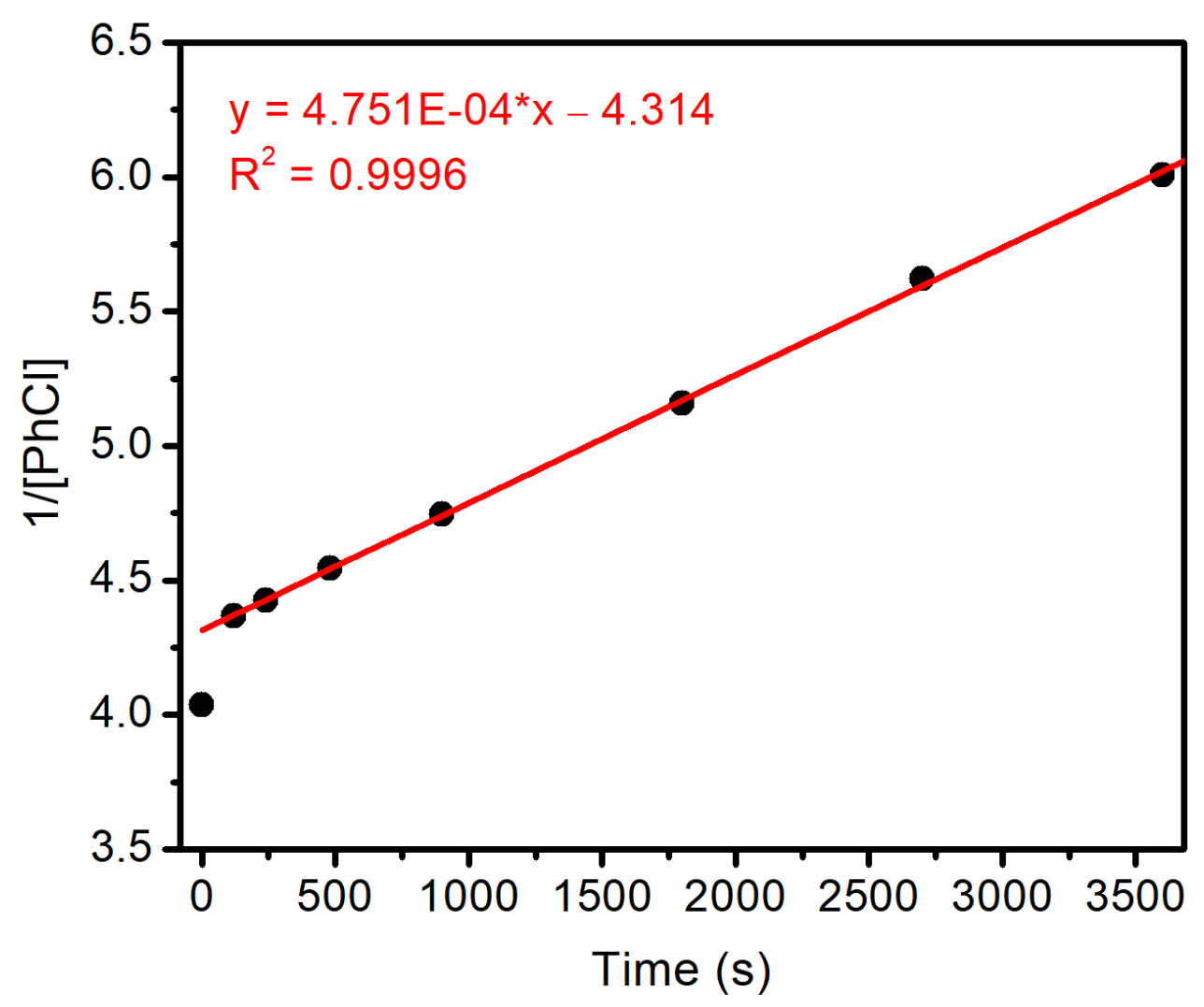

Figure S2. Second-order kinetic plot for the kinetic data from the standard reaction. The first data point was not included in the linear fit. 
Table S3. Kinetic data for the catalytic reaction of $\mathrm{PhCl}$ and $\mathrm{PhB}(\mathrm{OH})_{2}$ under the standard reaction conditions with twice the amount of $\mathrm{K}_{3} \mathrm{PO}_{4}$.

\begin{tabular}{ccc}
\hline Time $(\min )$ & \% PhCl Remaining & {$[\mathrm{PhCl}](\mathrm{M})^{a}$} \\
\hline 0 & 100 & 0.24 \\
2 & 97 & 0.24 \\
4 & 94 & 0.23 \\
8 & 91 & 0.22 \\
15 & 88 & 0.21 \\
30 & 81 & 0.20 \\
45 & 75 & 0.18 \\
60 & 71 & 0.17 \\
${ }^{a}$ Assuming that $\mathrm{PhCl}$ and dodecane are present entirely in the THF layer.
\end{tabular}

${ }^{a}$ Assuming that $\mathrm{PhCl}$ and dodecane are present entirely in the THF layer.

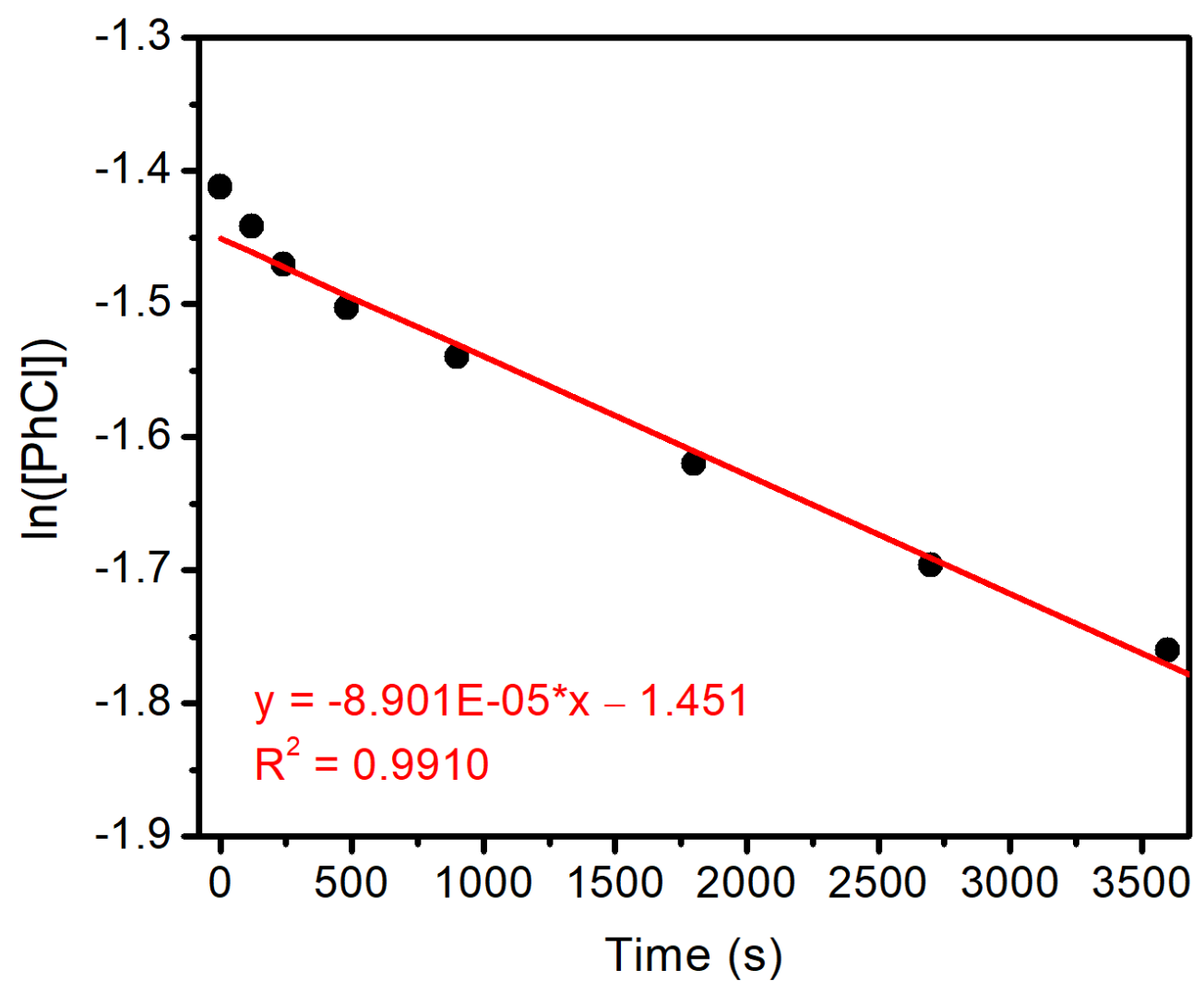

Figure S3. First-order kinetic plot for the data from the standard reaction with twice the amount of $\mathrm{K}_{3} \mathrm{PO}_{4}$. The first data point was not included in the linear fit. 
Table S4. Kinetic data for the catalytic reaction of $\mathrm{PhCl}$ and $\mathrm{PhB}(\mathrm{OH})_{2}$ under the standard reaction conditions with twice the amount of $\mathrm{PhB}(\mathrm{OH})_{2}$.

\begin{tabular}{ccc}
\hline Time $(\min )$ & \% PhCl Remaining & {$[\mathrm{PhCl}](\mathrm{M})^{a}$} \\
\hline 0 & 100 & 0.23 \\
2 & 89 & 0.20 \\
4 & 87 & 0.20 \\
8 & 78 & 0.18 \\
15 & 68 & 0.16 \\
30 & 50 & 0.12 \\
45 & 39 & 0.09 \\
60 & 30 & 0.07 \\
${ }^{a}$ Assuming that $\mathrm{PhCl}$ and dodecane are present entirely in the THF layer.
\end{tabular}

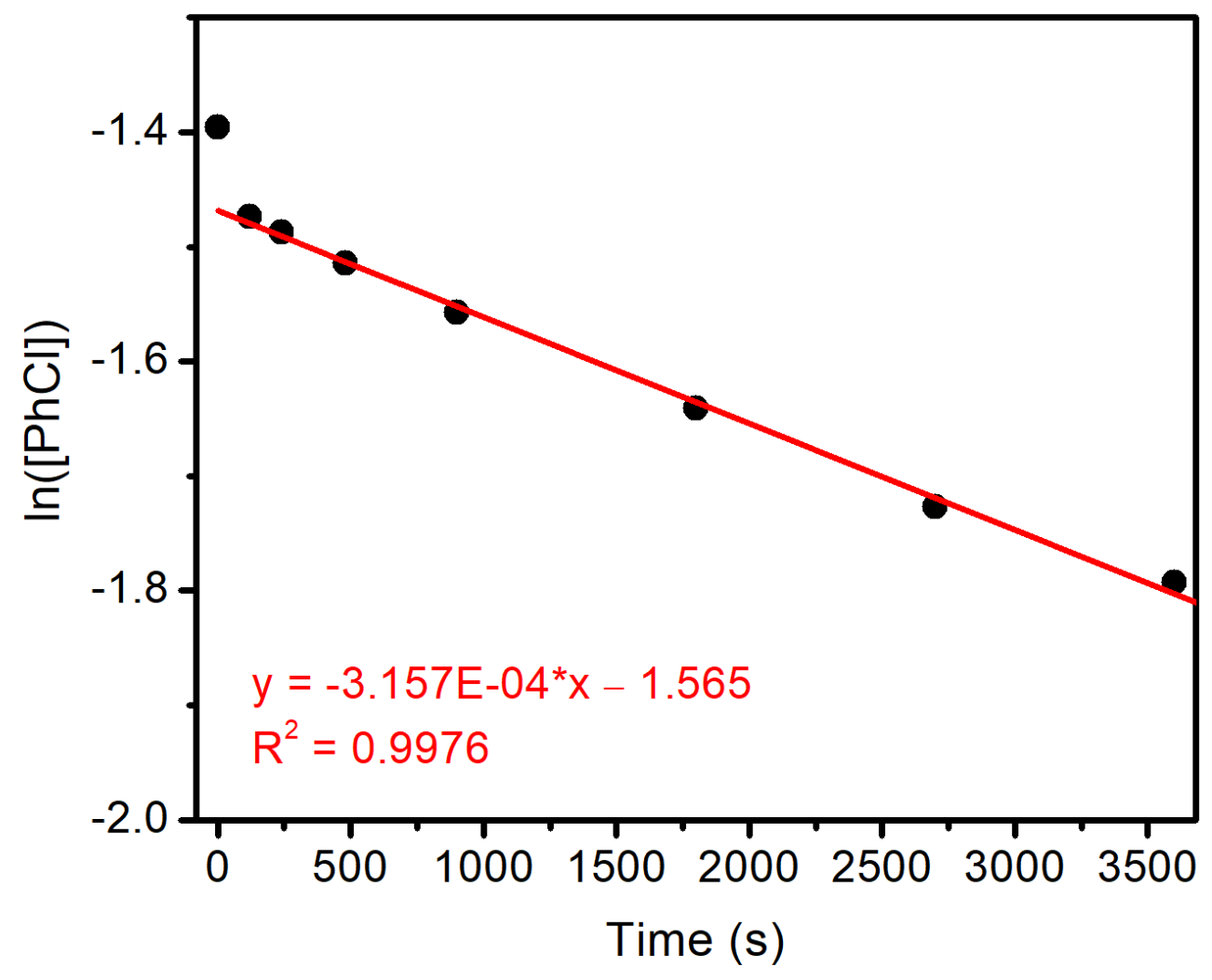

Figure S4. First-order kinetic plot for the data from the standard reaction with twice the amount of $\mathrm{PhB}(\mathrm{OH})_{2}$. The first data point was not included in the linear fit. 
Table S5. Kinetic data for the catalytic reaction of $\mathrm{PhCl}$ and $\mathrm{PhB}(\mathrm{OH})_{2}$ under the standard reaction conditions with twice the amount of $\mathbf{P h C l}$.

\begin{tabular}{ccc}
\hline Time $(\min )$ & \% PhCl Remaining $^{a}$ & {$[\mathrm{PhCl}](\mathrm{M})^{b}$} \\
\hline 0 & 200 & 0.56 \\
2 & 200 & 0.56 \\
4 & 197 & 0.56 \\
8 & 196 & 0.56 \\
15 & 183 & 0.54 \\
30 & 170 & 0.52 \\
45 & 155 & 0.50 \\
60 & 143 & 0.48 \\
\hline
\end{tabular}

${ }^{a}$ Relative to the standard reaction conditions. ${ }^{b}$ Assuming that $\mathrm{PhCl}$ and dodecane are present entirely in the THF layer.

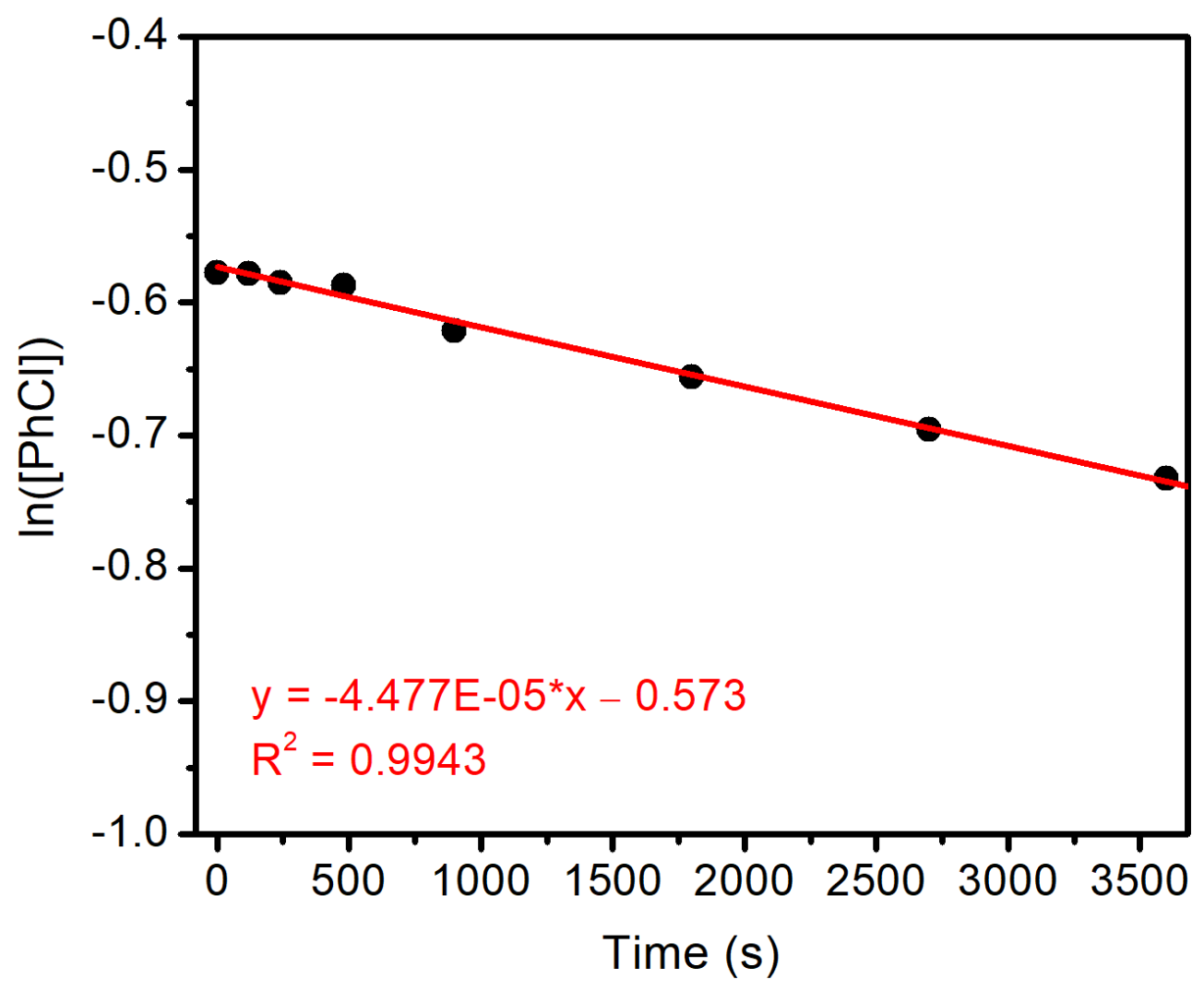

Figure S5. First-order kinetic plot for the data from the standard reaction with twice the amount of chlorobenzene. The first data point was not included in the linear fit. 
Table S6. Kinetic data for the catalytic reaction of $\mathrm{PhCl}$ and $\mathrm{PhB}(\mathrm{OH})_{2}$ under the standard reaction conditions with half the amount of $\mathrm{L1} \cdot \mathrm{Pd}(\mathrm{Ph}) \mathrm{Cl}$.

\begin{tabular}{ccc}
\hline Time $(\min )$ & \% PhCl Remaining $^{a}$ & {$[\mathrm{PhCl}](\mathrm{M})^{b}$} \\
\hline 0 & 100 & 0.25 \\
2 & 99 & 0.25 \\
4 & 98 & 0.24 \\
8 & 98 & 0.24 \\
15 & 93 & 0.23 \\
30 & 87 & 0.22 \\
45 & 82 & 0.20 \\
60 & 78 & 0.19
\end{tabular}

${ }^{a}$ Relative to the standard reaction conditions. ${ }^{b}$ Assuming that $\mathrm{PhCl}$ and dodecane are present entirely in the THF layer.

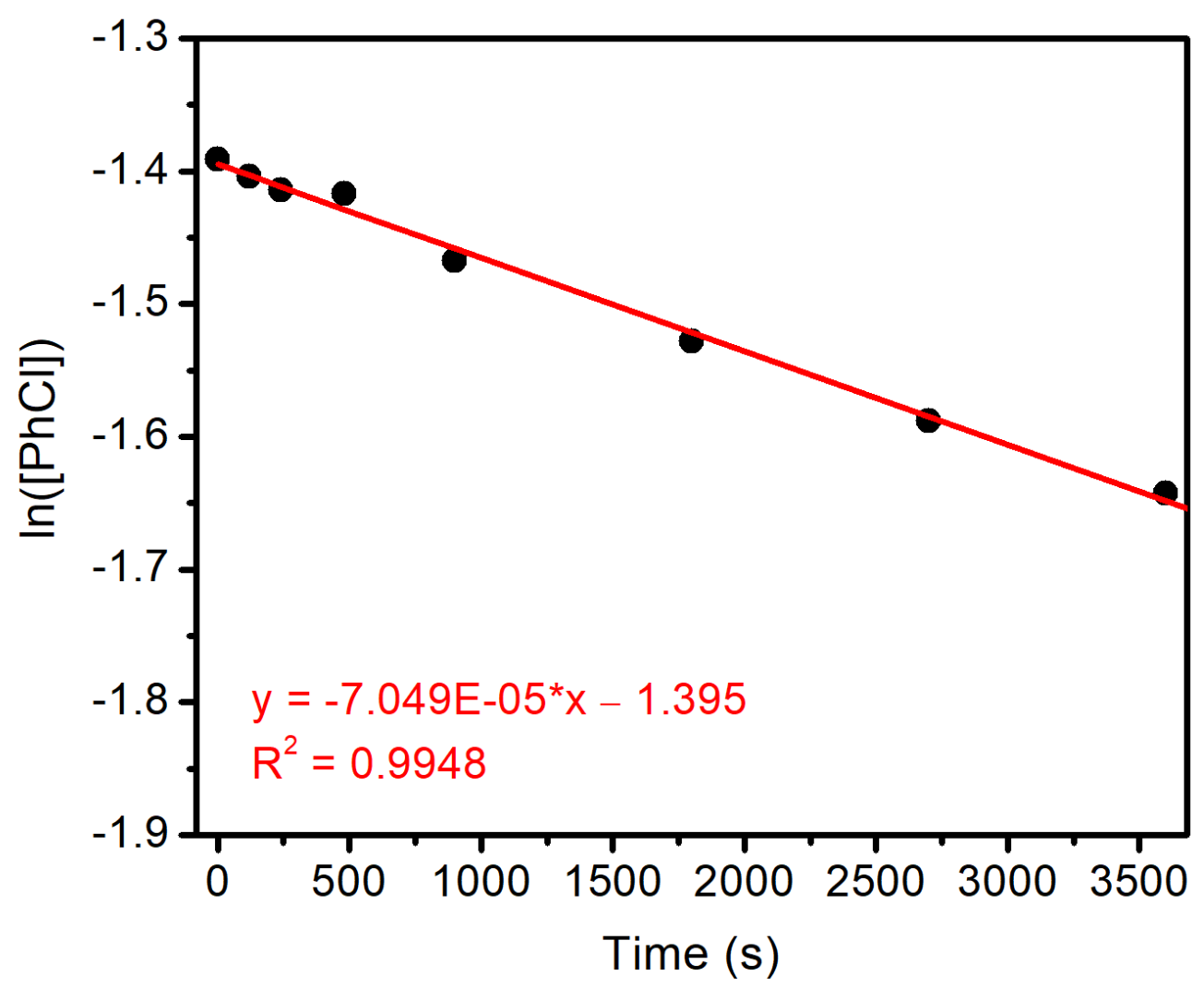

Figure S6. First-order kinetic plot for the data from the standard reaction with half the amount of $\mathbf{L 1} \cdot \mathrm{Pd}(\mathrm{Ph}) \mathrm{Cl}$. 


\section{Aryl halide effect on catalytic reactions (Figure 3).}

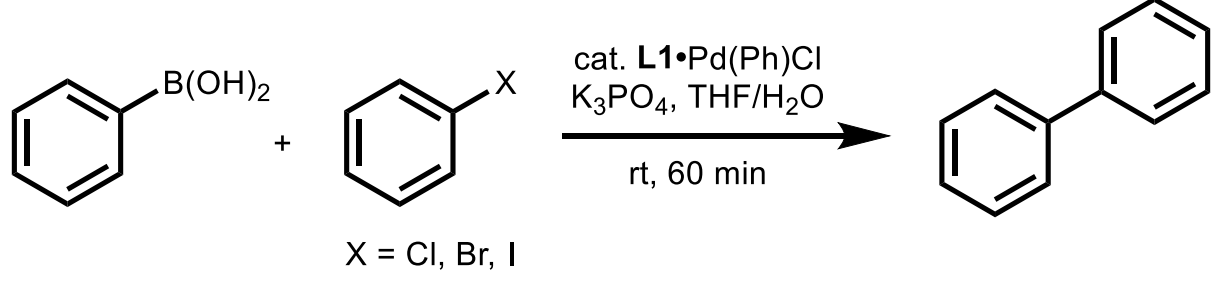

Standard procedure. A screw-cap reaction tube equipped with a stir bar was charged with $\mathbf{L 1} \cdot \mathrm{Pd}(\mathrm{Ph}) \mathrm{Cl}(6.29 \mathrm{mg}, 0.01 \mathrm{mmol}, 0.02$ equiv.) and phenylboronic acid (61.0 mg, $0.50 \mathrm{mmol}$, 1.00 equiv.). The reaction vessel was evacuated and backfilled with nitrogen (this process was repeated a total of three times). Then, the aryl halide ( $0.50 \mathrm{mmol}, 1.00$ equiv.), dodecane (114 $\mu \mathrm{L}$, $0.50 \mathrm{mmol}, 1.00$ equiv. $)$ and THF (2 mL) were added and the reaction mixture was briefly stirred until a homogeneous solution was obtained. The first aliquot $(50 \mu \mathrm{L})$ was taken as reference. Afterwards, a degassed solution of $1.0 \mathrm{M}$ aq. $\mathrm{K}_{3} \mathrm{PO}_{4}(1.0 \mathrm{~mL}, 1.0 \mathrm{mmol}, 2.0$ equiv. $)$ was injected rapidly and the reaction was allowed to stir at $400 \mathrm{rpm}$ at room temperature for $90 \mathrm{~min}$. The reaction was analyzed by withdrawing aliquots $(50 \mu \mathrm{L})$ from the reaction mixture by syringe after $2,4,8,15,30,45,60$, and $90 \mathrm{~min}$ and submitting them to $\mathrm{GC}$ analysis to determine the consumption of the starting material using dodecane as internal standard.

In all cases, extremely rapid consumption of starting material was observed during the first 2 min of the reaction, followed by slower conversion. As such, the first data point was excluded from subsequent kinetic analyses, as this initial rapid consumption is likely due to non-equilibrium effects at the start of the reaction. The kinetic data and corresponding first-order kinetic models are included below for each experiment. 
Table S7. Kinetic data for the catalytic reaction of $\mathrm{PhBr}$ and $\mathrm{PhB}(\mathrm{OH})_{2}$ under the standard reaction conditions.

\begin{tabular}{ccc}
\hline Time $(\min )$ & \% PhBr Remaining & {$[\mathrm{PhBr}](\mathrm{M})^{a}$} \\
\hline 0 & 100 & 0.23 \\
2 & 95 & 0.22 \\
4 & 94 & 0.22 \\
8 & 93 & 0.21 \\
15 & 91 & 0.21 \\
30 & 87 & 0.20 \\
45 & 84 & 0.19 \\
60 & 80 & 0.18 \\
90 & 75 & 0.17 \\
\hline
\end{tabular}

${ }^{a}$ Assuming that $\mathrm{PhBr}$ and dodecane are present entirely in the THF layer.

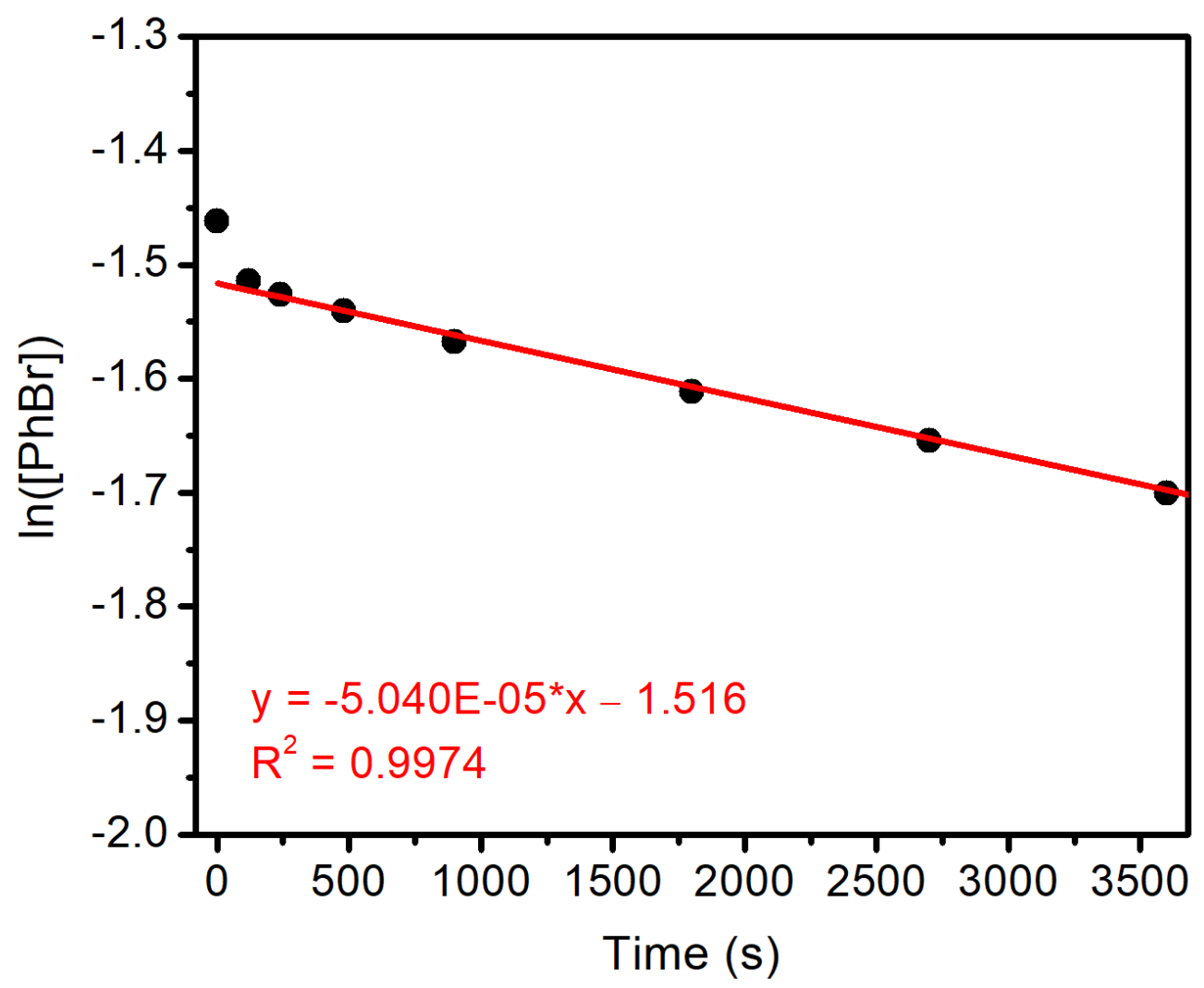

Figure S7. First-order kinetic plot for the data from the standard reaction using $\mathrm{PhBr}$. The first data point was not included in the linear fit. 
Table S8. Kinetic data for the catalytic reaction of $\mathrm{PhI}$ and $\mathrm{PhB}(\mathrm{OH})_{2}$ under the standard reaction conditions.

\begin{tabular}{ccc}
\hline Time $(\min )$ & \% PhBr Remaining & {$[\mathrm{PhI}](\mathrm{M})^{a}$} \\
\hline 0 & 100 & 0.24 \\
2 & 87 & 0.20 \\
4 & 85 & 0.20 \\
8 & 85 & 0.20 \\
15 & 83 & 0.19 \\
30 & 83 & 0.19 \\
45 & 80 & 0.19 \\
60 & 80 & 0.19 \\
90 & 79 & 0.18 \\
\hline
\end{tabular}

${ }^{a}$ Assuming that PhI and dodecane are present entirely in the THF layer.

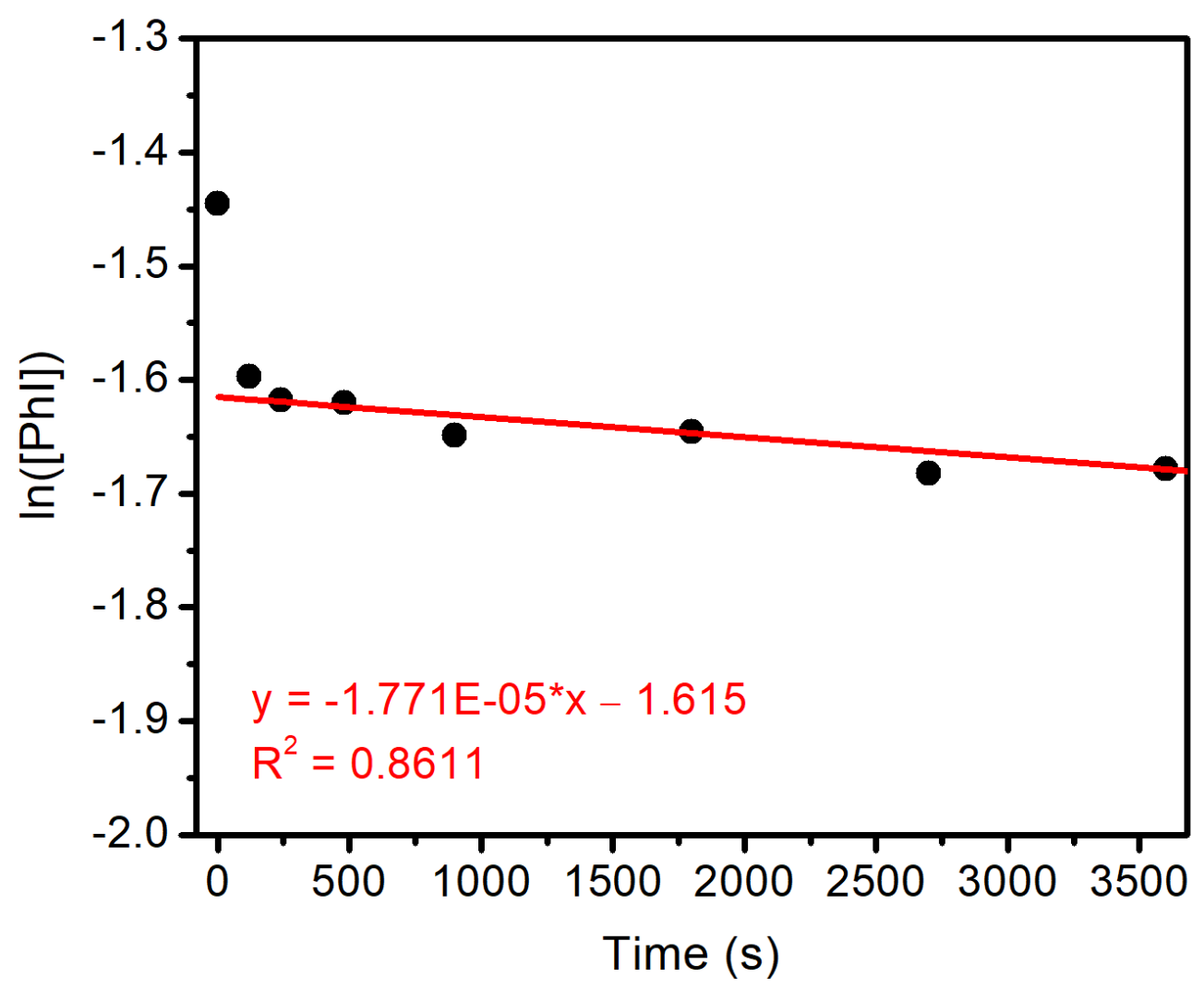

Figure S8. First-order kinetic plot for the data from the standard reaction using PhI. The first data point was not included in the linear fit. 


\section{Effect of added KX on catalytic reactions (Table 2).}

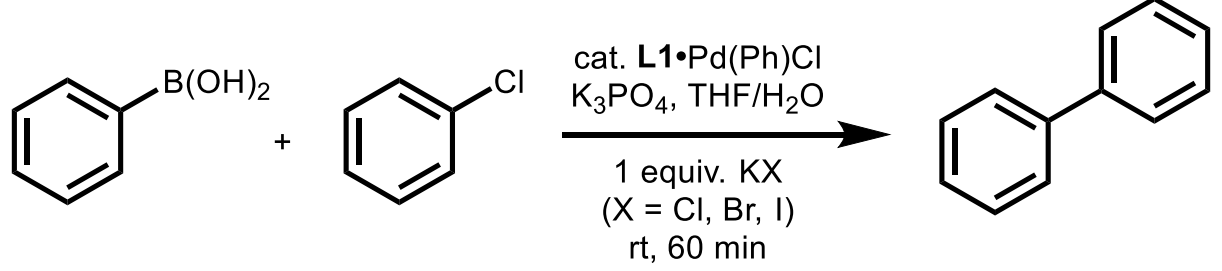

Standard procedure. A screw-cap reaction tube equipped with a stir bar was charged with L1·Pd(Ph)Cl (6.29 mg, $0.01 \mathrm{mmol}, 0.02$ equiv.), $\mathrm{KX}$ (0.50 mmol, 1.00 equiv.), and phenylboronic acid (61.0 mg, $0.50 \mathrm{mmol}, 1.00$ equiv.). The salts $\mathrm{KBr}$ and $\mathrm{KI}$ were weighed out in a nitrogenfilled glovebox, whereas $\mathrm{KCl}$ was weighed out in air. The reaction vessel was evacuated and backfilled with nitrogen (this process was repeated a total of three times). Then, chlorobenzene (50.7 $\mu \mathrm{L}, 0.50 \mathrm{mmol}, 1.00$ equiv.), dodecane (114 $\mu \mathrm{L}, 0.50 \mathrm{mmol}, 1.00$ equiv.) and THF (2 mL) were added and the reaction mixture was briefly stirred until a homogeneous solution was obtained. The first aliquot $(50 \mu \mathrm{L})$ was taken as reference. Afterwards, a degassed solution of 1.0 $\mathrm{M}$ aq. $\mathrm{K}_{3} \mathrm{PO}_{4}(1.0 \mathrm{~mL}, 1.0 \mathrm{mmol}, 2.0$ equiv.) was injected rapidly and the reaction was allowed to stir at $400 \mathrm{rpm}$ at room temperature for $60 \mathrm{~min}$. The reaction was analyzed by withdrawing aliquots $(50 \mu \mathrm{L})$ from the reaction mixture by syringe after 30 and $60 \mathrm{~min}$ and submitting them to GC analysis to determine the consumption of the starting material using dodecane as internal standard. The results of these experiments are included in Table 2 in the main text.

To examine the generality of KX inhibition during Suzuki-Miyaura couplings, the coupling of 3-chloroanisole with 2,6-difluorophenylboronic acid was also examined using the same procedure detailed above, except 1.50 equiv. of boronic acid was employed instead of 1.00 equiv. This reaction is significantly faster than the standard coupling under catalytic conditions and is complete within approximately $5 \mathrm{~min}$ in the absence of $\mathrm{KX}$ additives. The results of these experiments are included below in Figure S9 and corroborate the findings presented in Table 2 of the main text. In fact, the reaction in the presence of KI did not proceed to full conversion even after 90 min. 




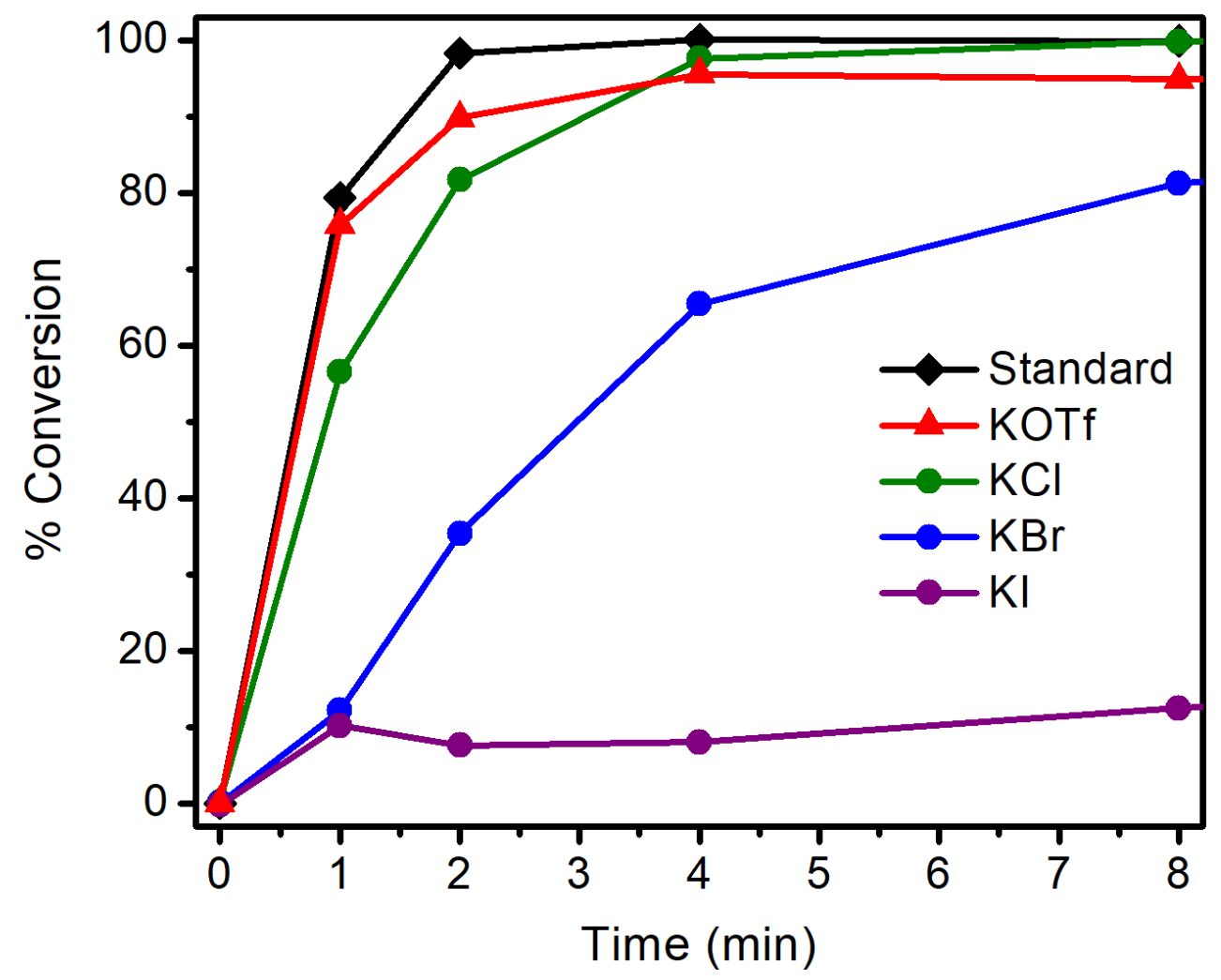

Figure S9. Initial rates for the reaction of 2,6-difluorophenylboronic acid and 3-chloroanisole under catalytic conditions in the presence of various KX salts. The order of these reactions is consistent with the results in Table 2, with KI demonstrating the most significant inhibitory effect. Lines are included between data points as a visual guide. 


\section{Stoichiometric transmetalation experiments (Figure 4).}

Reaction of $\mathrm{L1} \cdot \mathrm{Pd}(\mathrm{Ph}) \mathrm{Cl}$ with phenylboronic acid in the presence of water or aq. $\mathrm{K}_{3} \mathrm{PO}_{4}$

(Figure S10). Two separate oven-dried test tubes equipped with stir bars were charged with L1 $\cdot \mathrm{Pd}(\mathrm{Ph}) \mathrm{Cl}$ (31.5 mg, $0.05 \mathrm{mmol}, 1.00$ equiv.). The reaction tubes were evacuated and backfilled with argon (this process was repeated a total of three times). Dodecane $(10.0 \mu \mathrm{L}, 0.04 \mathrm{mmol}, 0.80$ equiv. ) and THF $(0.5 \mathrm{~mL})$ were added and the reaction mixtures were stirred at $60{ }^{\circ} \mathrm{C}$ for $1-2 \mathrm{~min}$ until homogeneous solutions were obtained. After cooling to room temperature, the first aliquot was taken as reference from each tube. Afterwards, phenylboronic acid $(9.75 \mathrm{mg}, 0.08 \mathrm{mmol}, 1.60$ equiv.) in THF $(0.5 \mathrm{~mL})$ was added to each tube simultaneously with either $\mathrm{H}_{2} \mathrm{O}(100 \mu \mathrm{L})$ or 1.5 $\mathrm{M}$ aq. $\mathrm{K}_{3} \mathrm{PO}_{4}(100 \mu \mathrm{L}, 0.15 \mathrm{mmol}, 3.00$ equiv.). The reactions were stirred at room temperature for $60 \mathrm{~min}$. An aliquot $(50 \mu \mathrm{L})$ was withdrawn from each reaction mixture after 1, 2, 5, 10, 20, 30, and $60 \mathrm{~min}$ and added to a solution of 2,6-difluorophenylboronic acid (10.0 mg, $0.06 \mathrm{mmol})$ in THF $(0.25 \mathrm{~mL})$, termed the "sampling mixture". After addition of $1.5 \mathrm{M}$ aq. $\mathrm{K}_{3} \mathrm{PO}_{4}(100 \mu \mathrm{L}, 0.15$ mmol), the "sampling mixture" was stirred for 15 min. The mixture was diluted with EtOAc $(0.5 \mathrm{~mL})$ and analyzed by GC using dodecane as internal standard. Because 2,6difluorophenylboronic acid reacts significantly faster than phenylboronic acid in the "sampling mixture," the amount of 2,6-difluorobiphenyl in the "sampling mixture" should correspond to the amount of unreacted $\mathbf{L 1} \cdot \mathrm{Pd}(\mathrm{Ph}) \mathrm{Cl}$ remaining in solution. ${ }^{6}$

When only water was added to a mixture of $\mathbf{L 1} \cdot \mathrm{Pd}(\mathrm{Ph}) \mathrm{Cl}$ and $\mathrm{PhB}(\mathrm{OH})_{2}$, minimal conversion of $\mathbf{L 1} \cdot \mathrm{Pd}(\mathrm{Ph}) \mathrm{Cl}$ was observed (Figure S10). However, when aq. $\mathrm{K}_{3} \mathrm{PO}_{4}$ was added along with phenylboronic acid, rapid consumption of $\mathbf{L 1} \cdot \mathrm{Pd}(\mathrm{Ph}) \mathrm{Cl}$ was observed (nearly full conversion in $<60 \mathrm{~min}$, Figure S10). This finding confirms that aqueous base is required for transmetalation to occur. 
<smiles>COc1ccccc1P(Cl)(Cl)(c1ccccc1)[Ge](Cl)(c1ccccc1)c1ccccc1OCc1ccccc1</smiles><smiles>CCC(C)(O)CC</smiles><smiles>c1ccc(-c2ccccc2)cc1</smiles>

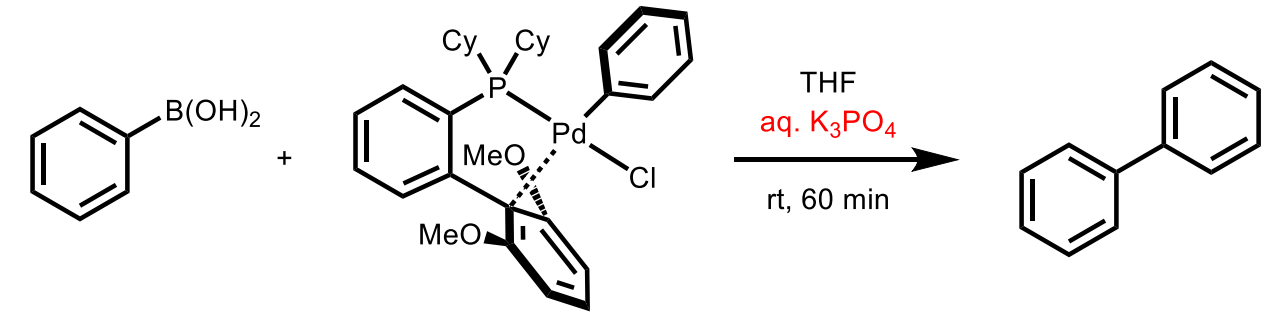

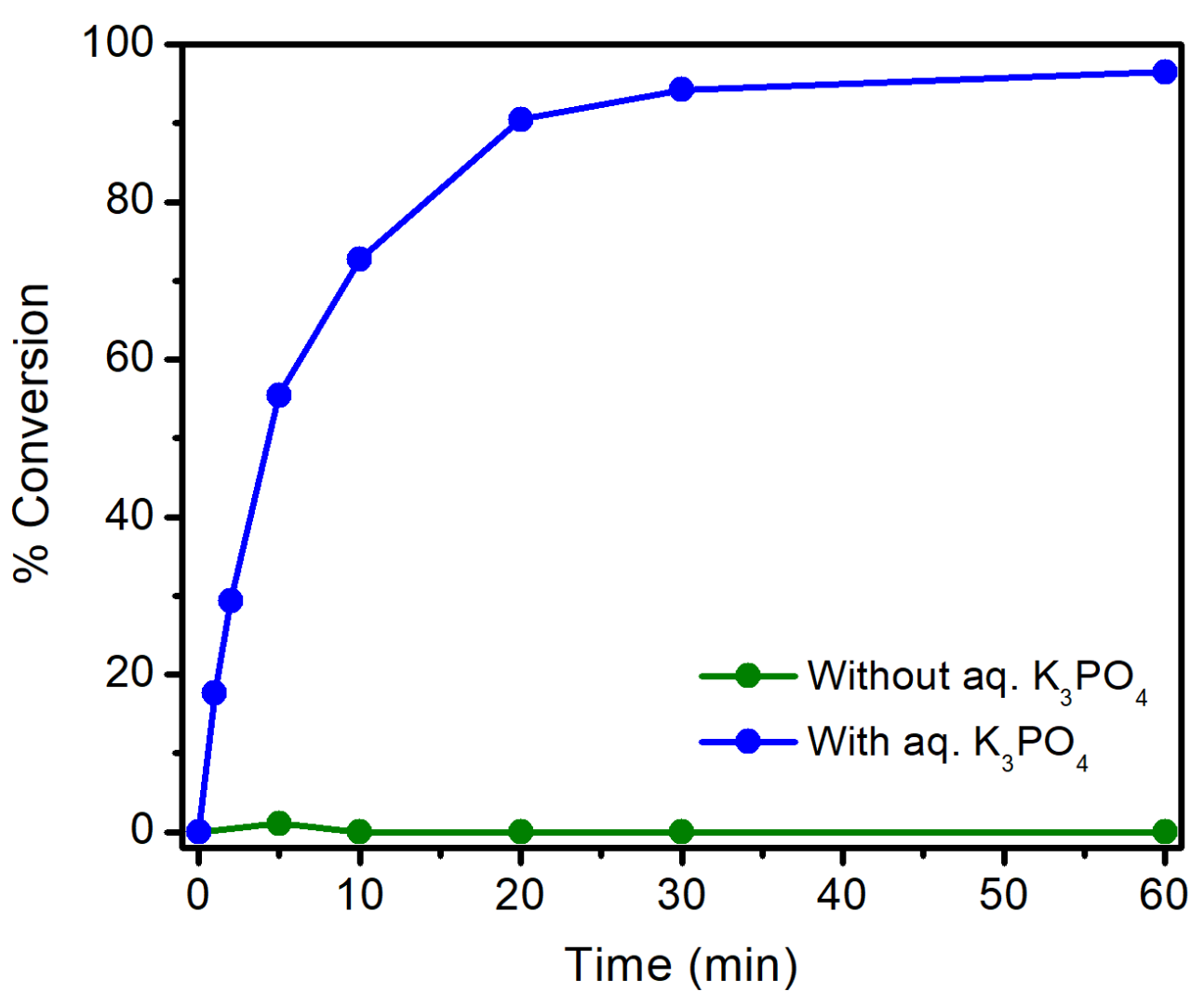

Figure S10. Results of the stoichiometric reactions of $\mathbf{L 1} \cdot \mathrm{Pd}(\mathrm{Ph}) \mathrm{Cl}$ with phenylboronic acid in the presence of water (green) or aq. $\mathrm{K}_{3} \mathrm{PO}_{4}$ solution (blue). Consumption of $\mathbf{L 1} \cdot \mathrm{Pd}(\mathrm{Ph}) \mathrm{Cl}$ was only observed in the presence of aqueous base. Lines are included between data points as a visual guide. 


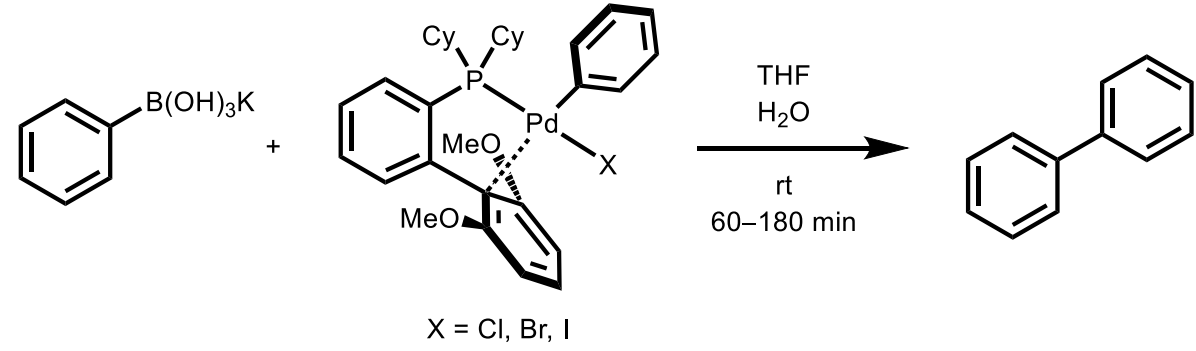

Reaction of $\mathrm{L} 1 \cdot \mathrm{Pd}(\mathrm{Ph}) \mathrm{X}(\mathrm{X}=\mathrm{Cl}, \mathrm{Br}$, I) with potassium phenylboronate (Figure 4). Three separate oven-dried test tubes equipped with stir bars were charged with $\mathbf{L} \mathbf{1} \cdot \mathrm{Pd}(\mathrm{Ph}) \mathrm{Cl}(31.5 \mathrm{mg}$, 0.05 mmol, 1.00 equiv.), $\mathbf{L 1} \cdot \mathrm{Pd}(\mathrm{Ph}) \mathrm{Br}(33.7 \mathrm{mg}, 0.05 \mathrm{mmol}, 1.00$ equiv.), or $\mathbf{L 1} \cdot \mathrm{Pd}(\mathrm{Ph}) \mathrm{I}(36.0$ mg, 0.05 mmol, 1.00 equiv.). The reaction tubes were evacuated and backfilled with argon (this process was repeated a total of three times). Dodecane $(10.0 \mu \mathrm{L}, 0.04 \mathrm{mmol}, 0.80$ equiv.) and THF $(1.0 \mathrm{~mL})$ were added to each tube and the reaction mixtures were stirred at $60{ }^{\circ} \mathrm{C}$ for $1-2 \mathrm{~min}$ until homogeneous solutions were obtained. After cooling to room temperature, the first aliquot was taken as reference from each tube. Afterwards, potassium phenylboronate $(14.2 \mathrm{mg}, 0.08 \mathrm{mmol}$, 1.60 equiv.) in $\mathrm{H}_{2} \mathrm{O}(100 \mu \mathrm{L})$ was added rapidly to each tube. The reactions were stirred at room temperature for 60,120 , or $180 \mathrm{~min}$, for $\mathrm{X}=\mathrm{Cl}, \mathrm{Br}$, and $\mathrm{I}$, respectively. An aliquot $(50 \mu \mathrm{L})$ was withdrawn from each reaction mixture after 1, 2, 5, 10, 20, 30, 60, 120, and 180 min and added to a solution of 2,6-difluorophenylboronic acid $(10.0 \mathrm{mg}, 0.06 \mathrm{mmol})$ in THF $(0.25 \mathrm{~mL})$. After addition of $1.5 \mathrm{M}$ aq. $\mathrm{K}_{3} \mathrm{PO}_{4}(100 \mu \mathrm{L}, 0.15 \mathrm{mmol})$, the sampling mixture was stirred for $15 \mathrm{~min}$. The mixture was diluted with EtOAc $(0.5 \mathrm{~mL})$ and analyzed by GC using dodecane as internal standard. Because 2,6-difluorophenylboronic acid reacts significantly faster than phenylboronic acid in the "sampling mixture," the amount of 2,6-difluorobiphenyl in the "sampling mixture" should correspond to the amount of unreacted $\mathbf{L 1} \cdot \mathrm{Pd}(\mathrm{Ph}) \mathrm{Cl}$ remaining in solution. ${ }^{6}$ Second-order kinetic fits for each of these reactions are included in Figures S11-S13 below. Note that when the reaction of $\mathbf{L 1} \cdot \mathrm{Pd}(\mathrm{Ph}) \mathrm{Cl}$ with potassium phenylboronate was evaluated by ${ }^{11} \mathrm{~B} \mathrm{NMR}$, no species other than the starting boronate and boric acid were observed. 


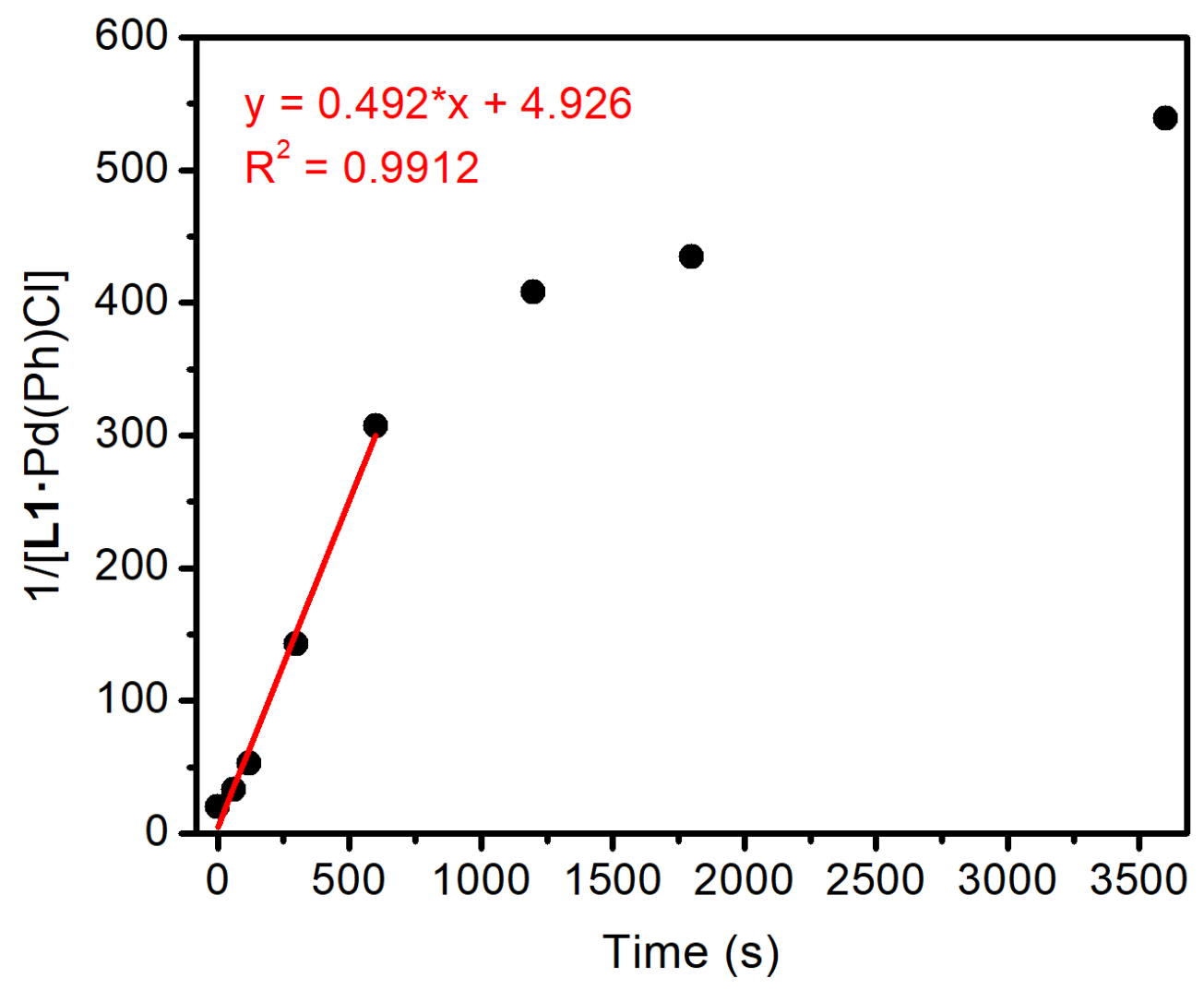

Figure S11. Second-order kinetic plot for the reaction of $\mathbf{L 1} \cdot \mathrm{Pd}(\mathrm{Ph}) \mathrm{Cl}$ with potassium phenylboronate. The reaction proceeded to $>90 \%$ conversion in $20 \mathrm{~min}$, and so only the early data points were used in the fit. This model assumes that $\mathrm{Pd}$ complex is present in the organic layer (i.e., $[\mathbf{L 1} \cdot \mathrm{Pd}(\mathrm{Ph}) \mathrm{Cl}]_{0}=0.05 \mathrm{M}$ ). 


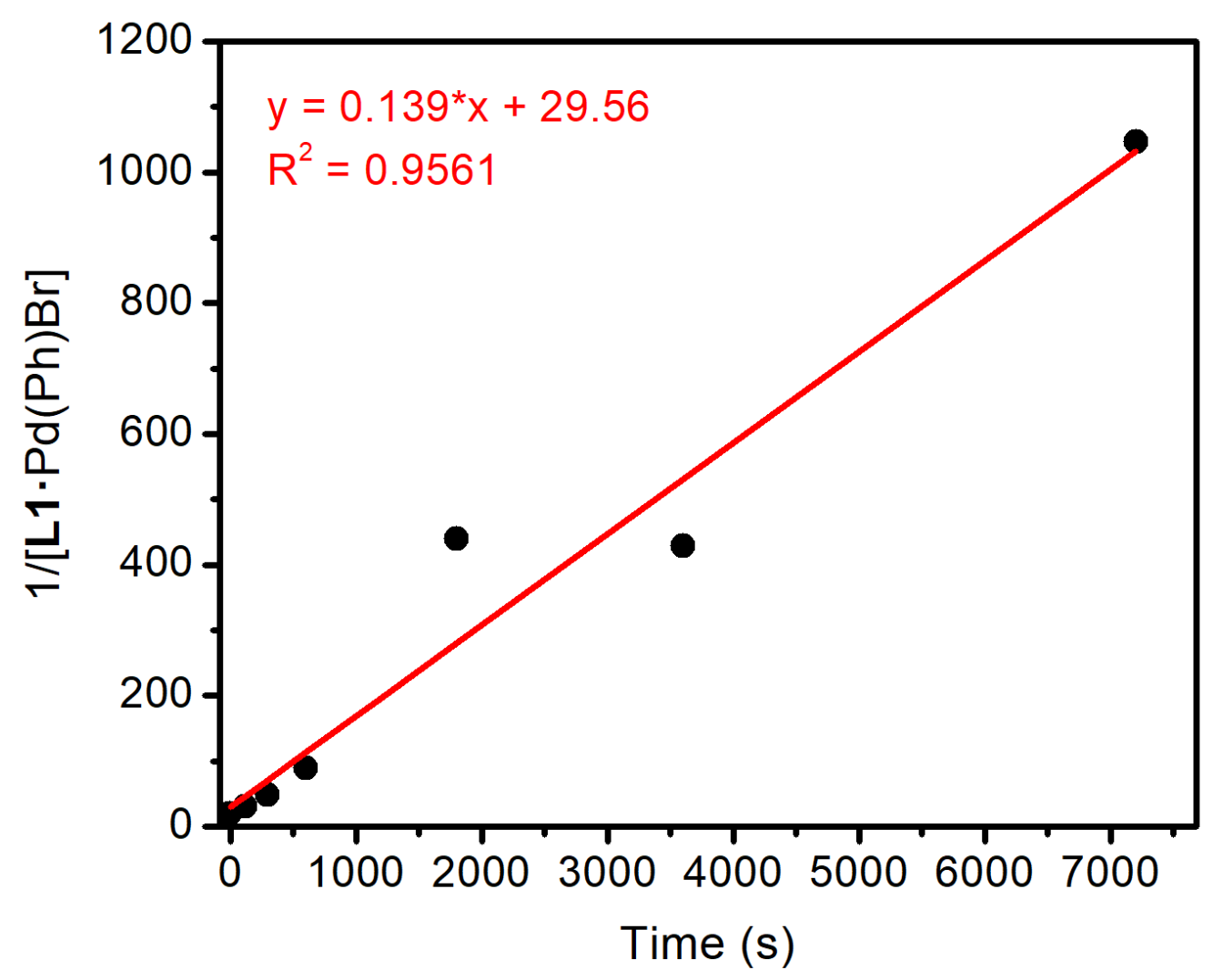

Figure S12. Second-order kinetic plot for the reaction of $\mathbf{L} 1 \cdot \mathrm{Pd}(\mathrm{Ph}) \mathrm{Br}$ with potassium phenylboronate. This model assumes that $\mathrm{Pd}$ complex is present in the organic layer (i.e., $\left.[\mathbf{L 1} \cdot \mathrm{Pd}(\mathrm{Ph}) \mathrm{Br}]_{0}=0.05 \mathrm{M}\right)$. Exclusion of the anomalous data point at $1800 \mathrm{~s}$ yielded an improved linear fit $\left(\mathrm{R}^{2}=0.9906\right)$ and a nearly identical second-order rate constant of $0.140 \mathrm{M}^{-1} \mathrm{~s}^{-1}$. 


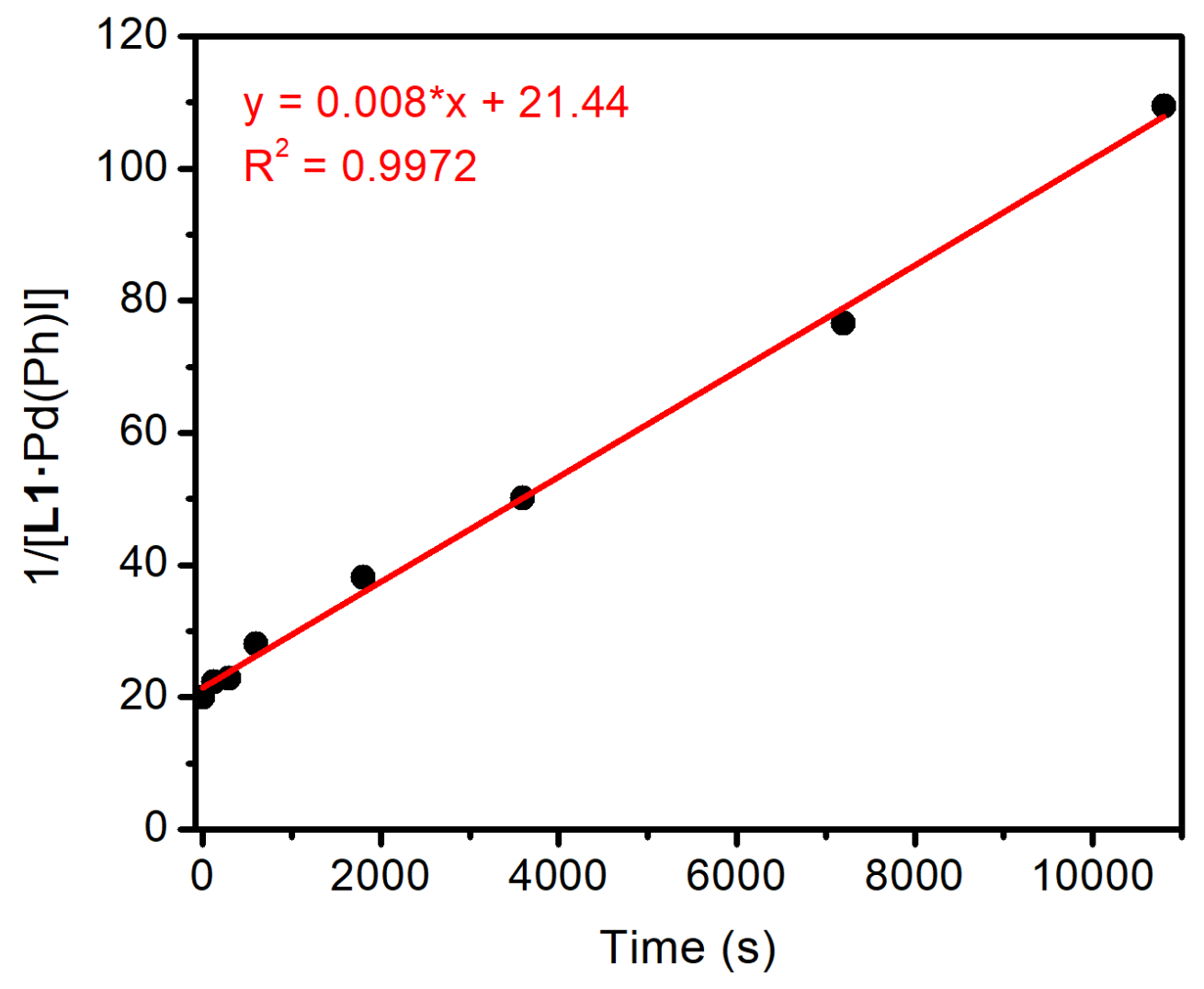

Figure S13. Second-order kinetic plot for the reaction of $\mathbf{L} 1 \cdot \mathrm{Pd}(\mathrm{Ph}) \mathrm{I}$ with potassium phenylboronate. This model assumes that Pd complex is present in the organic layer (i.e., $\left.[\mathbf{L} 1 \cdot \mathbf{P d}(\mathbf{P h}) \mathbf{I}]_{0}=0.05 \mathrm{M}\right)$. 


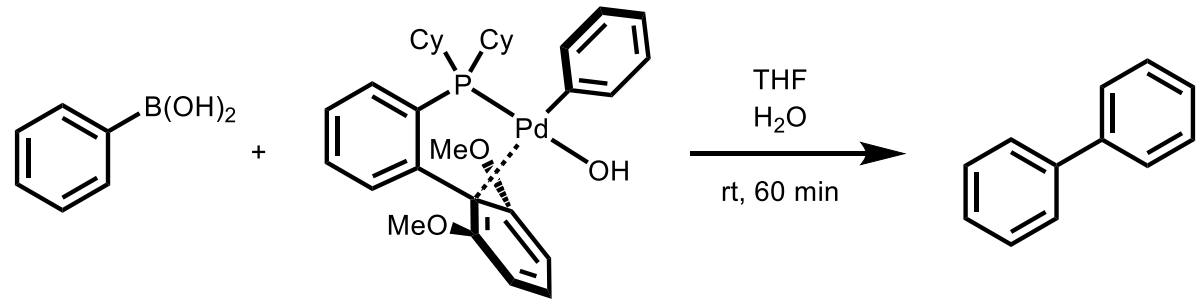

Reaction of L1•Pd(Ph)OH with phenylboronic acid (Figure 4). An oven-dried test tube equipped with a stir bar was charged with $\mathbf{L 1} \cdot \mathrm{Pd}(\mathrm{Ph}) \mathrm{OH}$ (30.1 $\mathrm{mg}, 0.05 \mathrm{mmol}, 1.00$ equiv.). The reaction tube was evacuated and backfilled with argon (this process was repeated a total of three times). Dodecane (10.0 $\mu \mathrm{L}, 0.04 \mathrm{mmol}, 0.80$ equiv.) and THF (0.5 mL) were added and the reaction mixture were stirred at $60{ }^{\circ} \mathrm{C}$ for $1-2$ min until a homogeneous solution was obtained. After cooling to room temperature, the first aliquot was taken as reference. Afterwards, phenylboronic acid $(9.75 \mathrm{mg}, 0.08 \mathrm{mmol}, 1.60$ equiv. $)$ in THF $(0.5 \mathrm{~mL})$ was added to each tube simultaneously with $\mathrm{H}_{2} \mathrm{O}(100 \mu \mathrm{L})$. The reaction was stirred at room temperature for $60 \mathrm{~min}$. An aliquot $(50 \mu \mathrm{L})$ was withdrawn from each reaction mixture after $1,2,5,10,20,30$, and 60 min and added to a solution of 2,6-difluorophenylboronic acid $(10.0 \mathrm{mg}, 0.06 \mathrm{mmol})$ in THF $(0.25$ $\mathrm{mL})$. After addition of $1.5 \mathrm{M}$ aq. $\mathrm{K}_{3} \mathrm{PO}_{4}(100 \mu \mathrm{L}, 0.15 \mathrm{mmol})$, the sampling mixture was stirred for $15 \mathrm{~min}$. The mixture was diluted with EtOAc $(0.5 \mathrm{~mL})$ and analyzed by GC using dodecane as internal standard. Because 2,6-difluorophenylboronic acid reacts significantly faster than phenylboronic acid in the "sampling mixture," the amount of 2,6-difluorobiphenyl in the "sampling mixture" should correspond to the amount of unreacted $\mathbf{L 1} \cdot \mathrm{Pd}(\mathrm{Ph}) \mathrm{OH}$ remaining in solution. ${ }^{6}$ A second-order kinetic fit for this reaction is included in Figure S14 below. Note that when the reaction of $\mathbf{L 1} \cdot \mathrm{Pd}(\mathrm{Ph}) \mathrm{OH}$ with phenylboronic acid was evaluated by ${ }^{11} \mathrm{~B} \mathrm{NMR}$, no species other than the starting boronic acid and boric acid were observed. 


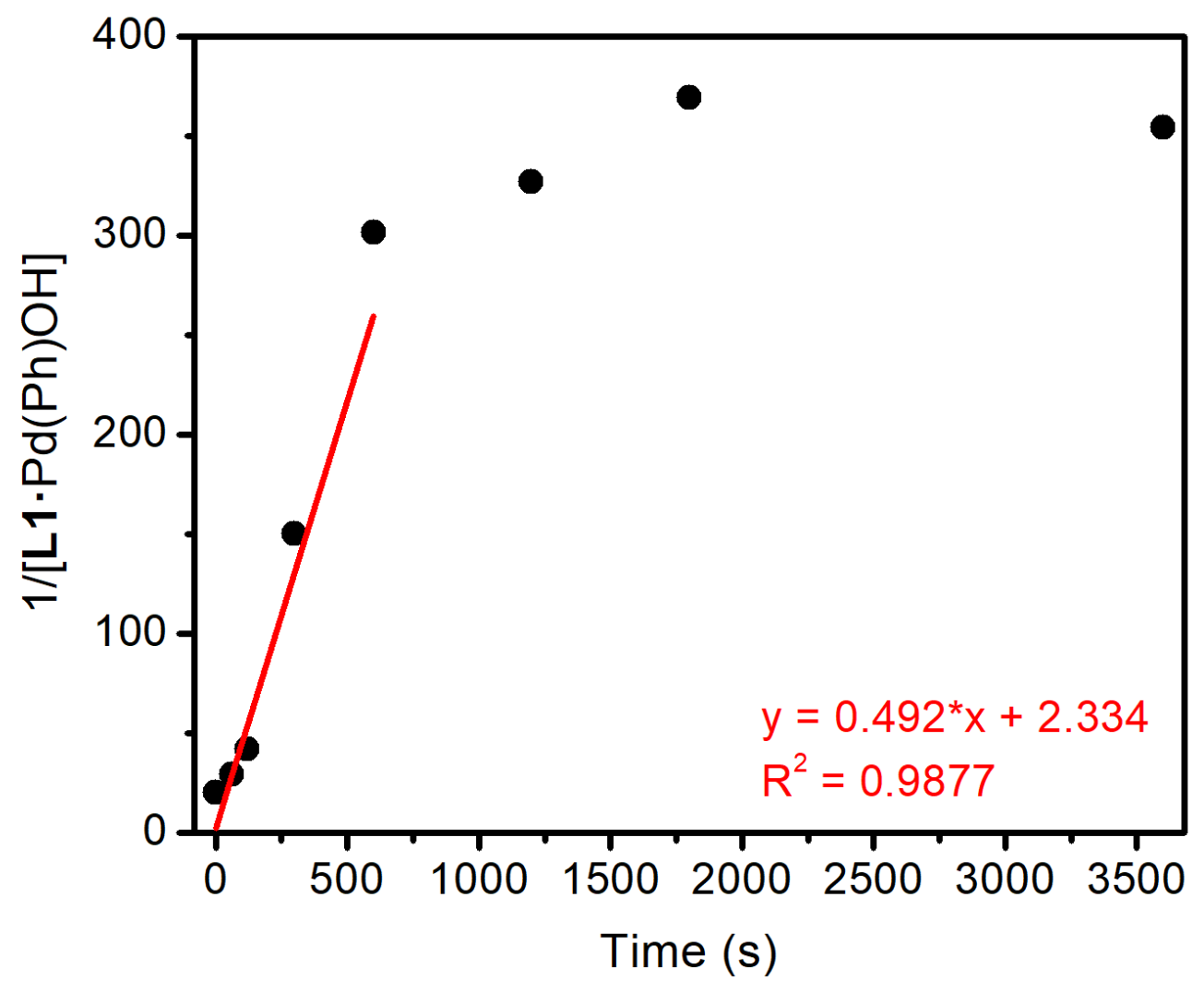

Figure S14. Second-order kinetic plot for the reaction of $\mathbf{L 1} \cdot \mathrm{Pd}(\mathrm{Ph}) \mathrm{OH}$ with phenylboronic acid. The reaction proceeded to $>90 \%$ conversion in $10 \mathrm{~min}$, and so only the early data points were used in the fit. This model assumes that $\mathrm{Pd}$ complex is present in the organic layer (i.e., $[\mathbf{L 1} \cdot \mathrm{Pd}(\mathrm{Ph}) \mathrm{OH}]_{0}$ $=0.05 \mathrm{M})$. 


\section{Reaction of $\mathrm{L1} \cdot \mathrm{Pd}(\mathrm{Ph}) \mathrm{X}(\mathrm{X}=\mathrm{Cl}, \mathrm{Br}, \mathrm{I})$ with aqueous potassium carbonate (Figure S15).}

Three separate oven-dried reaction tubes equipped with stir bars were charged with $\mathbf{L} 1 \cdot \mathrm{Pd}(\mathrm{Ph}) \mathrm{Cl}$ (8.82 mg, $14.0 \mu \mathrm{mol}, 1.00$ equiv.), $\mathbf{L 1} \cdot \mathrm{Pd}(\mathrm{Ph}) \mathrm{Br}(9.44 \mathrm{mg}, 14.0 \mu \mathrm{mol}, 1.00$ equiv.), and L1•Pd(Ph)I (10.1 mg, $14.0 \mu \mathrm{mol}, 1.00$ equiv.). The reaction tubes were evacuated and backfilled with argon (this process was repeated a total of three times). THF $(0.5 \mathrm{~mL})$ was added, and the reaction mixtures were stirred until a homogenous solution was obtained (in the case of L1·Pd(Ph)I, intermittent mild heating and subsequent cooling was required to achieve a homogeneous solution). Next, $1.5 \mathrm{M}$ aq. $\mathrm{K}_{2} \mathrm{CO}_{3}(218 \mu \mathrm{L}, 0.33 \mathrm{mmol}, 24.0$ equiv.) was added. The ratio of $\mathbf{L 1} \cdot \mathrm{Pd}(\mathrm{Ph}) \mathrm{X}(\mathrm{X}=\mathrm{I}, \mathrm{Br}, \mathrm{Cl})$ to $\mathbf{L 1} \cdot \mathrm{Pd}(\mathrm{Ph}) \mathrm{OH}$ was monitored by ${ }^{31} \mathrm{P}$ NMR spectroscopy. This procedure was repeated three times for each measurement to ensure accuracy; a standard deviation of $<3 \%$ was obtained for each data point. Notably, $<5 \%$ of $\mathbf{L 1} \cdot \mathrm{Pd}(\mathrm{Ph}) \mathrm{OH}$ was detected by ${ }^{31} \mathrm{P}$ NMR from the reaction with $\mathbf{L 1} \cdot \mathrm{Pd}(\mathrm{Ph}) \mathrm{I}$ even after $60 \mathrm{~min}$ of reaction time (not shown). 

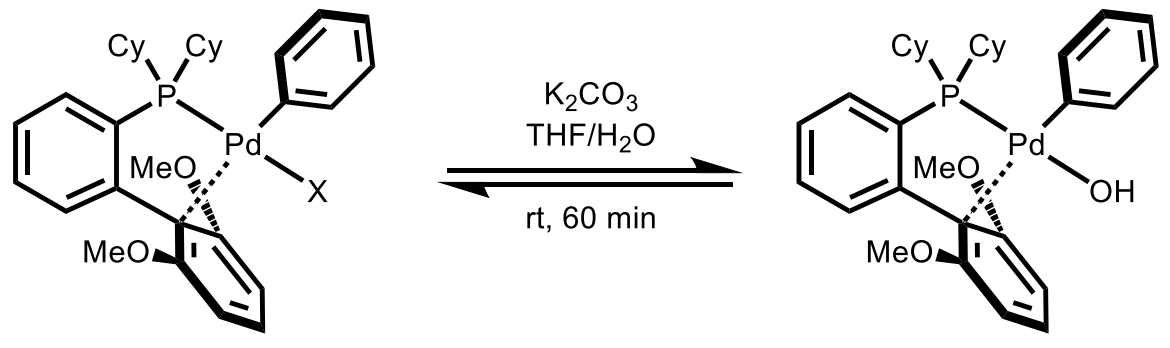

$\mathrm{X}=\mathrm{Cl}, \mathrm{Br}, \mathrm{I}$

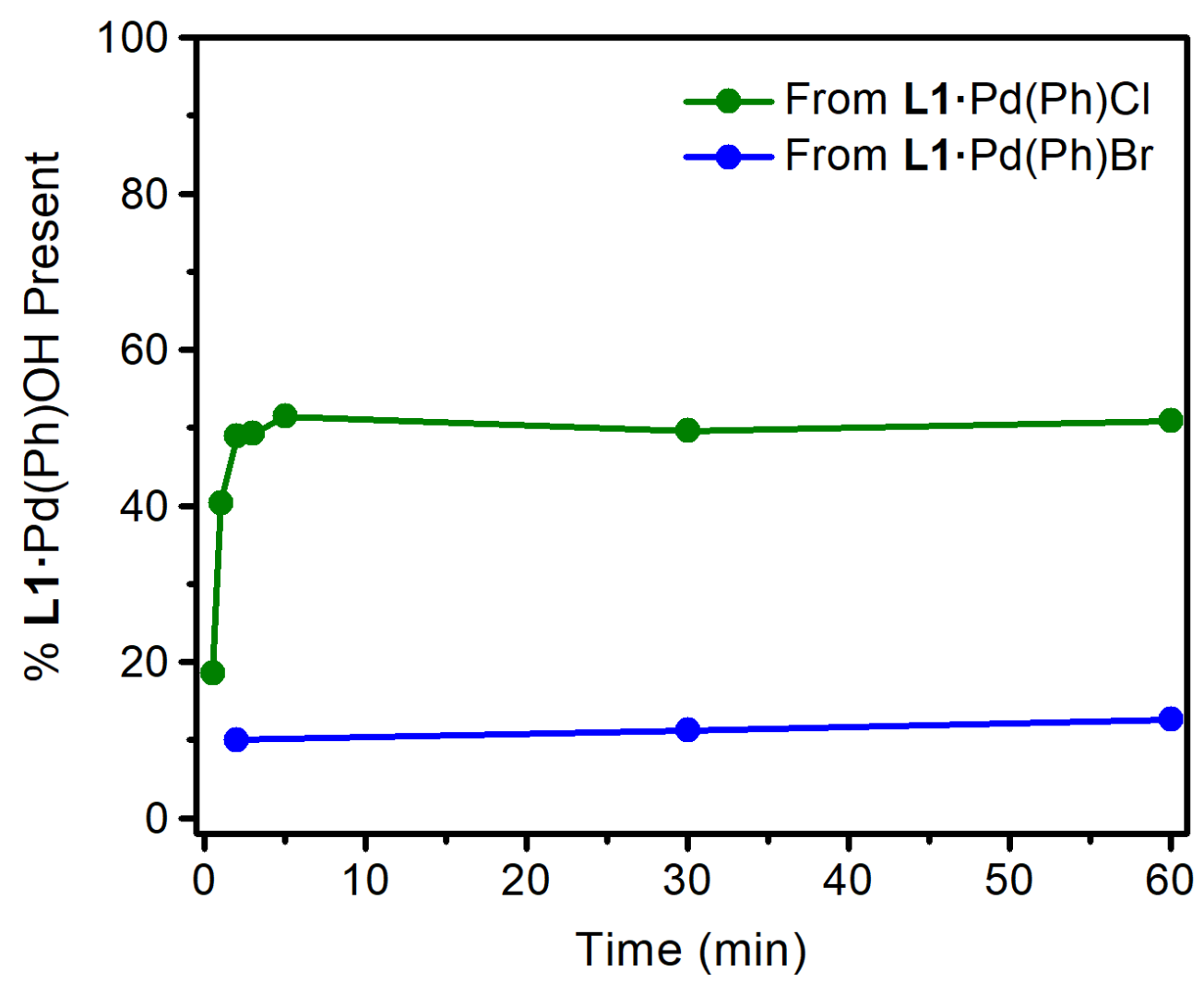

Figure S15. Kinetics of the equilibration of $\mathbf{L 1} \cdot \mathrm{Pd}(\mathrm{Ph}) \mathrm{X}(\mathrm{X}=\mathrm{Cl}, \mathrm{Br})$ with $\mathbf{L 1} \cdot \mathrm{Pd}(\mathrm{Ph}) \mathrm{OH}$ in the presence of aqueous $\mathrm{K}_{2} \mathrm{CO}_{3}$, as monitored by ${ }^{31} \mathrm{P}$ NMR. The shown data are an average of three separate experiments.

Note that while these experiments were carried out with a different base $\left(\mathrm{K}_{2} \mathrm{CO}_{3}\right)$ than other stoichiometric and catalytic experiments $\left(\mathrm{K}_{3} \mathrm{PO}_{4}\right)$ in order to minimize ${ }^{31} \mathrm{P}$ NMR signal broadening from $\mathrm{K}_{3} \mathrm{PO}_{4}$, we have found that the equilibrium ratio between $\mathbf{L 1} \cdot \mathrm{Pd}(\mathrm{Ph}) \mathrm{Br}$ and $\mathbf{L 1} \cdot \mathrm{Pd}(\mathrm{Ph}) \mathrm{OH}$ is relatively insensitive to the identity of the base (Figure S17). Therefore, these results suggest that similar conclusions can be drawn for experiments with either $\mathrm{K}_{2} \mathrm{CO}_{3}$ or $\mathrm{K}_{3} \mathrm{PO}_{4}$. 

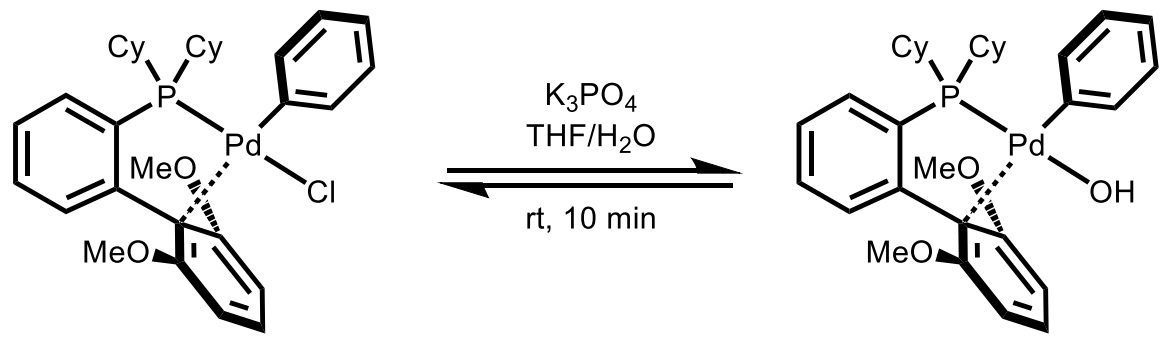

The rapid rate of equilibration between $\mathbf{L 1} \cdot \mathrm{Pd}(\mathrm{Ph}) \mathrm{Cl}$ and $\mathbf{L 1} \cdot \mathrm{Pd}(\mathrm{Ph}) \mathrm{OH}$ under biphasic conditions was corroborated by reaction calorimetry. To a $16 \mathrm{~mL}$ calorimeter vial equipped with a magnetic stirring bar under $\mathrm{Ar}$ was added a mixture of $1.5 \mathrm{M}$ aq. $\mathrm{K}_{3} \mathrm{PO}_{4}(1.0 \mathrm{~mL}, 1.50 \mathrm{mmol}$, 30.0 equiv. $)$ and THF $(0.5 \mathrm{~mL})$. A syringe was charged with a solution of $\mathbf{L 1} \cdot \mathrm{Pd}(\mathrm{Ph}) \mathrm{Cl}(31.5 \mathrm{mg}$, $0.05 \mathrm{mmol}, 1.00$ equiv. $)$ in THF $(0.5 \mathrm{~mL})$ and placed in the calorimeter. After thermal equilibration of the calorimeter to $23{ }^{\circ} \mathrm{C}$, the content of the syringe was injected into the calorimeter vial and the heat evolution was measured. As reference, THF $(0.5 \mathrm{~mL})$ was added to a mixture of $1.5 \mathrm{M}$ aq. $\mathrm{K}_{3} \mathrm{PO}_{4}(1.0 \mathrm{~mL})$ and $\mathrm{THF}(0.5 \mathrm{~mL})$. The reaction was stirred until the heat flow on the calorimeter returned to the baseline. A correction was then applied to the raw data due to the delay between the moment that the heat is given off and the moment that it is detected.

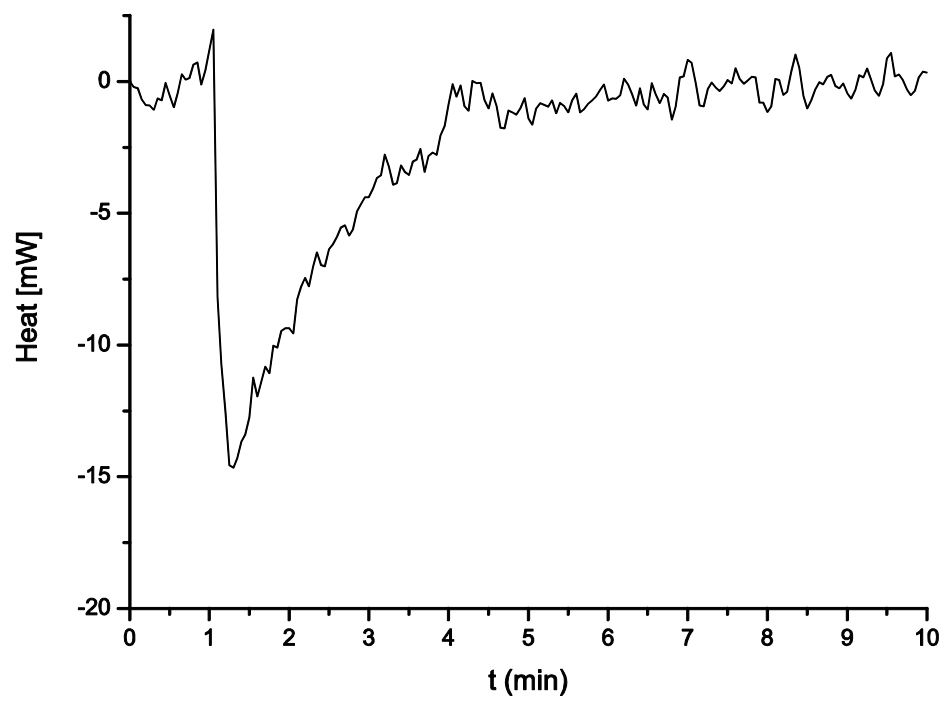

Figure S16. Calorimetric heat trace of the rapid equilibration between $\mathbf{L} 1 \bullet \mathrm{Pd}(\mathrm{Ph}) \mathrm{Cl}$ and $\mathbf{L} 1 \cdot \mathrm{Pd}(\mathrm{Ph}) \mathrm{OH}$ under aqueous biphasic conditions. 


\section{Equilibria between L1•Pd(Ph)X $(\mathrm{X}=\mathrm{Cl}, \mathrm{Br}$, I) and L1•Pd(Ph)OH (Figure 5).}
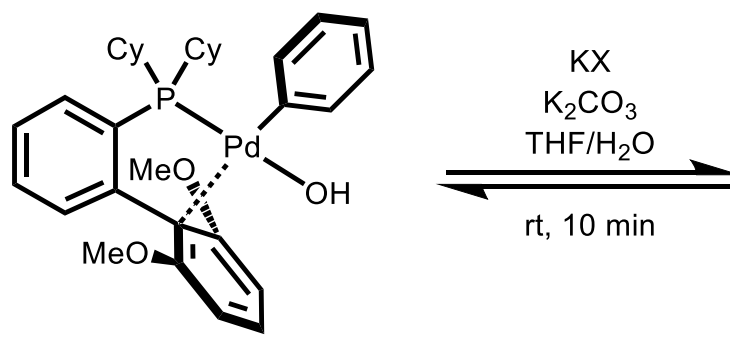

$\mathrm{rt}, 10 \mathrm{~min}$

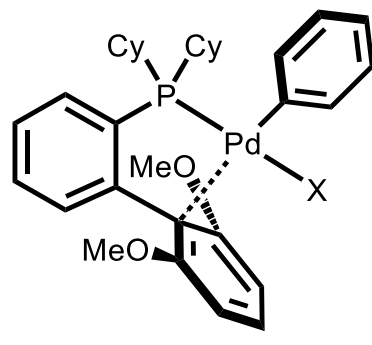

$\mathrm{X}=\mathrm{Cl}, \mathrm{Br}, \mathrm{I}$

An oven-dried test tube was charged with $\mathbf{L 1} \cdot \mathrm{Pd}(\mathrm{Ph}) \mathrm{OH}(5.00 \mathrm{mg}, 8.00 \mu \mathrm{mol}, 1.00$ equiv.) and the appropriate amount of solid $\mathrm{KX}(\mathrm{X}=\mathrm{Cl}, \mathrm{Br}, \mathrm{I})(0,0.5,1.0,5.0,20,50$ equiv. $)$. The reaction vessel was evacuated and backfilled with argon (this process was repeated a total of three times). Next, THF (0.5 mL) and $1.5 \mathrm{M}$ aq. $\mathrm{K}_{2} \mathrm{CO}_{3}(218 \mu \mathrm{L}, 0.33 \mathrm{mmol}, 40.0$ equiv. $)$ were added and the reaction mixture was stirred for $60 \mathrm{~min}$ to ensure complete equilibration. The biphasic mixture was transferred to an NMR tube and the ratio of $\mathbf{L 1} \cdot \mathrm{Pd}(\mathrm{Ph}) \mathrm{OH}$ to $\mathbf{L 1} \cdot \mathrm{Pd}(\mathrm{Ph}) \mathrm{X}(\mathrm{X}=\mathrm{Cl}, \mathrm{Br}, \mathrm{I})$ in the organic layer was determined by ${ }^{31} \mathrm{P}$ NMR spectroscopy. The results of these studies are summarized in Figure 5 in the main text.

While these experiments were carried out with a different base $\left(\mathrm{K}_{2} \mathrm{CO}_{3}\right)$ than other stoichiometric and catalytic experiments $\left(\mathrm{K}_{3} \mathrm{PO}_{4}\right)$ in order to minimize ${ }^{31} \mathrm{P}$ NMR signal broadening from $\mathrm{K}_{3} \mathrm{PO}_{4}$, we have found that the equilibrium ratio between $\mathbf{L 1} \cdot \mathrm{Pd}(\mathrm{Ph}) \mathrm{Br}$ and $\mathbf{L} \mathbf{1} \cdot \mathrm{Pd}(\mathrm{Ph}) \mathrm{OH}$ is relatively insensitive to the identity of the base (Figure S17). Therefore, these results suggest that similar conclusions can be drawn for experiments with either $\mathrm{K}_{2} \mathrm{CO}_{3}$ or $\mathrm{K}_{3} \mathrm{PO}_{4}$. In addition, the exact excess of base relative to Pd in these experiments also had a minimal effect on the outcome (Figure S18). 


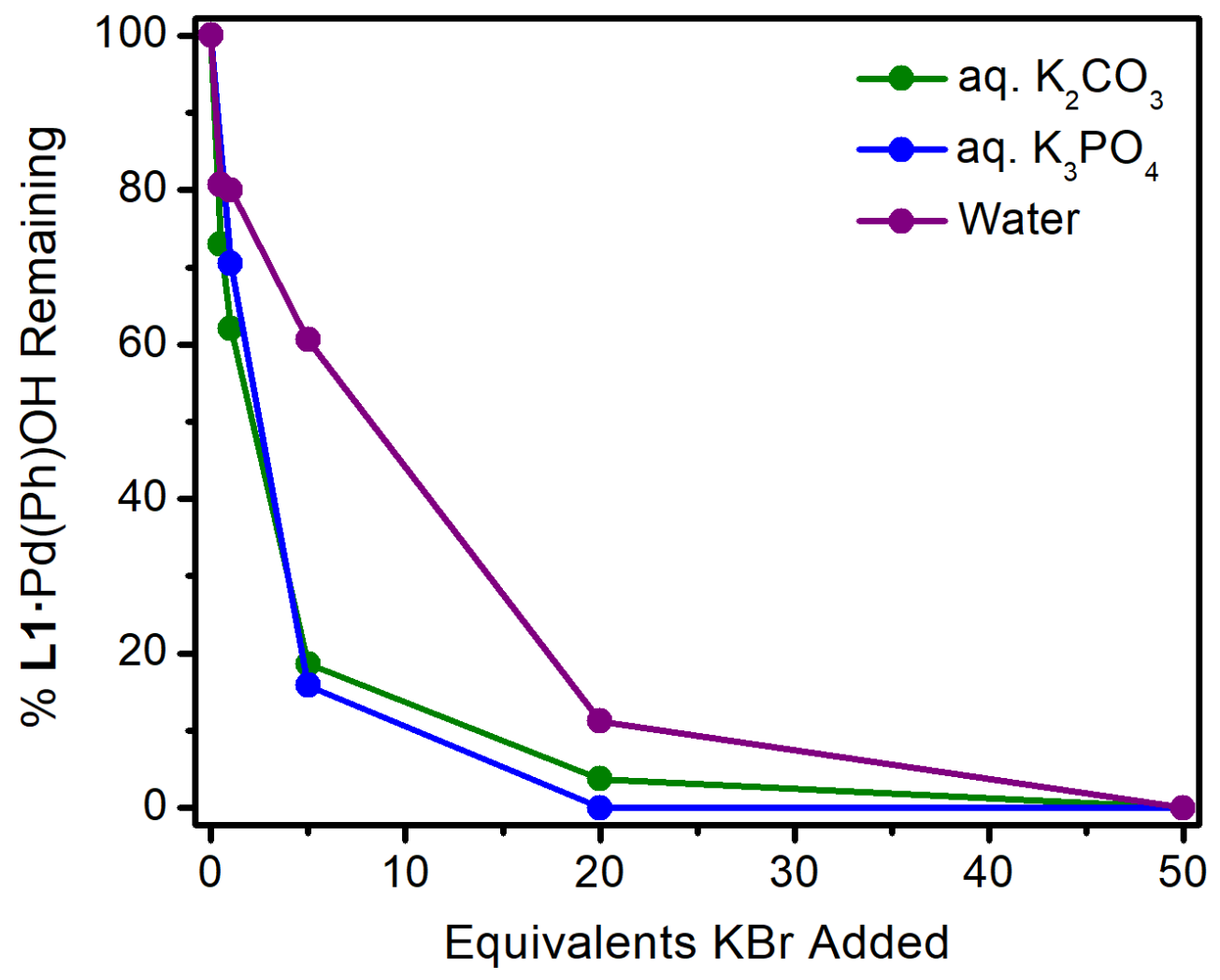

Figure S17. Effect of the base $\left(\mathrm{K}_{2} \mathrm{CO}_{3}, \mathrm{~K}_{3} \mathrm{PO}_{4}\right.$, no base $)$ on the equilibrium between $\mathbf{L 1} \cdot \mathrm{Pd}(\mathrm{Ph}) \mathrm{OH}$ and $\mathbf{L 1} \cdot \mathrm{Pd}(\mathrm{Ph}) \mathrm{Br}$. Only minor differences were observed between $\mathrm{K}_{2} \mathrm{CO}_{3}$ and $\mathrm{K}_{3} \mathrm{PO}_{4}$, but the data quality was more reliable using $\mathrm{K}_{2} \mathrm{CO}_{3}$ due to a lack of ${ }^{31} \mathrm{P}$ NMR signal broadening. 


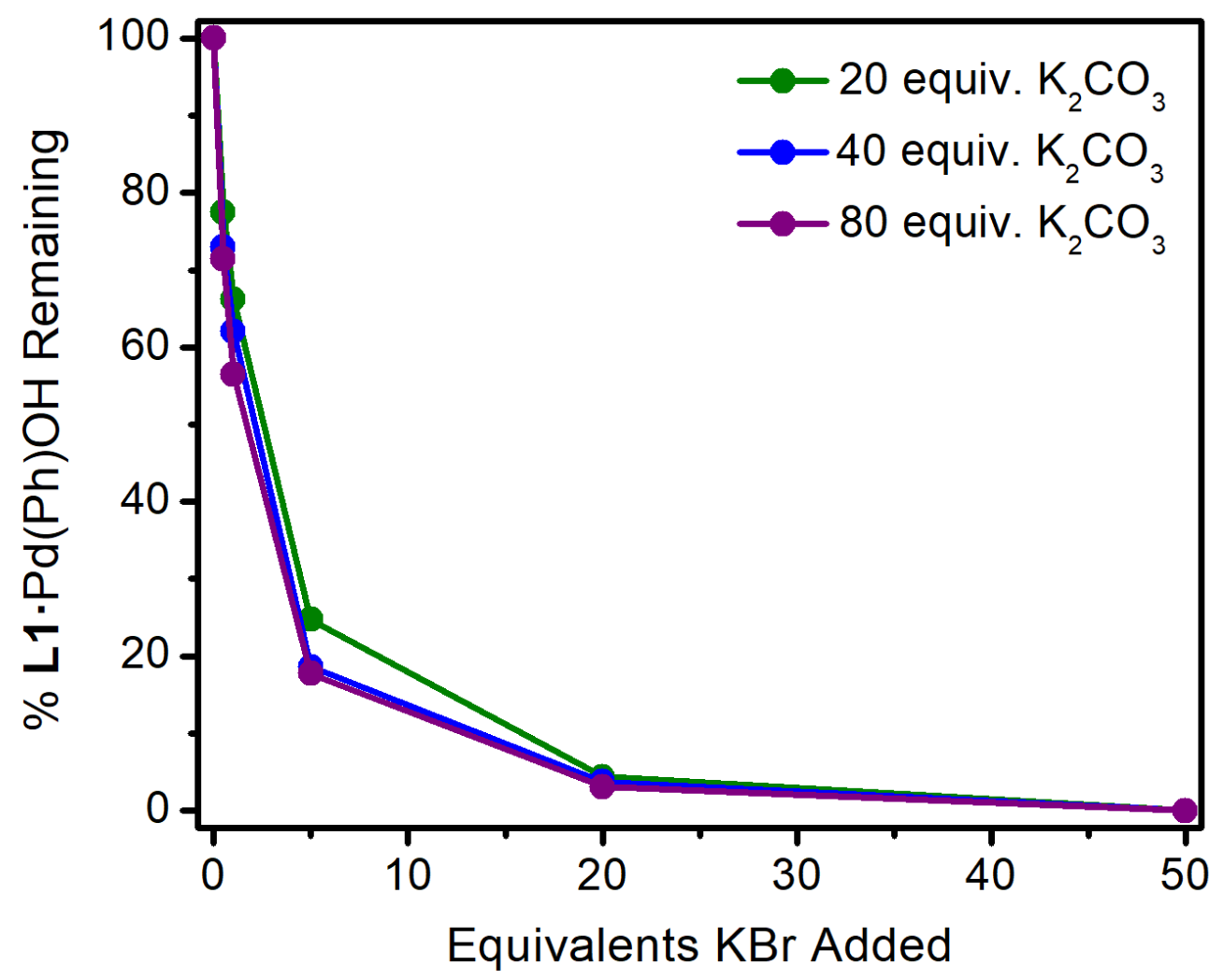

Figure S18. Effect of the excess of base relative to Pd (20, 40, or 80 equiv.) on the equilibrium between $\mathbf{L 1} \cdot \mathrm{Pd}(\mathrm{Ph}) \mathrm{OH}$ and $\mathbf{L 1} \cdot \mathrm{Pd}(\mathrm{Ph}) \mathrm{Br}$. Only minor differences were observed between these experiments. The experiments in Figure 5 in the main text were carried out using 40 equiv. of $\mathrm{K}_{2} \mathrm{CO}_{3}$. 
10. Additional catalytic experiments.

Table S9. Kinetic data for the catalytic reaction of $\mathrm{PhCl}$ and $\mathrm{PhB}(\mathrm{OH})_{2}$ under the standard reaction conditions with twice the rate of stirring.

\begin{tabular}{ccc}
\hline Time $(\min )$ & \% PhCl Remaining & {$[\mathrm{PhCl}](\mathrm{M})^{a}$} \\
\hline 0 & 100 & 0.25 \\
2 & 94 & 0.23 \\
4 & 86 & 0.21 \\
8 & 76 & 0.19 \\
15 & 60 & 0.15 \\
30 & 44 & 0.11 \\
45 & 35 & 0.09 \\
60 & 29 & 0.07 \\
\hline
\end{tabular}

${ }^{a}$ Assuming that $\mathrm{PhCl}$ and dodecane are present entirely in the THF layer.

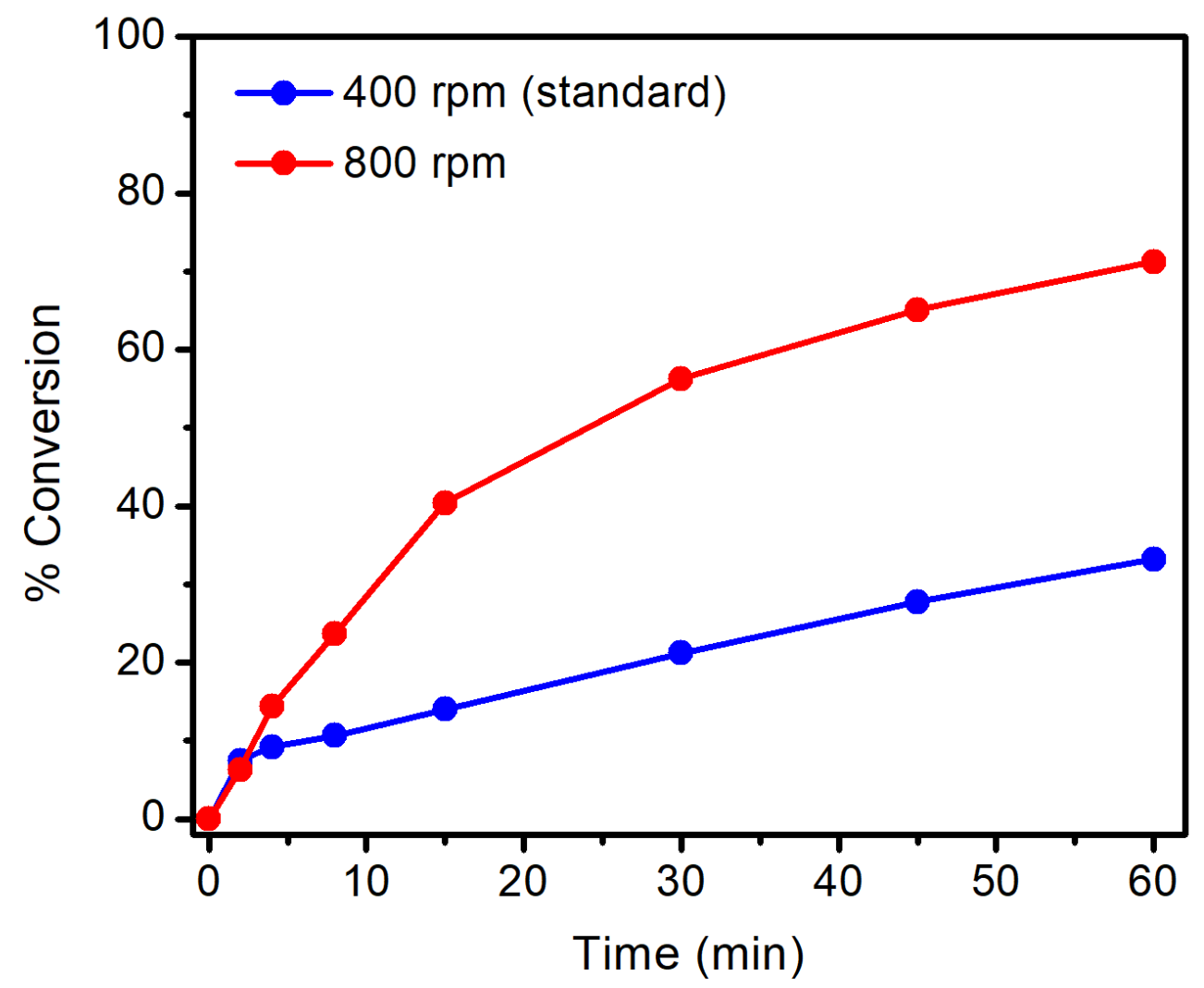

Figure S19. Effect of stirring rate on the reaction kinetics. 


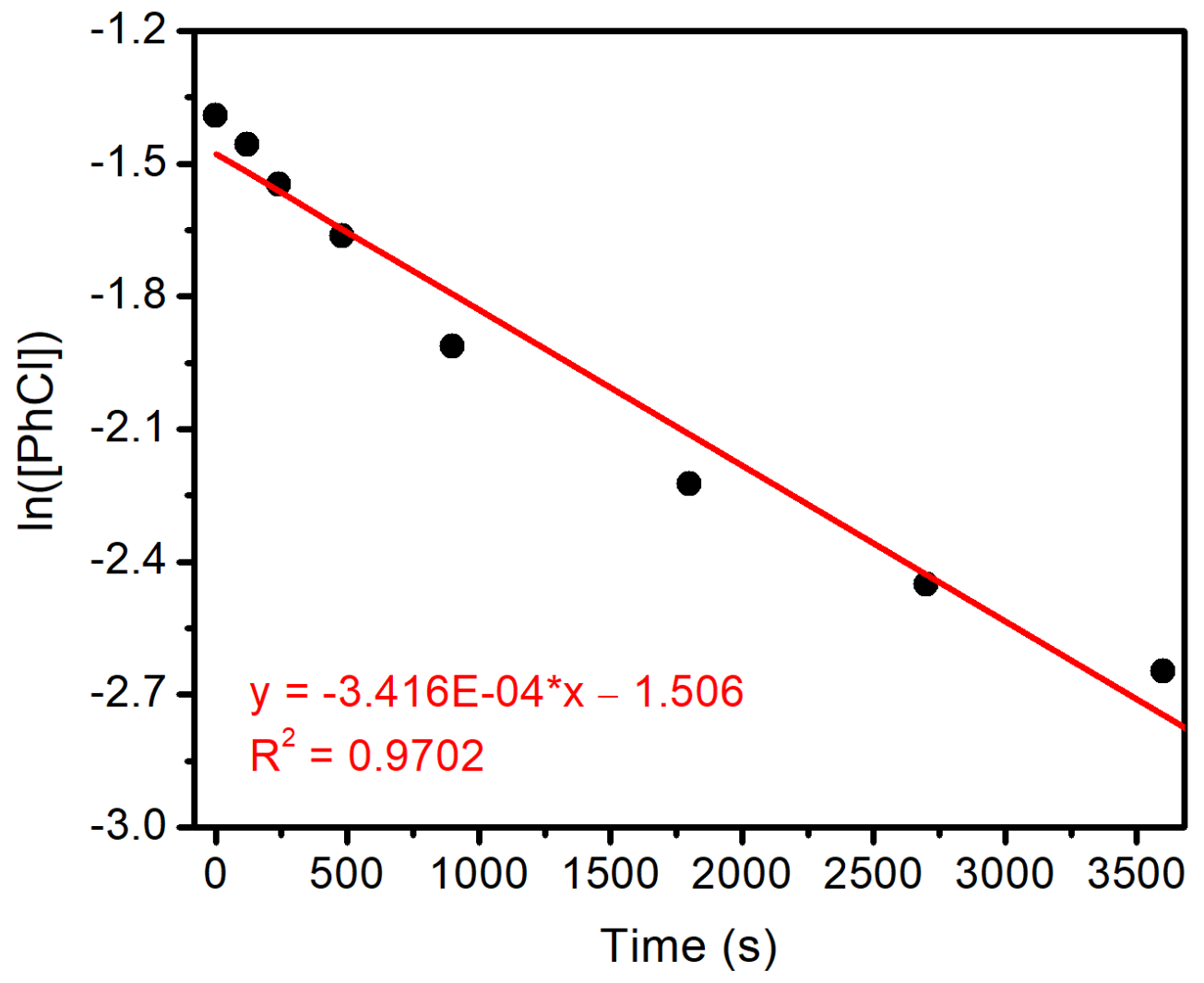

Figure S20. First-order kinetic plot for the data from the standard reaction with twice the rate of stirring. The first data point was not included in the linear fit. 


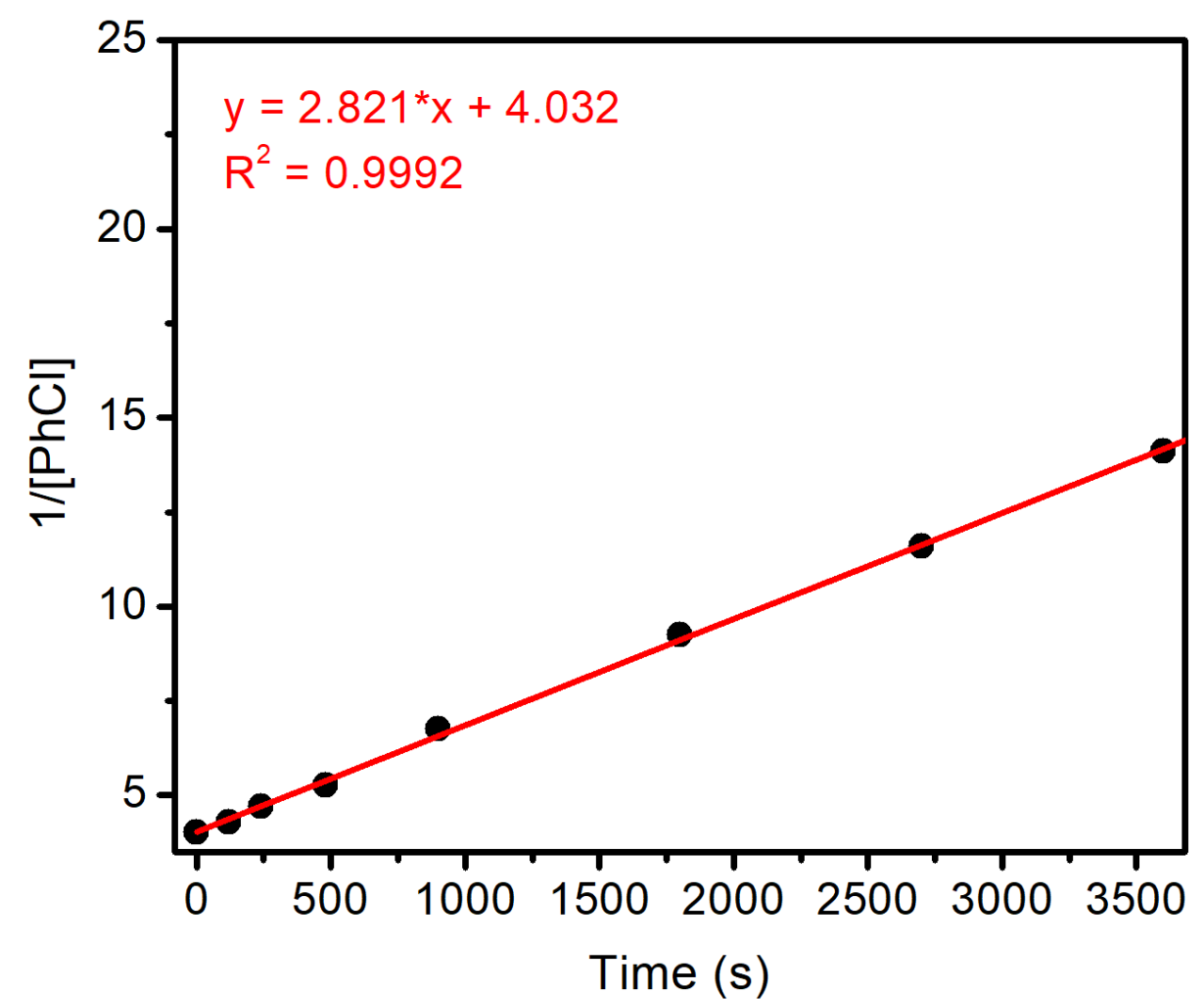

Figure S21. Second-order kinetic plot for the data from the standard reaction with twice the rate of stirring. 
Table S10. Kinetic data for the catalytic reaction of $\mathrm{PhCl}$ and $\mathrm{PhB}(\mathrm{OH})_{2}$ under the standard reaction conditions with twice the amount of catalyst.

\begin{tabular}{ccc}
\hline Time $(\min )$ & \% PhCl Remaining & {$[\mathrm{PhCl}](\mathrm{M})^{a}$} \\
\hline 0 & 100 & 0.23 \\
2 & 94 & 0.22 \\
4 & 92 & 0.21 \\
8 & 88 & 0.20 \\
15 & 86 & 0.20 \\
30 & 80 & 0.18 \\
45 & 73 & 0.17 \\
60 & 69 & 0.16 \\
\hline
\end{tabular}

${ }^{a}$ Assuming that $\mathrm{PhCl}$ and dodecane are present entirely in the THF layer.

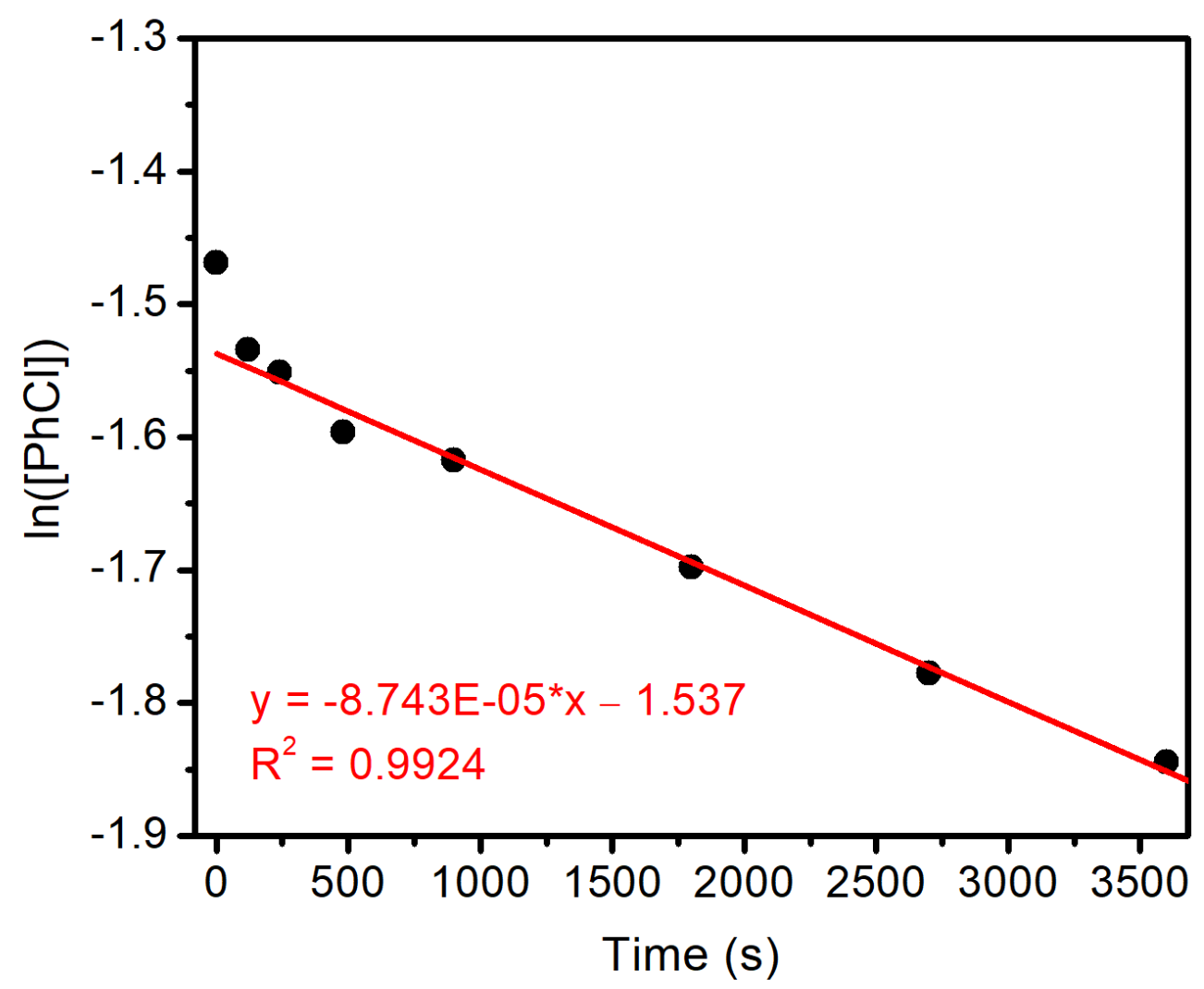

Figure S22. First-order kinetic plot for the data from the standard reaction with twice the amount of catalyst. The first data point was not included in the linear fit. 
Table S10b. Reproduced kinetic data for the catalytic reaction of $\mathrm{PhCl}$ and $\mathrm{PhB}(\mathrm{OH})_{2}$ under the standard reaction conditions with twice the amount of catalyst.

\begin{tabular}{ccc}
\hline Time $(\min )$ & \% PhCl Remaining & {$[\mathrm{PhCl}](\mathrm{M})^{a}$} \\
\hline 0 & 100 & 0.29 \\
2 & 93 & 0.27 \\
4 & 92 & 0.26 \\
8 & 90 & 0.26 \\
15 & 87 & 0.25 \\
30 & 81 & 0.23 \\
45 & 75 & 0.21 \\
60 & 71 & 0.20 \\
\hline
\end{tabular}

${ }^{a}$ Assuming that $\mathrm{PhCl}$ and dodecane are present entirely in the THF layer.

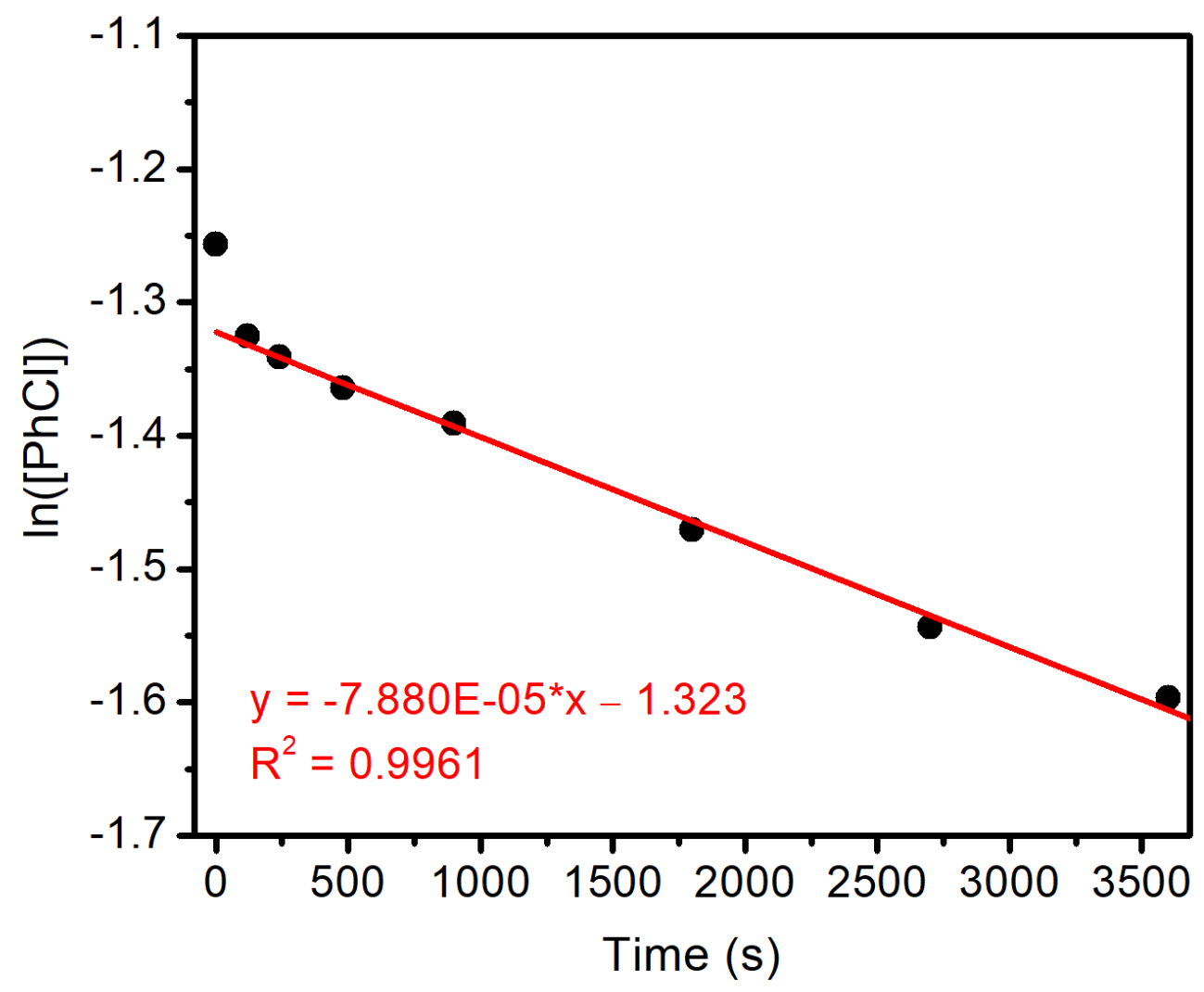

Figure S22b. Reproduced first-order kinetic plot for the data from the standard reaction with twice the amount of catalyst. The first data point was not included in the linear fit. 
Table S11. Survey of bases for the catalytic Suzuki-Miyaura coupling of $\mathbf{P h I}$ in THF/water. ${ }^{a}$

\begin{tabular}{ccc}
\hline Base & \% PhI remaining after 90 min & \% PhI remaining after $16 \mathrm{~h}$ \\
\hline $\mathrm{K}_{3} \mathrm{PO}_{4}$ & 75 & 71 \\
$\mathrm{~K}_{2} \mathrm{CO}_{3}$ & 83 & 76 \\
$\mathrm{Li}_{3} \mathrm{PO}_{4}$ & 81 & 80 \\
$\mathrm{Li}_{2} \mathrm{CO}_{3}$ & 84 & 80 \\
$\mathrm{Na}_{3} \mathrm{PO}_{4}$ & 77 & 62 \\
$\mathrm{Na}_{2} \mathrm{CO}_{3}$ & 79 & 74 \\
$\mathrm{Cs}_{2} \mathrm{CO}_{3}$ & 75 & 65 \\
$\mathrm{Ag}_{2} \mathrm{CO}_{3}$ & 79 & 73 \\
$\mathrm{AgO}$ & 73 & 0 \\
\hline
\end{tabular}

${ }^{a}$ Standard reaction conditions: $\mathrm{PhI}(0.50 \mathrm{mmol})$, phenylboronic acid $(0.50 \mathrm{mmol}), \mathbf{L 1} \cdot \mathrm{Pd}(\mathrm{Ph}) \mathrm{Cl}$ $(0.01 \mathrm{mmol}, 2.0 \%)$, base $(1.00 \mathrm{mmol})$, THF $(2.0 \mathrm{~mL}), \mathrm{H}_{2} \mathrm{O}(1.0 \mathrm{~mL})$, room temperature, 1000 rpm stirring rate. Conversion determined by gas chromatography compared to an internal standard of dodecane.

Table S12. Survey of organic phases for the standard Suzuki-Miyaura coupling of PhI. ${ }^{a}$

\begin{tabular}{cc}
\hline Organic Solvent & \% PhI remaining after $16 \mathrm{~h}$ \\
\hline $\mathrm{THF}$ & 71 \\
$\mathrm{Et}_{2} \mathrm{O}$ & 41 \\
Toluene & 0
\end{tabular}

${ }^{a}$ Standard reaction conditions: $\mathrm{PhI}(0.50 \mathrm{mmol})$, phenylboronic acid $(0.50 \mathrm{mmol}), \mathbf{L} \mathbf{1} \cdot \mathrm{Pd}(\mathrm{Ph}) \mathrm{Cl}$ $(0.01 \mathrm{mmol}, 2.0 \%), \mathrm{K}_{3} \mathrm{PO}_{4}(1.00 \mathrm{mmol})$, organic solvent $(2.0 \mathrm{~mL}), \mathrm{H}_{2} \mathrm{O}(1.0 \mathrm{~mL})$, room temperature, $1000 \mathrm{rpm}$ stirring rate. Conversion determined by gas chromatography compared to an internal standard of dodecane. 


\section{Catalytic reactions of aryl iodides in toluene/water (Figure 6).}

General Procedure 2. A screw-cap reaction tube equipped with a stir bar was charged with SPhos Pd G3 ${ }^{1}$ (7.80 mg, $0.01 \mathrm{mmol}, 0.02$ equiv.), arylboronic acid (0.75 mmol, 1.50 equiv.), and aryl iodide ( $0.50 \mathrm{mmol}, 1.00$ equiv.). The reaction vessel was evacuated and backfilled with nitrogen (this process was repeated a total of three times). Then, toluene $(2 \mathrm{~mL})$ and a freshly degassed solution of $1.0 \mathrm{M}$ aq. $\mathrm{K}_{3} \mathrm{PO}_{4}(1.0 \mathrm{~mL}, 1.0 \mathrm{mmol}, 2.0$ equiv.) were added via syringe. The reaction mixture was allowed to stir at $1000 \mathrm{rpm}$ at $100{ }^{\circ} \mathrm{C}$ for $14 \mathrm{~h}$. At this time, the reaction tubes were allowed to cool to room temperature, and the reaction mixture was diluted with ethyl acetate (10 $\mathrm{mL})$ and water $(5 \mathrm{~mL})$. The phases were separated, and the aqueous phase was further extracted with ethyl acetate $(2 \times 10 \mathrm{~mL})$. The combined organic phases were dried over $\mathrm{MgSO}_{4}$ and filtered through a short silica plug, eluting with ethyl acetate $(50 \mathrm{~mL})$. The solution was concentrated using a rotary evaporator and the crude product was further purified as detailed below.

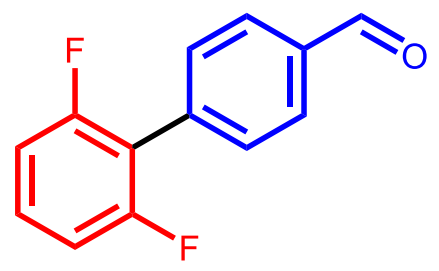

Following General Procedure 2, 1,3-difluoro-2-iodobenzene (120 mg, 0.50 mmol, 1.00 equiv.), 4-formylphenylboronic acid (113 mg, 0.75 mmol, 1.50 equiv.), SPhos Pd G3 (7.80 mg, 0.01 mmol, 0.02 equiv. $)$, toluene (2.0 mL), and $1 \mathrm{M}$ aq. $\mathrm{K}_{3} \mathrm{PO}_{4}(1.0 \mathrm{~mL}, 1.0 \mathrm{mmol}, 2.0$ equiv.) were combined and allowed to react for $14 \mathrm{~h}$. The crude product was suspended in hexanes $(5 \mathrm{~mL})$, sonicated briefly, cooled to $-20{ }^{\circ} \mathrm{C}$, and filtered, yielding 4-(2',6'-difluorophenyl)benzaldehyde (92 mg, 84\%) as an off-white solid. ${ }^{1} \mathbf{H}$ NMR (500 MHz, $\left.\mathrm{CDCl}_{3}\right): \delta 10.1(\mathrm{~s}, 1 \mathrm{H}), 7.97(\mathrm{~d}, J=8$ $\mathrm{Hz}, 2 \mathrm{H}), 7.65(\mathrm{~d}, J=8 \mathrm{~Hz}, 2 \mathrm{H}), 7.34(\mathrm{~m}, 1 \mathrm{H}), 7.02(\mathrm{t}, \mathrm{J}=8 \mathrm{~Hz}) \mathrm{ppm} ;{ }^{13} \mathbf{C} \mathbf{N M R}(125 \mathrm{MHz}$, $\left.\mathrm{CDCl}_{3}\right): \delta 191.2,159.9(\mathrm{~d}, J=249 \mathrm{~Hz}), 159.8(\mathrm{~d}, J=248 \mathrm{~Hz}), 135.8,135.5,131.0(\mathrm{pt}, J=3$ Hz), $129.9(\mathrm{pt}, J=11 \mathrm{~Hz}), 129.5,117.3(\mathrm{pt}, J=19 \mathrm{~Hz}), 111.9(\mathrm{~d}, J=6 \mathrm{~Hz}), 111.8(\mathrm{~d}, J=5 \mathrm{~Hz})$ 
ppm; ${ }^{19} \mathbf{F}$ NMR $\left(470 \mathrm{MHz}, \mathrm{CDCl}_{3}\right): \delta-114.4 \mathrm{ppm}$. These spectra are consistent with those reported in the literature. ${ }^{7}$<smiles>COc1ccc(OC)c(-c2cccnc2)c1</smiles>

Following General Procedure 2, 3-iodopyridine (103 mg, $0.50 \mathrm{mmol}, 1.00$ equiv.), 2,5dimethoxyphenylboronic acid (137 mg, $0.75 \mathrm{mmol}, 1.50$ equiv.), SPhos Pd G3 (7.80 mg, 0.01 mmol, 0.02 equiv.), toluene (2.0 mL), and $1 \mathrm{M}$ aq. $\mathrm{K}_{3} \mathrm{PO}_{4}(1.0 \mathrm{~mL}, 1.0 \mathrm{mmol}, 2.0$ equiv.) were combined and allowed to react for $14 \mathrm{~h}$. The crude product was purified by flash chromatography $(0 \rightarrow 20 \rightarrow 40 \%$ ethyl acetate in hexanes), yielding 3-(2,5dimethoxyphenyl)pyridine (96 mg, 89\%) as a pale yellow oil. ${ }^{\mathbf{1}} \mathbf{H} \mathbf{N M R}\left(500 \mathrm{MHz}, \mathrm{CDCl}_{3}\right): \delta$ $8.77(\mathrm{~d}, J=2 \mathrm{~Hz}, 1 \mathrm{H}), 8.55(\mathrm{dd}, J=5,2 \mathrm{~Hz}, 1 \mathrm{H}), 7.85(\mathrm{dt}, J=8,2 \mathrm{~Hz}, 1 \mathrm{H}), 7.31(\mathrm{dd}, \mathrm{J}=8,5$ $\mathrm{Hz}, 1 \mathrm{H}), 6.87-6.95(\mathrm{~m}, 3 \mathrm{H}), 3.80(\mathrm{~s}, 3 \mathrm{H}), 3.75$ (s, 3H) ppm; ${ }^{13} \mathbf{C}$ NMR $\left(125 \mathrm{MHz}, \mathrm{CDCl}_{3}\right): \delta$ $153.8,150.8,150.1,148.0,136.7,134.0,127.9,122.8,116.5,113.9,112.6,56.1,55.8$ ppm. These spectra are consistent with those reported in the literature. ${ }^{8}$

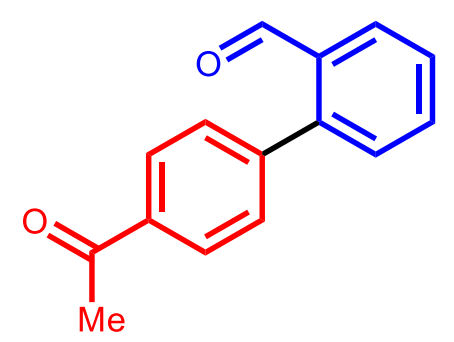

Following General Procedure 2, 4'-iodoacetophenone (123 mg, $0.50 \mathrm{mmol}, 1.00$ equiv.), 2formylphenylboronic acid (113 mg, $0.75 \mathrm{mmol}, 1.50$ equiv.), SPhos Pd G3 (7.80 mg, 0.01 mmol, 0.02 equiv.), toluene (2.0 mL), and $1 \mathrm{M}$ aq. $\mathrm{K}_{3} \mathrm{PO}_{4}(1.0 \mathrm{~mL}, 1.0 \mathrm{mmol}, 2.0$ equiv.) were combined and allowed to react for $14 \mathrm{~h}$. The crude product was purified by flash chromatography $(0 \rightarrow 10 \rightarrow 20 \rightarrow 30 \rightarrow 40 \rightarrow 50 \%$ ethyl acetate in hexanes), yielding 4'acetyl-[1,1'-biphenyl]-2-carbaldehyde (94 mg, 84\%) as an off-white solid. ${ }^{1} \mathbf{H}$ NMR (500 MHz, $\left.\mathrm{CDCl}_{3}\right): \delta 9.97(\mathrm{~s}, 1 \mathrm{H}), 8.04-8.08(\mathrm{~m}, 3 \mathrm{H}), 7.68(\mathrm{td}, J=8,2 \mathrm{~Hz}, 1 \mathrm{H}), 7.56(\mathrm{t}, J=7 \mathrm{~Hz}, 1 \mathrm{H})$, 
$7.50(\mathrm{~d}, J=8 \mathrm{~Hz}, 2 \mathrm{H}), 7.45(\mathrm{~d}, \mathrm{~J}=8 \mathrm{~Hz}, 1 \mathrm{H}), 2.67(\mathrm{~s}, 3 \mathrm{H}) \mathrm{ppm} ;{ }^{13} \mathbf{C} \mathbf{N M R}\left(125 \mathrm{MHz}, \mathrm{CDCl}_{3}\right)$ : $\delta 197.5,191.7,144.5,142.6,136.6,133.7,133.6,130.6,130.3,128.5,128.4,128.1,26.7$ ppm. These spectra are consistent with those reported in the literature. ${ }^{9}$

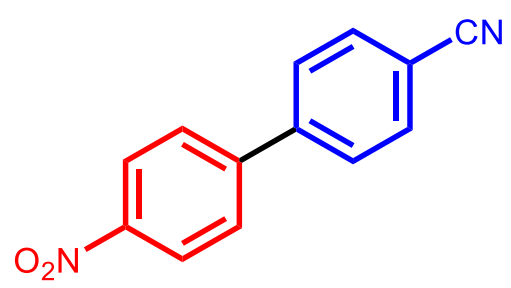

Following General Procedure 2, 1-iodo-4-nitrobenzene (125 mg, $0.50 \mathrm{mmol}, 1.00$ equiv.), 4cyanophenylboronic acid (110 mg, 0.75 mmol, 1.50 equiv.), SPhos Pd G3 (7.80 mg, 0.01 mmol, 0.02 equiv.), toluene (2.0 mL), and $1 \mathrm{M}$ aq. $\mathrm{K}_{3} \mathrm{PO}_{4}(1.0 \mathrm{~mL}, 1.0 \mathrm{mmol}, 2.0$ equiv.) were combined and allowed to react for $14 \mathrm{~h}$. The crude product was purified by flash chromatography (20\% ethyl acetate in hexanes), yielding 4'-nitro-[1,1'-biphenyl]-4-carbonitrile (89 mg, 80\%) as a bright yellow solid. ${ }^{1} \mathbf{H}$ NMR (500 MHz, $\left.\mathrm{CDCl}_{3}\right): \delta \mathrm{ppm} ;{ }^{13} \mathbf{C}$ NMR (125 $\left.\mathrm{MHz}, \mathrm{CDCl}_{3}\right): \delta \mathrm{ppm}$. These spectra are consistent with those reported in the literature. ${ }^{10}$

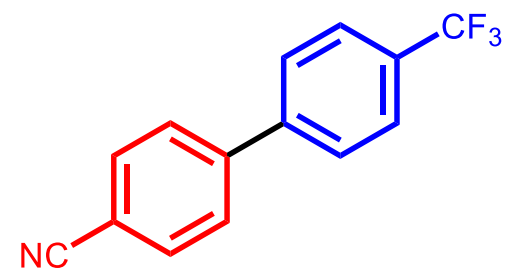

Following General Procedure 2, 1-iodo-4-cyanobenzene (125 mg, 0.50 mmol, 1.00 equiv.), 4(trifluoromethyl)phenylboronic acid (143 mg, $0.75 \mathrm{mmol}, 1.50$ equiv.), SPhos Pd G3 (7.80 mg, $0.01 \mathrm{mmol}, 0.02$ equiv.), toluene (2.0 mL), and $1 \mathrm{M}$ aq. $\mathrm{K}_{3} \mathrm{PO}_{4}(1.0 \mathrm{~mL}, 1.0 \mathrm{mmol}, 2.0$ equiv.) were combined and allowed to react for $14 \mathrm{~h}$. The crude product was suspended in hexanes ( 5 $\mathrm{mL}$ ), sonicated briefly, cooled to $-20{ }^{\circ} \mathrm{C}$, and filtered, yielding 4'-(trifluoromethyl)-[1, $1^{\prime}-$ biphenyl]-4-carbonitrile (89 mg, 72\%) as a beige solid. ${ }^{1} \mathbf{H}$ NMR (500 MHz, $\left.\mathrm{CDCl}_{3}\right): \delta 7.73-$ $7.79(\mathrm{~m}, 4 \mathrm{H}), 7.67-7.72(\mathrm{~m}, 4 \mathrm{H}) \mathrm{ppm} ;{ }^{13} \mathbf{C} \mathbf{N M R}\left(125 \mathrm{MHz}, \mathrm{CDCl}_{3}\right): \delta$ 144.1, 142.6, 132.8, $130.7(\mathrm{q}, J=32 \mathrm{~Hz}), 127.9,127.6,126.1(\mathrm{q}, J=4 \mathrm{~Hz}), 124.0(\mathrm{q}, J=271 \mathrm{~Hz}), 118.6,112.0 \mathrm{ppm}$; 
${ }^{19}$ F NMR (470 MHz, $\left.\mathrm{CDCl}_{3}\right): \delta-114.4 \mathrm{ppm}$. These spectra are consistent with those reported in the literature. ${ }^{11}$ 


\section{References}

(1) Bruno, N. C.; Tudge, M. T.; Buchwald, S. L. Design and Preparation of New Palladium Precatalysts for C-C and C-N Cross-Coupling Reactions. Chem. Sci. 2013, 4 (3), 916920. https://doi.org/10.1039/C2SC20903A.

(2) Fields, C. L.; Doyle, J. R. The Thermal Decomposition of Salts of Boronic Acids. Thermochim. Acta 1974, 8 (3), 239-248. https://doi.org/10.1016/0040-6031(74)87016-4.

(3) Pan, Y. Syntheses and Spectroscopic Characteristics of Dialkylpalladium(II) Complexes; $\mathrm{PdR}_{2}(\mathrm{Cod})$ as Precursors for Derivatives with N- or P-Donor Ligands. J. Organomet. Chem. 1999, 577 (2), 257-264. https://doi.org/10.1016/S0022-328X(98)01071-7.

(4) Barder, T. E.; Biscoe, M. R.; Buchwald, S. L. Structural Insights into Active Catalyst Structures and Oxidative Addition to (Biaryl)Phosphine-Palladium Complexes via Density Functional Theory and Experimental Studies. Organometallics 2007, 26 (9), 2183-2192. https://doi.org/10.1021/om0701017.

(5) Düfert, M. A.; Billingsley, K. L.; Buchwald, S. L. Suzuki-Miyaura Cross-Coupling of Unprotected, Nitrogen-Rich Heterocycles: Substrate Scope and Mechanistic Investigation. J. Am. Chem. Soc. 2013, 135 (34), 12877-12885. https://doi.org/10.1021/ja4064469.

(6) Kinzel, T.; Zhang, Y.; Buchwald, S. L. A New Palladium Precatalyst Allows for the Fast Suzuki-Miyaura Coupling Reactions of Unstable Polyfluorophenyl and 2-Heteroaryl Boronic Acids. J. Am. Chem. Soc. 2010, 132 (40), 14073-14075. https://doi.org/10.1021/ja1073799.

(7) Yan, T.; Bheeter, C. B.; Doucet, H. Influence of 1,3-Difluorobenzene Substituents for Palladium-Catalyzed Direct Arylations: Palladium-Catalyzed Direct Arylations. Eur. J. Org. Chem. 2013, 2013 (31), 7152-7163. https://doi.org/10.1002/ejoc.201301131.

(8) Juncosa, J. I.; Hansen, M.; Bonner, L. A.; Cueva, J. P.; Maglathlin, R.; McCorvy, J. D.; Marona-Lewicka, D.; Lill, M. A.; Nichols, D. E. Extensive Rigid Analogue Design Maps the Binding Conformation of Potent $N$-Benzylphenethylamine 5-HT 2A Serotonin Receptor Agonist Ligands. ACS Chem. Neurosci. 2013, 4 (1), 96-109. https://doi.org/10.1021/cn3000668.

(9) Farina, V.; Krishnan, B.; Marshall, D. R.; Roth, G. P. Palladium-Catalyzed Coupling of Arylstannanes with Organic Sulfonates: A Comprehensive Study. J. Org. Chem. 1993, 58 (20), 5434-5444. https://doi.org/10.1021/jo00072a028.

(10) Yamamoto, E.; Ukigai, S.; Ito, H. Boryl Substitution of Functionalized Aryl-, Heteroaryland Alkenyl Halides with Silylborane and an Alkoxy Base: Expanded Scope and Mechanistic Studies. Chem. Sci. 2015, 6 (5), 2943-2951. https://doi.org/10.1039/C5SC00384A.

(11) Chung, J. W.; You, Y.; Huh, H. S.; An, B.-K.; Yoon, S.-J.; Kim, S. H.; Lee, S. W.; Park, S. Y. Shear- and UV-Induced Fluorescence Switching in Stilbenic $\pi$-Dimer Crystals Powered by Reversible [2 + 2] Cycloaddition. J. Am. Chem. Soc. 2009, 131 (23), 81638172. https://doi.org/10.1021/ja900803d. 
13. NMR spectra of isolated substrates (Table 6). 




${ }^{1} \mathrm{H} \mathrm{NMR}, 500 \mathrm{MHz}, \mathrm{CDCl}_{3}$
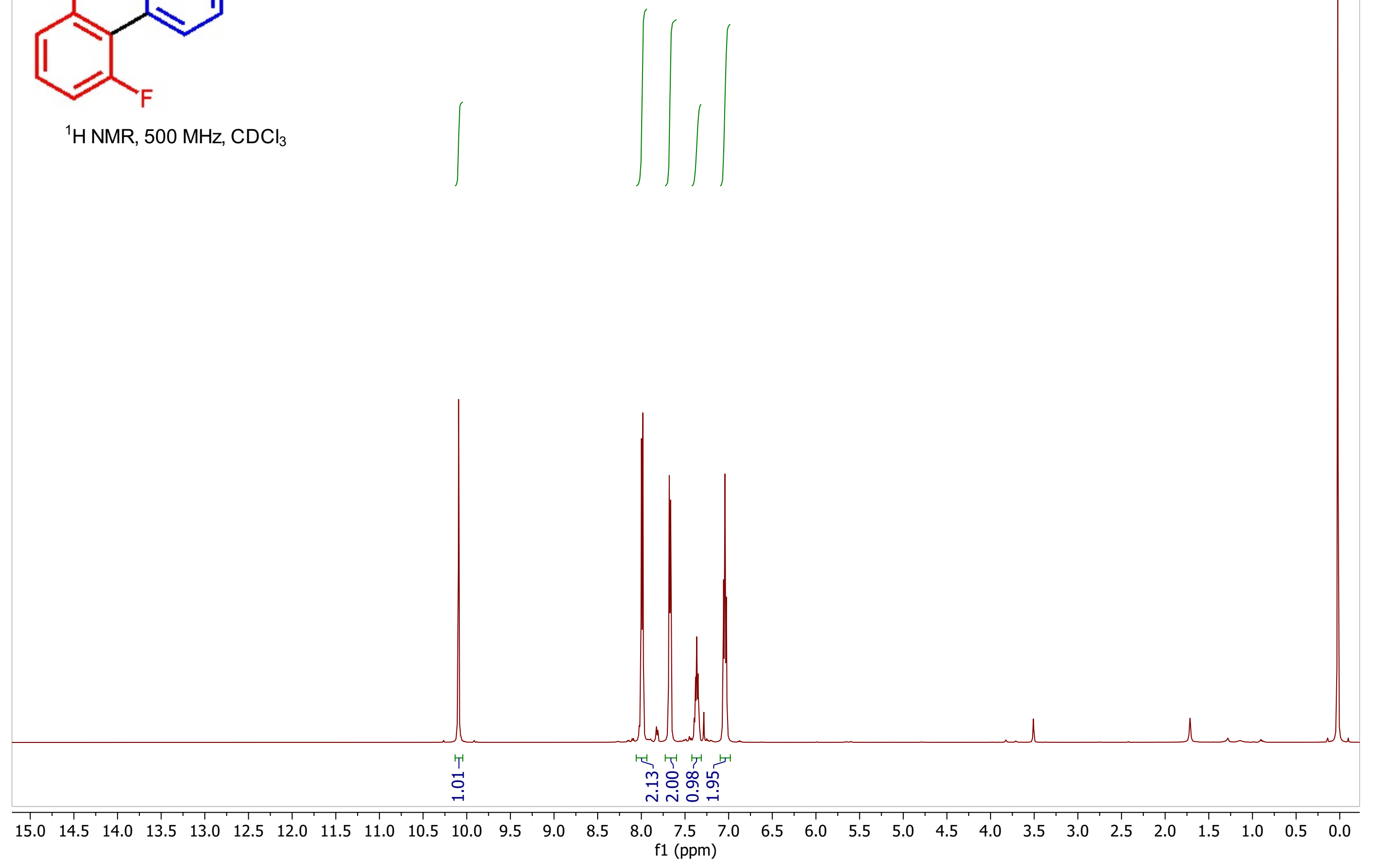


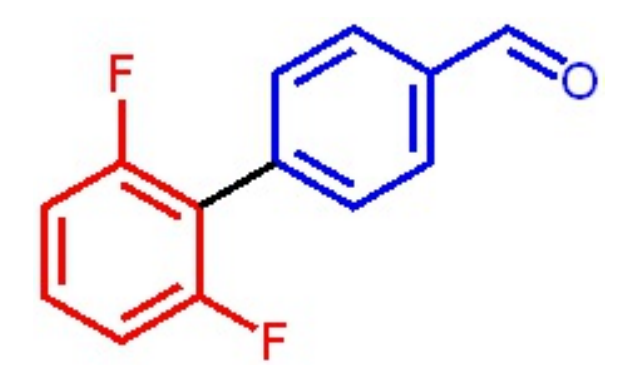

${ }^{13} \mathrm{C} \mathrm{NMR}, 125 \mathrm{MHz}, \mathrm{CDCl}_{3}$

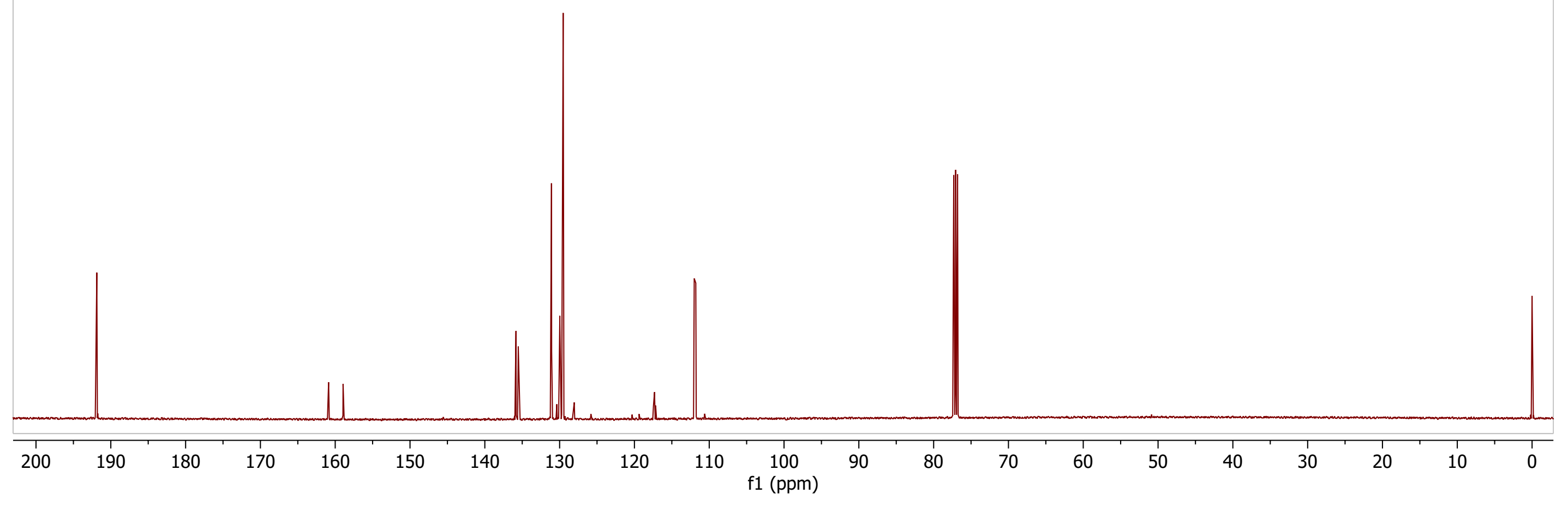




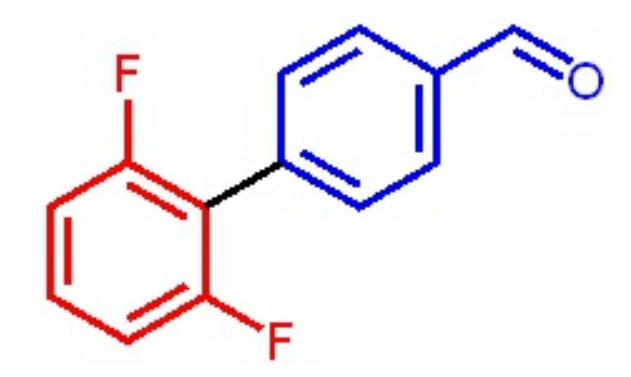

${ }^{19} \mathrm{~F} \mathrm{NMR,}, 470 \mathrm{MHz}, \mathrm{CDCl}_{3}$

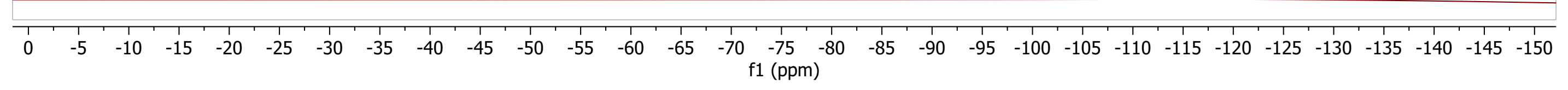




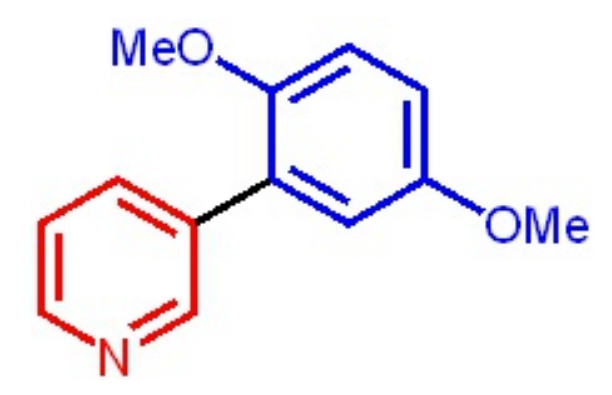

${ }^{1} \mathrm{H} \mathrm{NMR}, 500 \mathrm{MHz}, \mathrm{CDCl}_{3}$
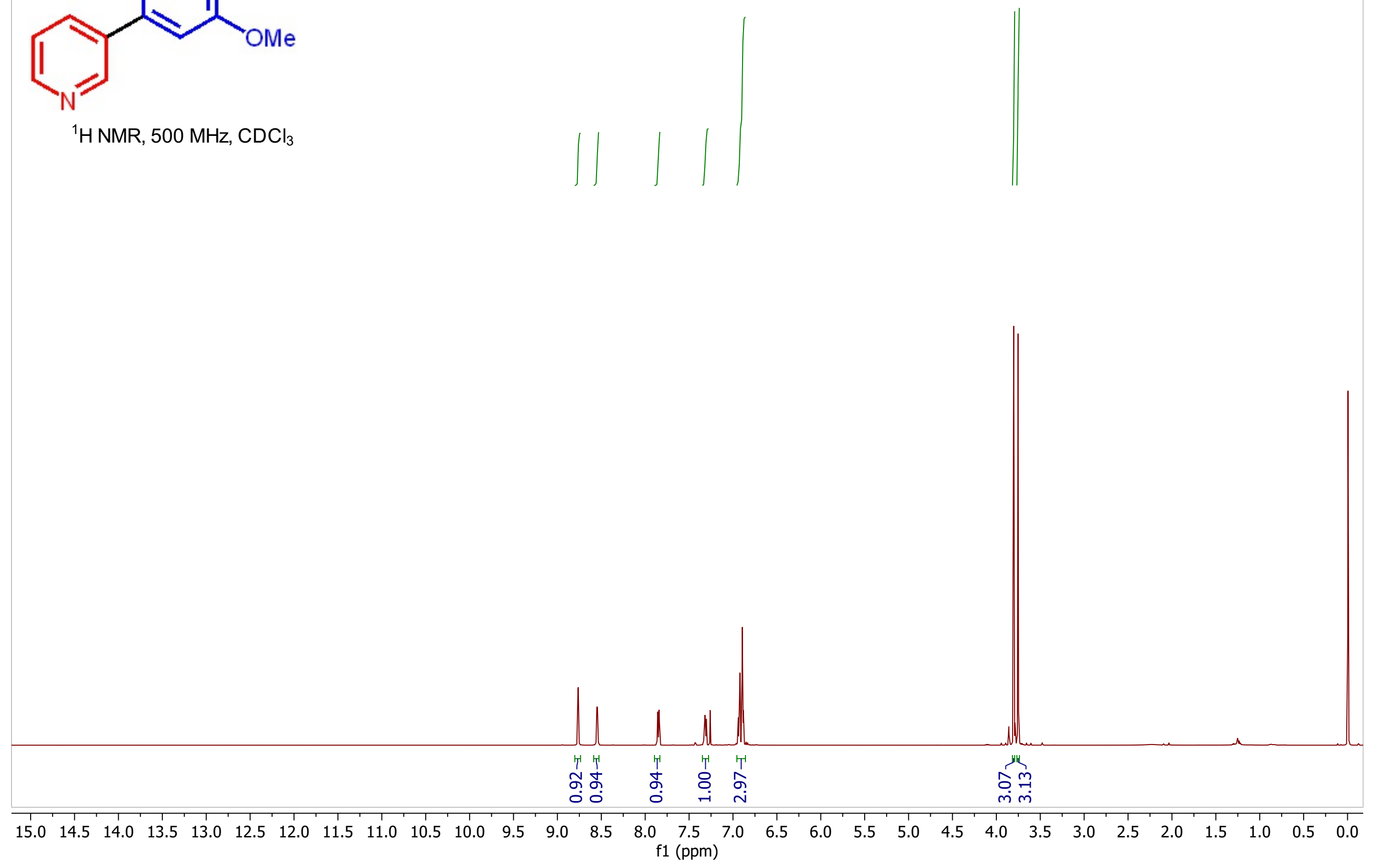


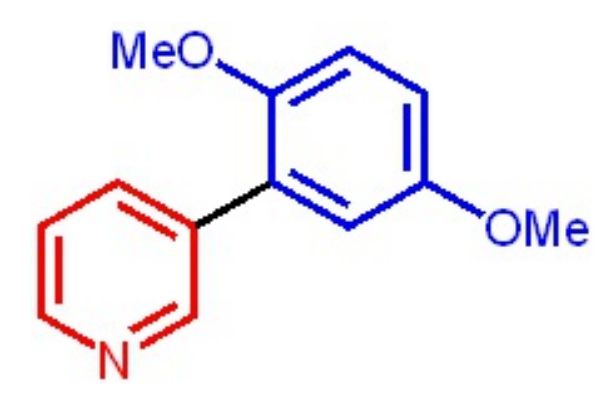

${ }^{13} \mathrm{C} \mathrm{NMR}, 125 \mathrm{MHz}, \mathrm{CDCl}_{3}$

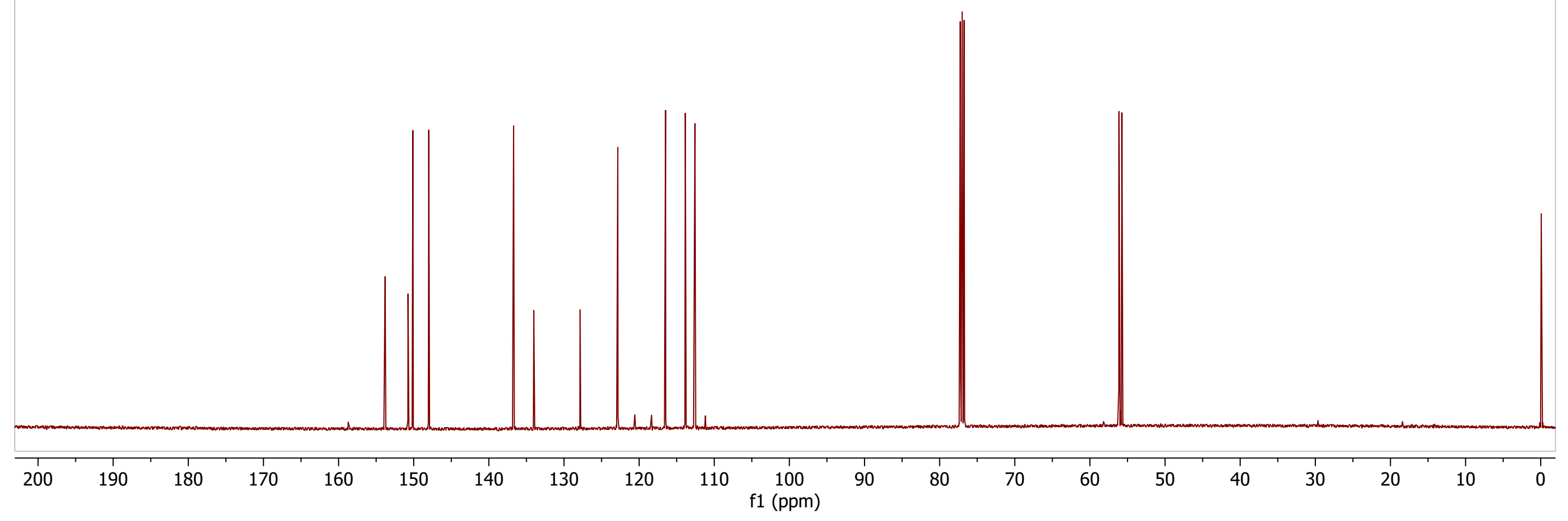




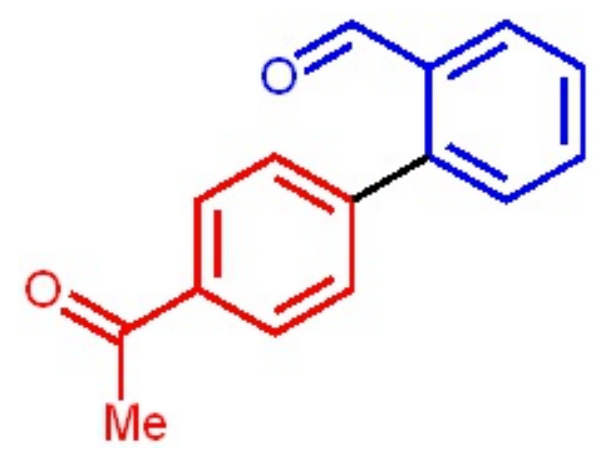

${ }^{1} \mathrm{H} \mathrm{NMR}, 500 \mathrm{MHz}, \mathrm{CDCl}_{3}$
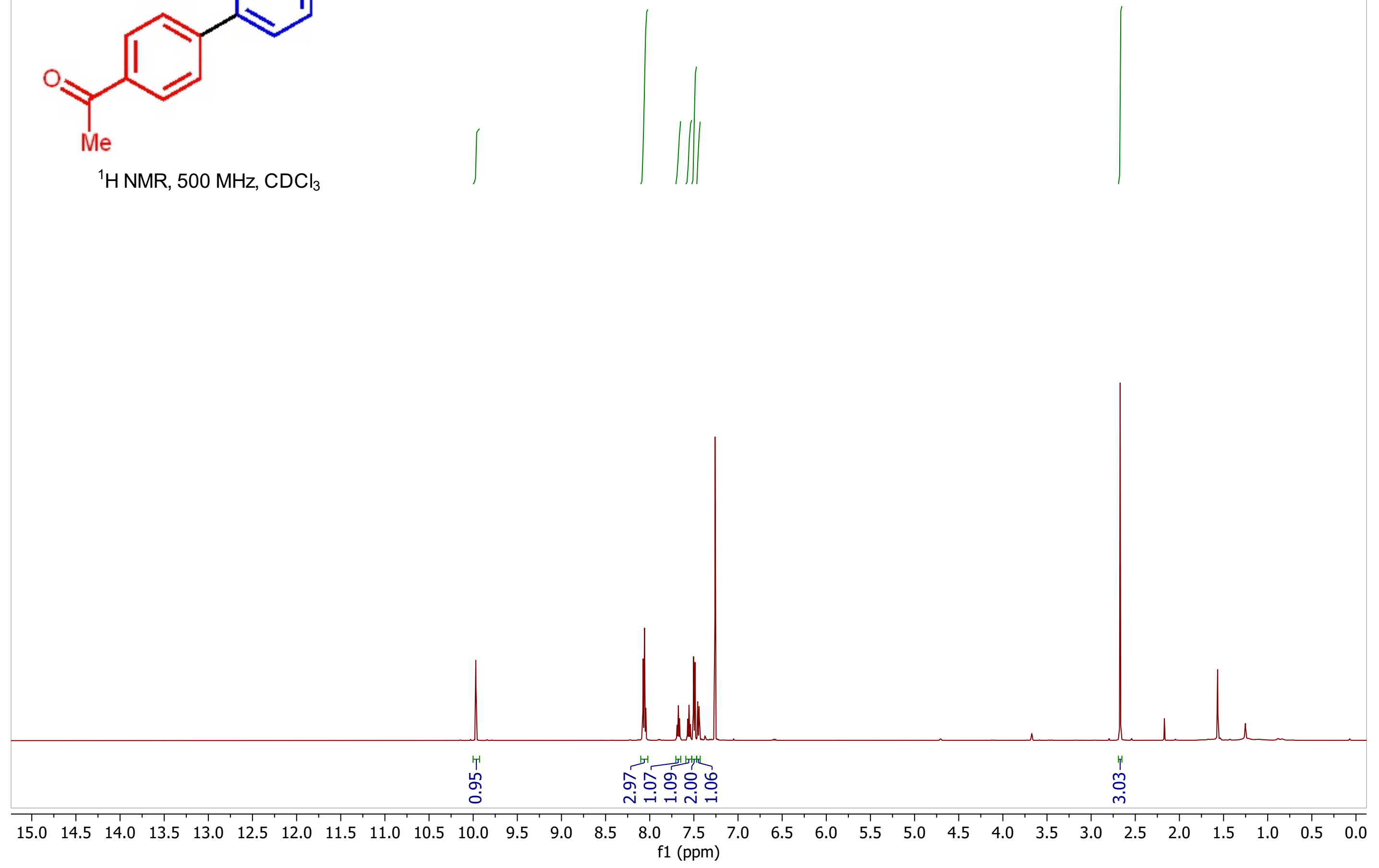


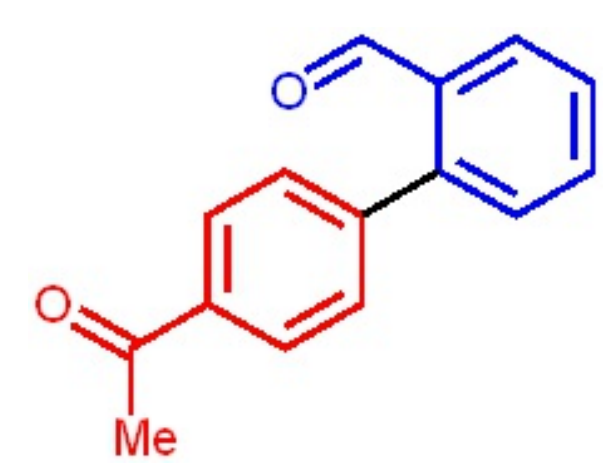

${ }^{13} \mathrm{C} \mathrm{NMR}, 125 \mathrm{MHz}, \mathrm{CDCl}_{3}$

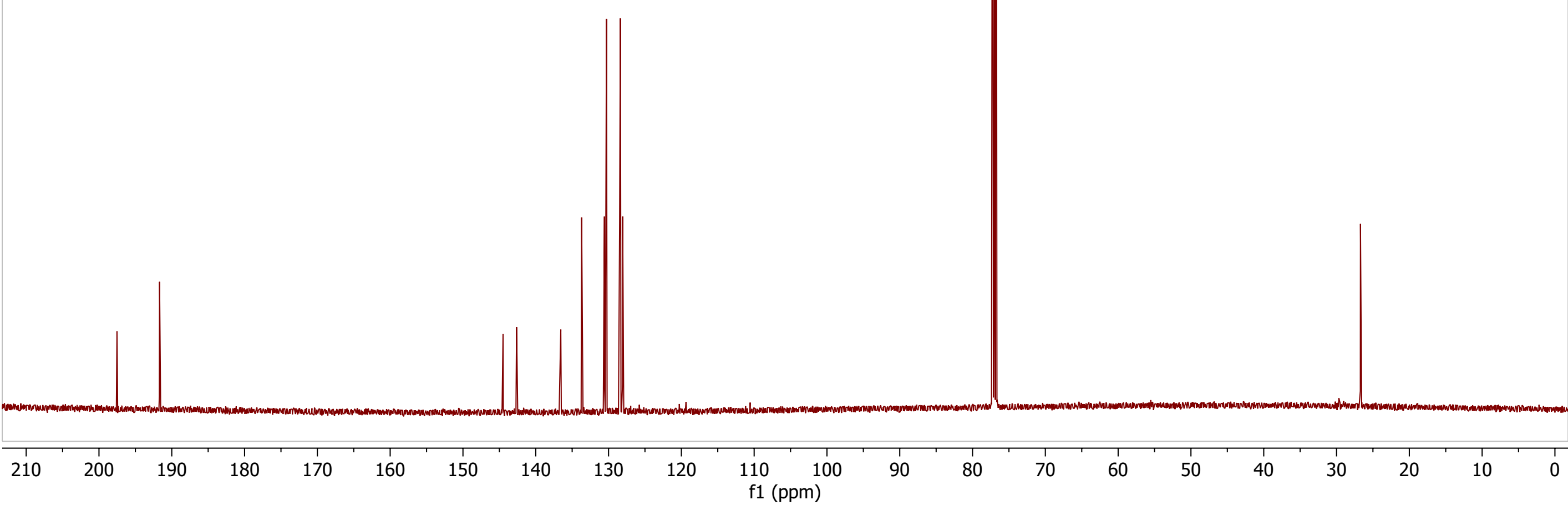



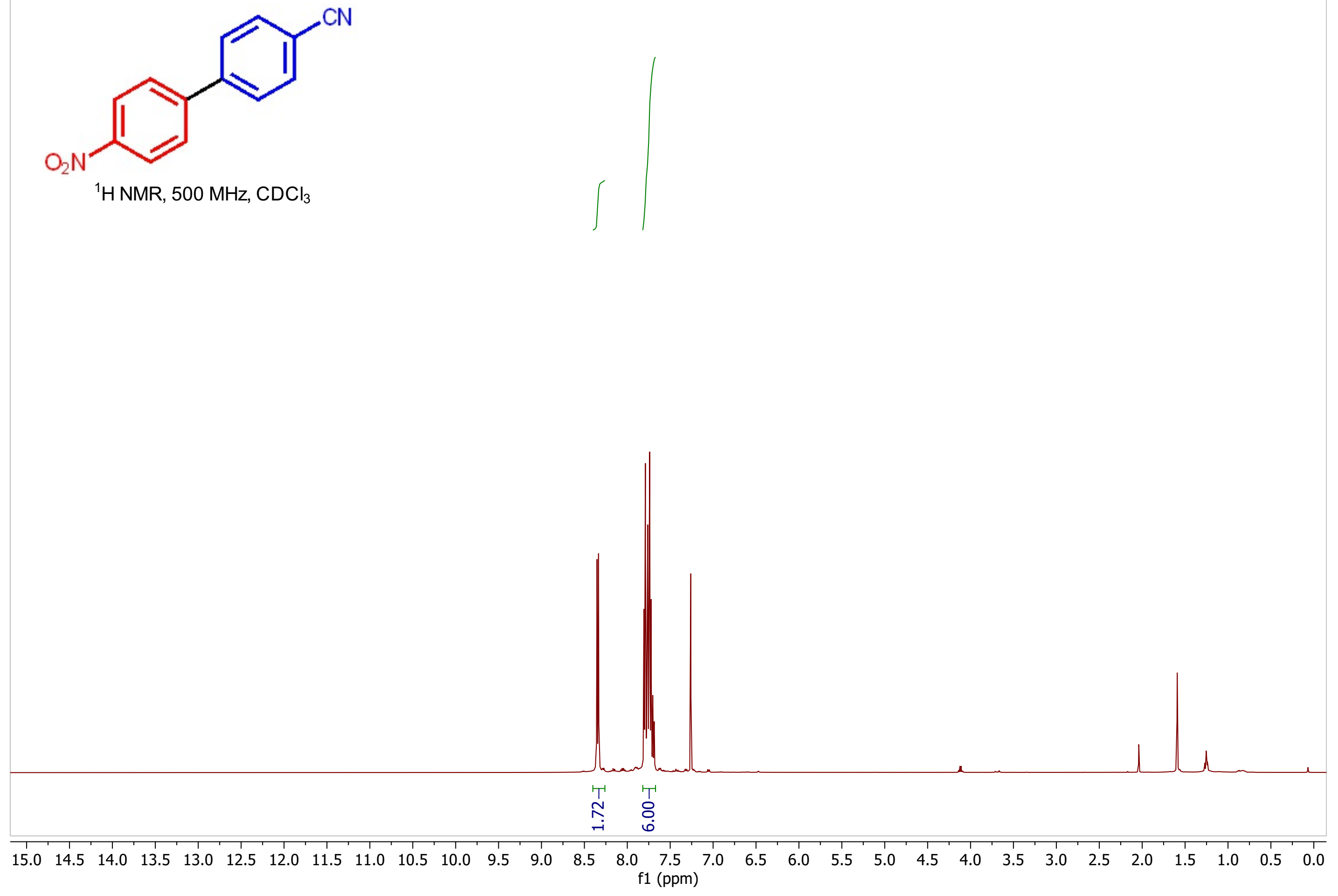


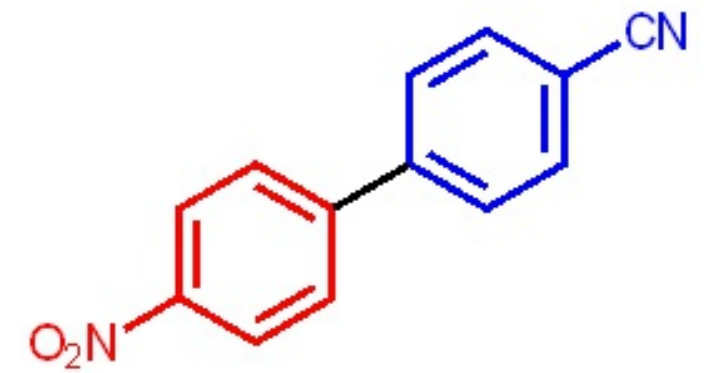

${ }^{13} \mathrm{C} \mathrm{NMR}, 125 \mathrm{MHz}, \mathrm{CDCl}_{3}$

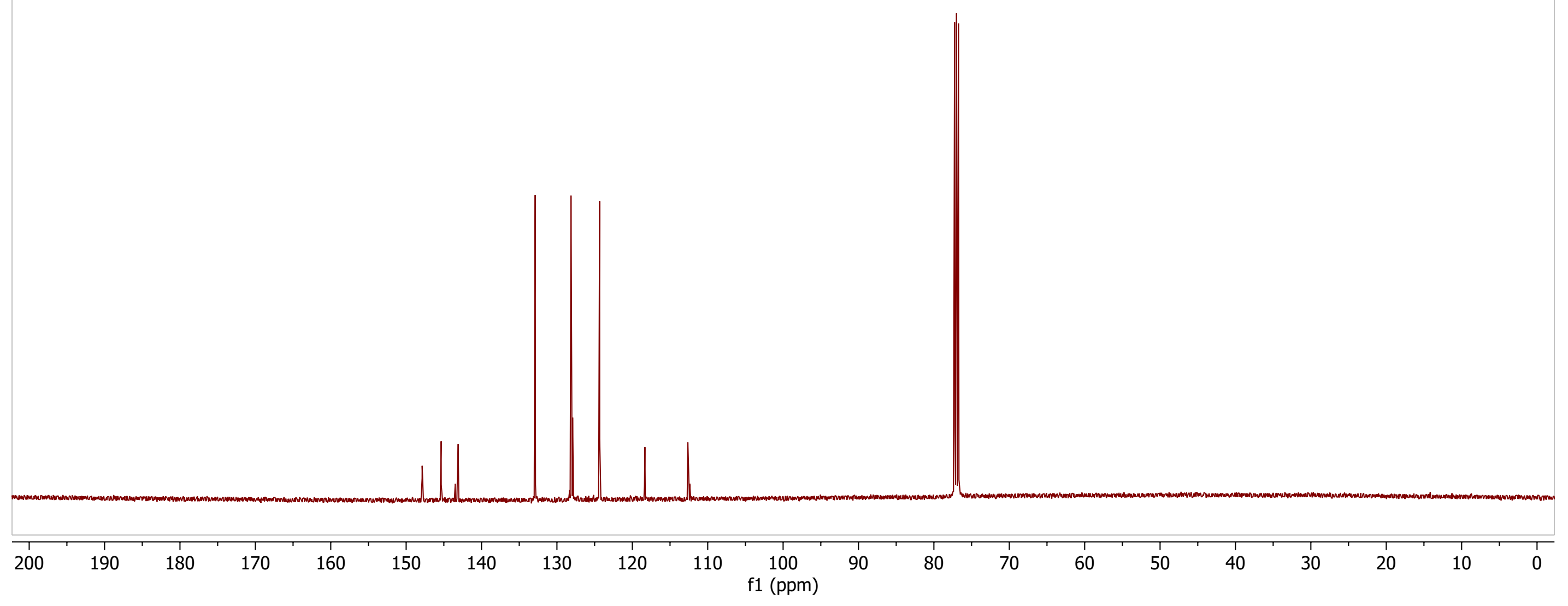




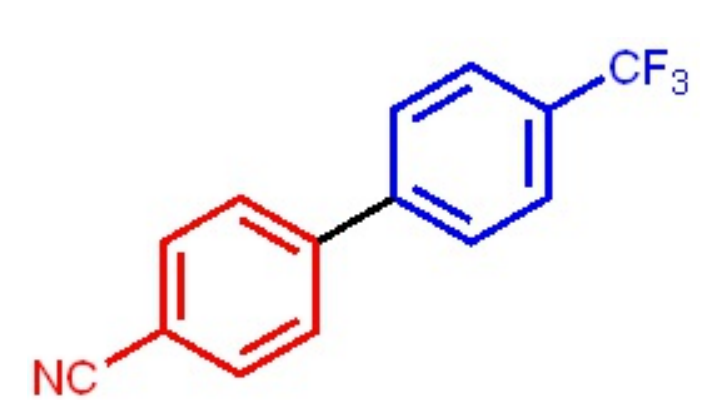

${ }^{1} \mathrm{H} \mathrm{NMR}, 500 \mathrm{MHz}, \mathrm{CDCl}_{3}$

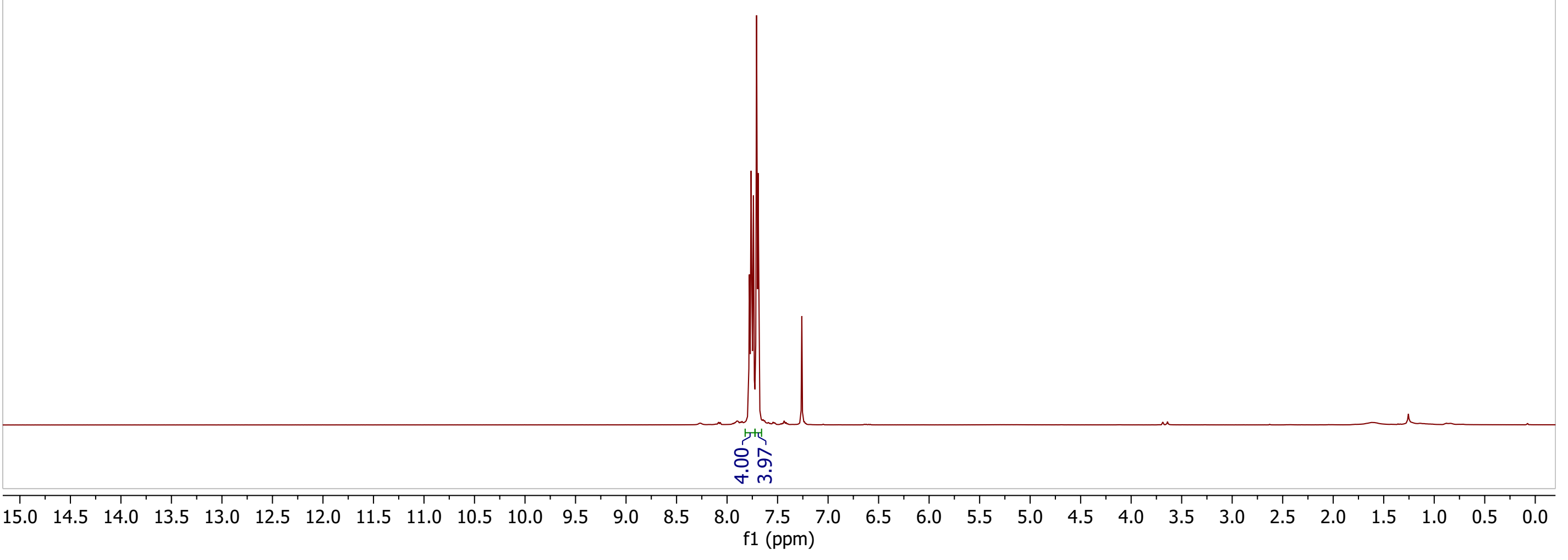




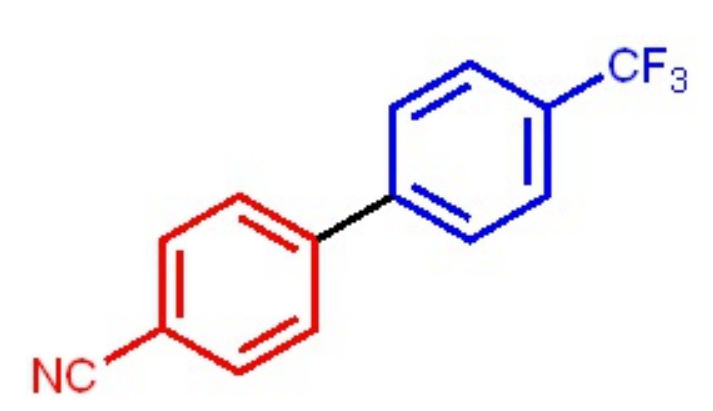

${ }^{13} \mathrm{C}$ NMR, $125 \mathrm{MHz}, \mathrm{CDCl}_{3}$






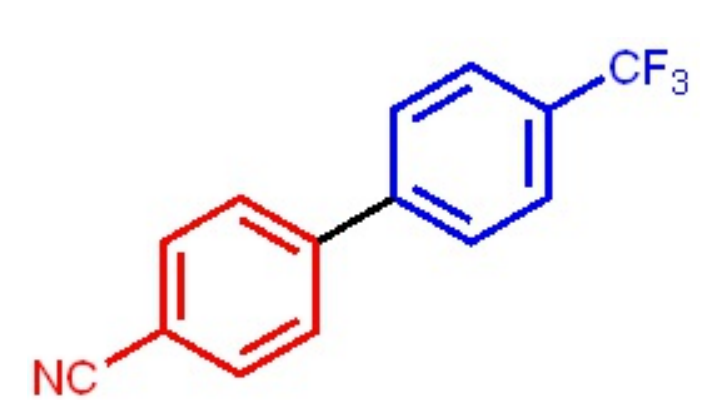

${ }^{19} \mathrm{~F} \mathrm{NMR}, 470 \mathrm{MHz}, \mathrm{CDCl}_{3}$

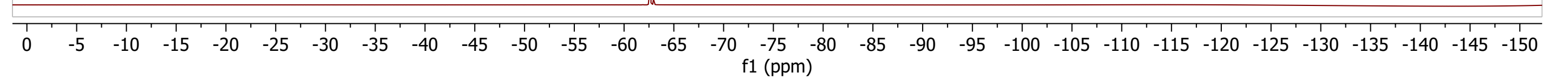

